\title{
AN INTERPRETATIVE PHENOMENOLOGICAL ANALYSIS OF 'BEING RELIGIOUS' IN EMERGING ADULTS WITHIN A TERTIARY EDUCATION SETTING
}

BY

THOMAS DRAVITZKI

A thesis submitted to the Victoria University of Wellington

in fulfilment of the requirements for the degree of

Master of Education

Victoria University of Wellington

2015 



\begin{abstract}
Research in the last 30 years has shown that young people have been increasingly turning away from religion during the period of emerging adulthood, despite the benefits that religious people experience. The present hermeneutic phenomenological study explored the meaning of young adults' experiences of being religious in a New Zealand tertiary education setting. Phenomenological interviewing was used to capture the experiences of 10 religious students, including how they practise their religion and what they believe, with the aim of developing a deeper understanding of what being religious meant for them. An interpretative phenomenological analysis (IPA) of the findings showed that being religious meant: having a relationship with God, being different to one's secular peers, experiencing challenges, and that being religious was ultimately constructive. Many of the students experienced challenges to their religious beliefs and identities from fellow students, teachers and at an institutional level. The benefits of being religious outweighed the challenges and included: praying being therapeutic, religion providing support and helping define the students' life purpose and identity. The implications of the study are discussed in relation to raising awareness about the importance of mutual respect, moving beyond religious tolerance to fully inclusive education and improving the integration of religious students in tertiary environments through curricular and cocurricular activities and programmes. Recommendations for future research include a greater focus on assessing the extent of the challenges religious tertiary students' experience, and examining whether students of particular religious traditions experience unique challenges and benefits.
\end{abstract}

Key words: religious, interpretative phenomenology, students 


\section{ACKNOWLEDGEMENTS}

I wish to extend my sincerest and heartfelt thanks to the following people whom this thesis is dedicated to:

Chris Bowden, for first sparking my interest in Education. You are a wonderfully engaging lecturer and have been an outstanding thesis supervisor. I could not have asked for better.

My participants, for your openness and interest in my study. You have broadened my knowledge of what it means to be religious and helped me fulfil my goal of completing a Master's degree.

Isabella McCafferty, for being my best friend. UBI.

Stan and Mary-Rose Dravitzki, for making the reality of postgraduate study possible through your incredibly generous support.

Anna, Daniel and Krystyna Wells, Lucy, Peter, James, Jessica, Sophia, Oliver, Priscilla and Jerome Smithson and Jane Dravitzki for being a constant source of joy and encouragement.

My Grandparents Mick and Jean Dravitzki, Ned and Joan Radich, Godparents Tony Dravitzki and Anne-Marita Gilmour, extended family, friends and anyone who has supported me throughout my life. Your positive witness has had a profound influence on me.

God, the Father, Son and Holy Spirit, for Deus Caritas Est! 


\section{CONTENTS}

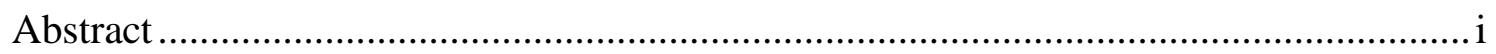

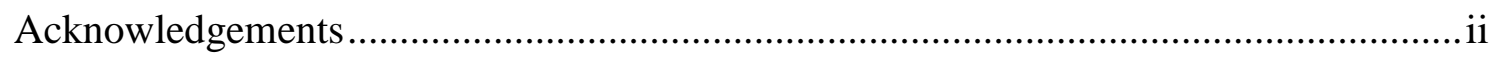

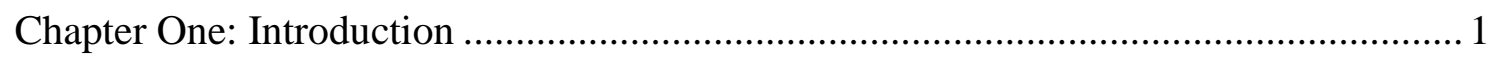

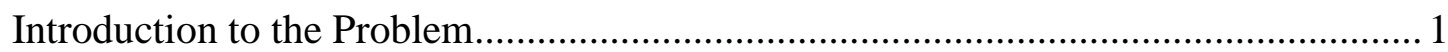

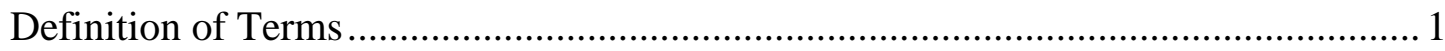

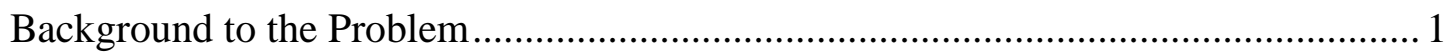

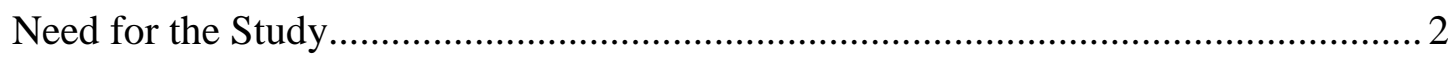

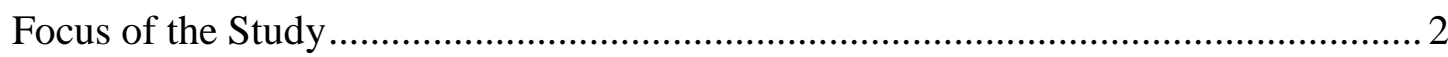

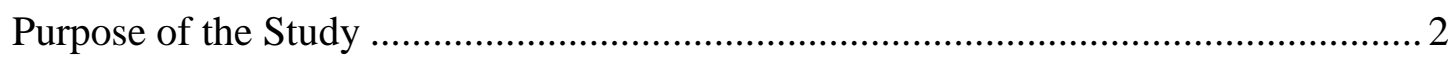

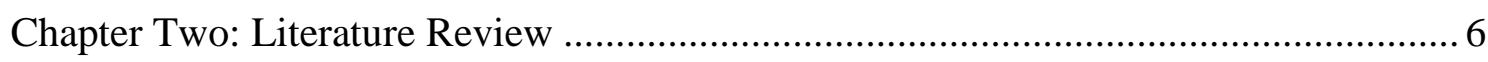

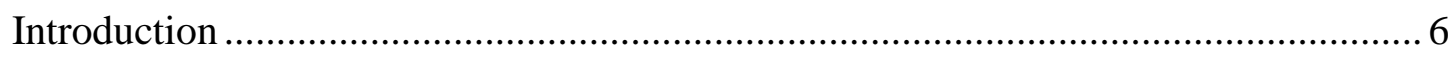

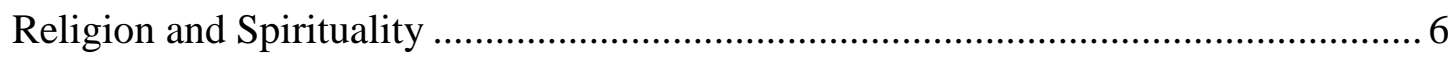

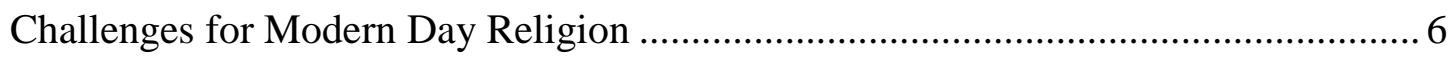

Positive Youth Development and Religion ........................................................ 7

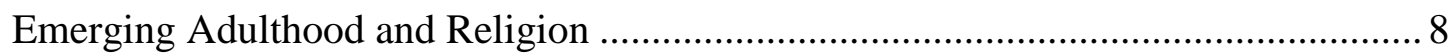

Emerging Adults' Religiosity and Experiences of Religion ................................... 8

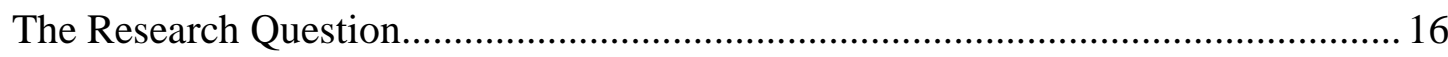

Chapter Three: Research Methodology …............................................................. 17

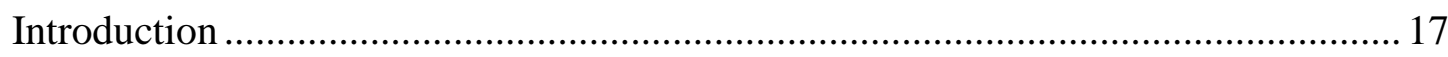

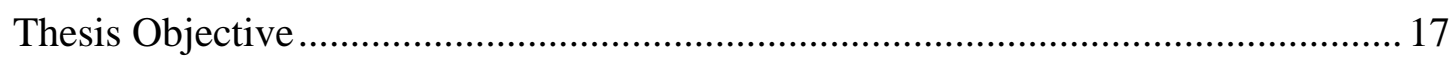

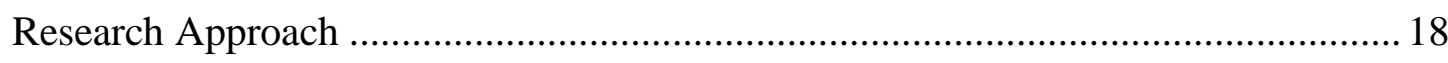

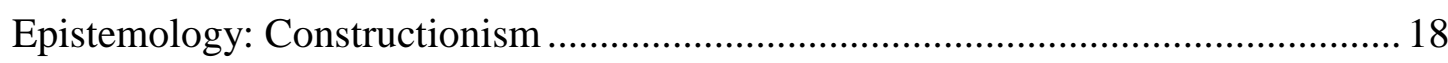

Theoretical Perspective: (Interpretative) Phenomenology ........................................ 19

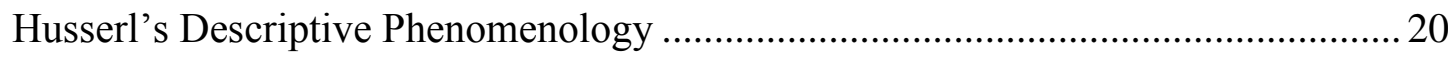

Heidegger's Interpretative (Hermeneutic) Phenomenology .................................... 21 


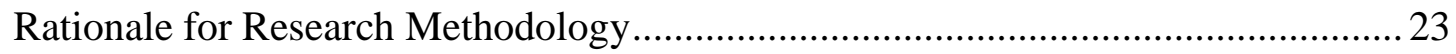

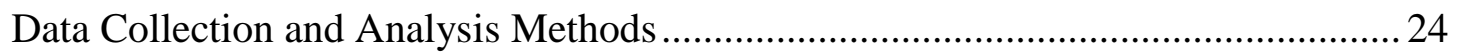

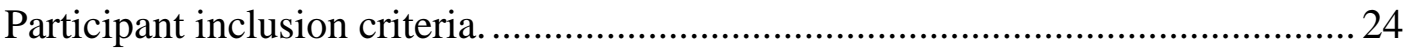

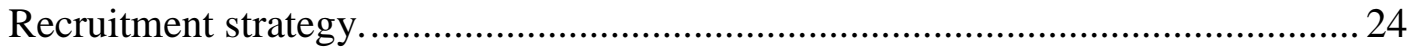

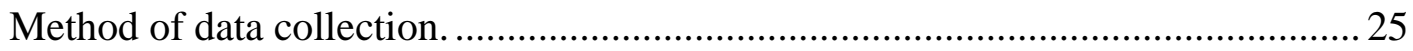

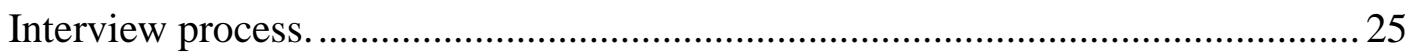

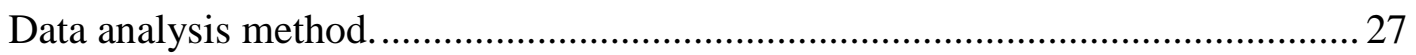

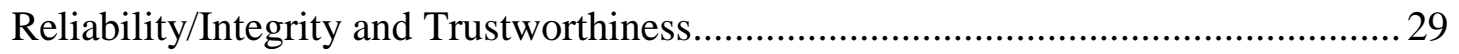

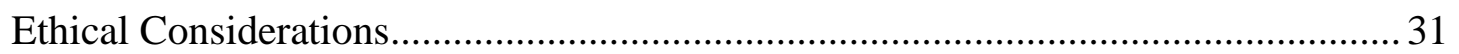

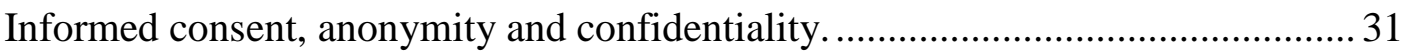

Protection of students and the reputation of the university from risk or harm........ 32

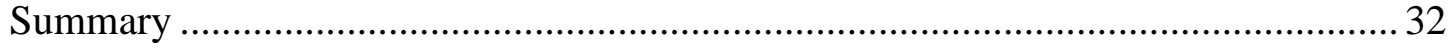

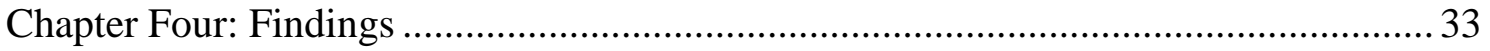

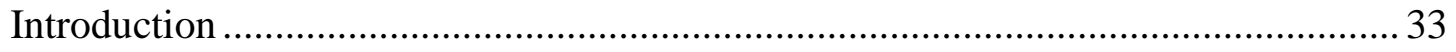

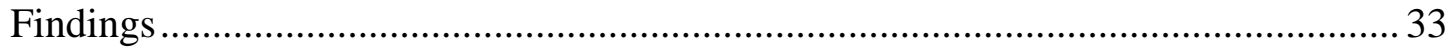

Table A: Essential themes of the students' religious experiences ............................. 35

Super-Theme 1: Having a Relationship with God ................................................. 35

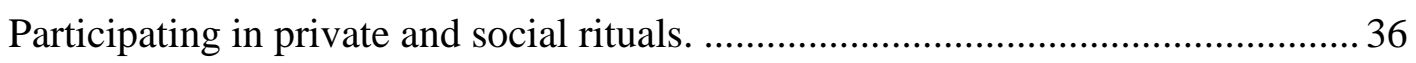

The relationship required personal commitment................................................. 38

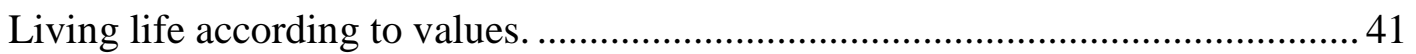

Having a 'real' and respectful relationship with a powerful friend....................... 43

Super-Theme 2: Being Different to Secular Peers .................................................. 45

Having different beliefs, values and philosophies............................................. 46

Feeling confused resolving conflict of being stigmatised/stereotyped....................48

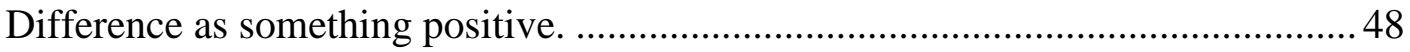

Super-Theme 3: Being Religious Involved Inter/Intrapersonal Challenges ............... 49 


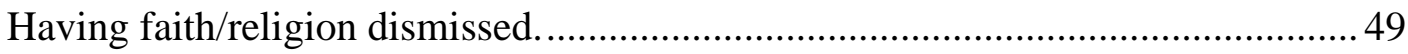

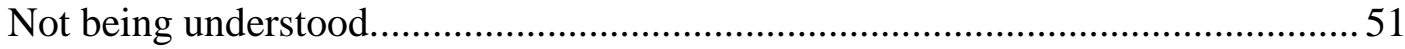

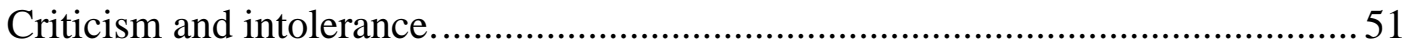

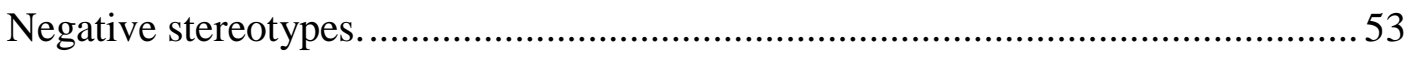

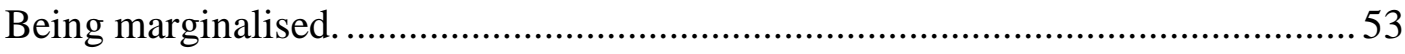

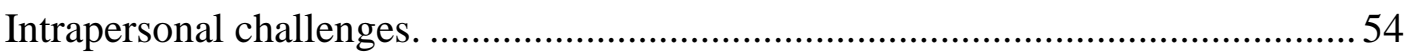

Super-Theme 4: Being Religious is Constructive ................................................... 55

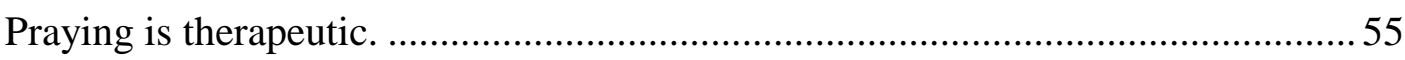

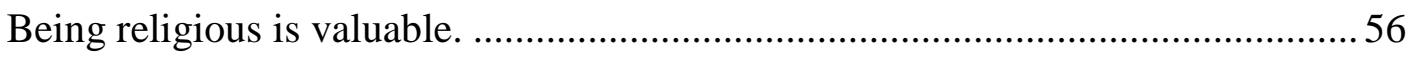

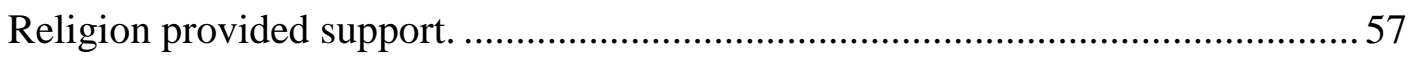

Religion helps defines your purpose and identity. ..............................................5 57

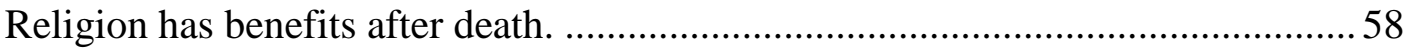

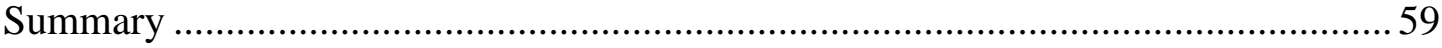

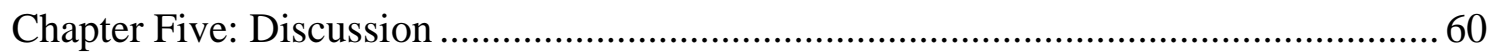

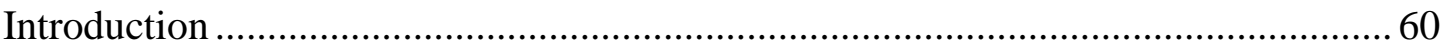

The Challenges of Being a Religious Student.........................................................6 60

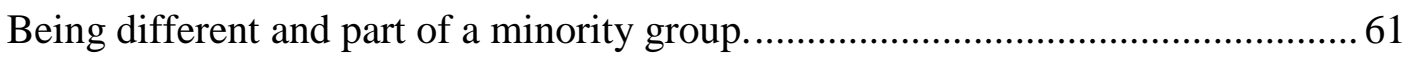

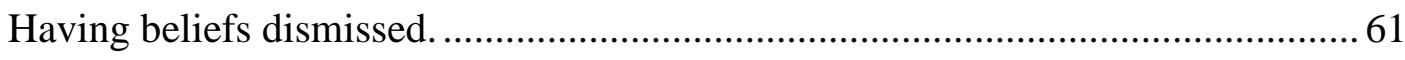

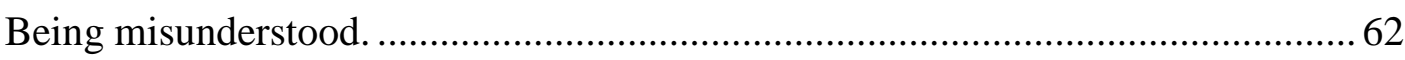

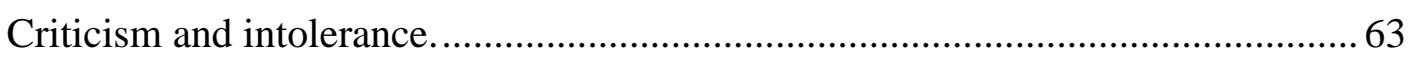

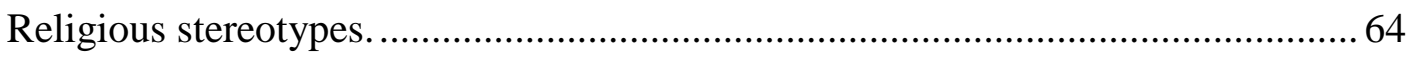

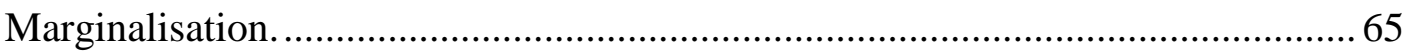

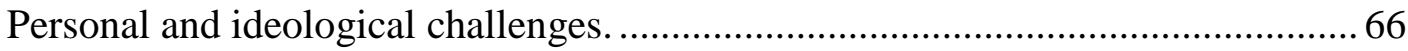

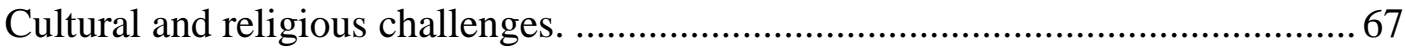

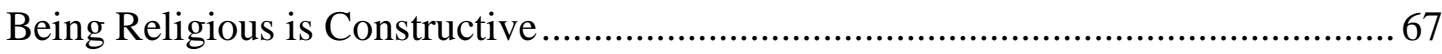

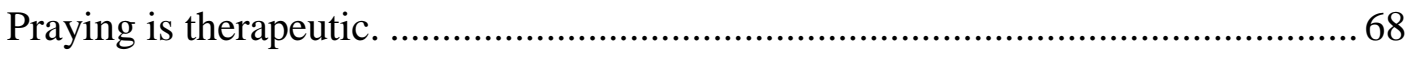

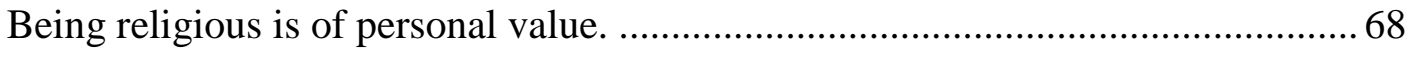


Religion provides support.

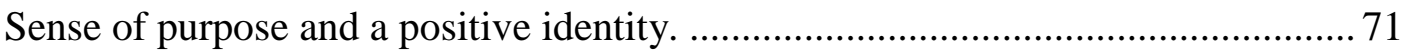

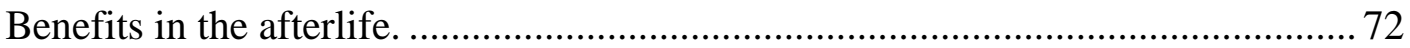

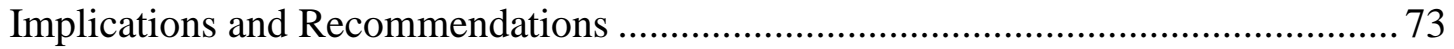

Understanding the lived experience of religious university students.................... 73

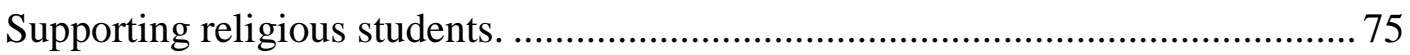

Integrating religion into the curriculum and inclusive teaching practice. ............... 78

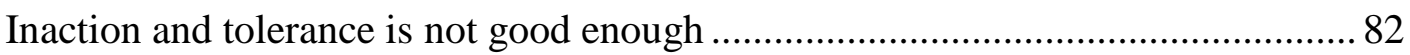

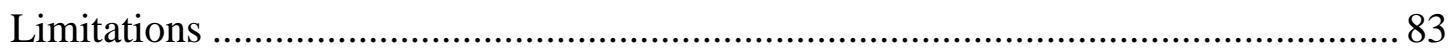

Phenomenology and Interpretative Phenomenological Analysis. ......................... 87

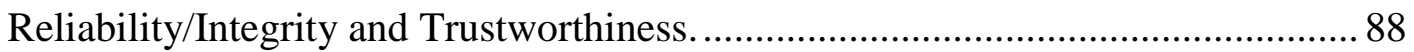

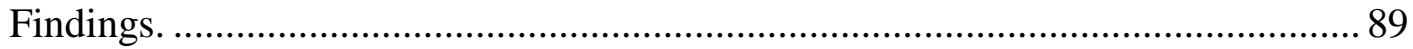

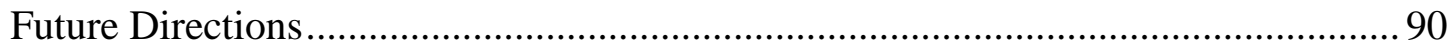

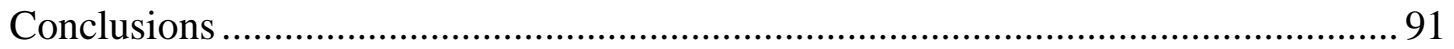

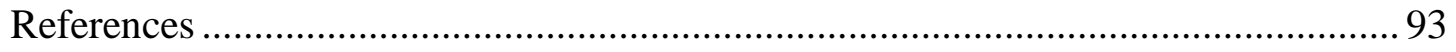

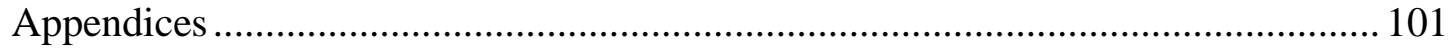




\section{CHAPTER ONE: INTRODUCTION}

\section{Introduction to the Problem}

A phenomenon that has received attention in the literature is the change in religious convictions of young people during emerging adulthood. For many young people this change involves giving up their religion. Empirical literature has demonstrated that religion is at its lowest level of popularity in emerging adulthood, which includes young people in the 18-25 age bracket (Arnett, 2000), with tertiary experience being suggested as a key contributor to this phenomenon (Uecker, Regnerus, \& Vaaler, 2007). The problem that results from such apostasy is that young people lose an avenue of support and positive youth development in a time characterised by significant changes and transitions.

\section{Definition of Terms}

In recent years, the body of literature exploring the topic of religion has steadily grown. Despite this growth there is no universal definition of 'religion'. Religion has been described as a complex term with multiple definitions and a multifaceted nature (Pargament, Magyar-Russell, \& Murray-Swank, 2005). Love (2001) defines religion as "a shared system of beliefs, principles or doctrines related to a belief in and worship of a supernatural power or powers regarded as creator(s) and governor(s) of the universe" ( $p$. 8). Other authors such as Pargament (2001) say religion involves a "search for significance in ways related to the sacred" (p. 32). Religion in this study is defined as a belief system concerning a sacred power or being. The phenomenon being explored in this study is 'being religious' and involved an examination and interpretation of students' beliefs, practices, values and their particular ways of being in the world.

\section{Background to the Problem}

The decline of religiosity is "not new news" (Uecker et al., 2007, p. 1667). Studies from the 1980s have highlighted a decline in church attendance and religious beliefs as young people transition from being teenagers to adults (See for example Willits and Crider 1989). Various suggestions have been made about why young people give up their religion. One suggestion is based on the freedom accorded to young people when they 
leave their parental home. This freedom gives young people the opportunity to cease religious activities such as attending church services and engage in activities typically frowned upon in their various religious traditions such as pre-marital sex (Uecker et al., 2007). A second suggestion related to tertiary settings is that "Higher education tends to expand one's horizons and may also mean greater exposure to countercultural values" (Hadaway \& Roof, 1988, p. 36). Such exposure can erode religious values especially when they have been poorly maintained or not understood (Hadaway \& Roof, 1988).

\section{Need for the Study}

Little is known about why people give up being religious, just that they do. As a result of much of the research being conducted in an overseas setting and employing quantitative research designs, there is a gap in the literature for empirical research that explores religious experience qualitatively. In order to gain a deep and rich understanding of religious experience, interpretative phenomenology is an ideal research methodology that will give insight into the contexts that shape this experience and foster a greater understanding about this phenomenon.

\section{Focus of the Study}

The focus of this study is on young people aged 17-25 who have lived experience of being religious. It is not the participants' perceptions, thoughts or opinions that are key to this study, but rather their accounts of their own experiences. The experiences that they share are analysed and interpreted to contribute to the understanding of what it means to be religious in a tertiary education setting.

\section{Purpose of the Study}

The purpose of this study is to explore what it is like to be a religious tertiary student. In a time of increasing secularism in New Zealand, the phenomenon of being religious presents an interesting area of investigation, because approximately $40-50 \%$ of emerging adults still state they have a religion (Statistics New Zealand, 2014). In addition, the developmental period of emerging adulthood has not yet been explored with great depth. It is during this period that many young people transition from secondary school and pursue further education in tertiary settings and question and give up religious traditions they have been a part of since childhood. Whilst there has been 
extensive research about religion and emerging adulthood conducted overseas, especially in an American context, there is a paucity of research in New Zealand. Research needs to be conducted that illuminates religious emerging adults' involvement in religion, the importance of religion in their lives and the meanings ascribed to their experiences.

In light of this gap in empirical research the present study uses hermeneutic phenomenology to not only describe the experiences of religious young people, but to interpret what these experiences mean. The distinguishing feature of the emerging adults in this study is that they are all tertiary students from Victoria University of Wellington.

Chapter Two is a review of literature on empirical research focusing on religion and emerging adults, who in many cases are tertiary students. Emerging adulthood is discussed regarding the place it occupies in the human lifespan and the developmental tasks that young people are faced with at this time in their lives. A second focus of the review is an examination, summary and critique of empirical studies that focus on religion and emerging adults in tertiary settings. The two areas of empirical research reviewed include studies that identify factors and variables that lead to religious change and the effects of religion and spirituality on the positive well-being of young people.

Thirdly, the review shows that the majority of studies are international and focus on changes in religiosity/spirituality and the support and benefits that can be gained from being religious/spiritual. These studies have been predominantly quantitative, although several have employed mixed method designs. There are few New Zealand studies, which have examined religion/spirituality and international students' quality of life and the relationship between religious coping, stress and quality of life of domestic and international Muslim university students.

Finally, the review highlights the empirical gaps that exist within the field of religion and emerging adulthood and establishes the contribution of this study by exploring the phenomenon of being a religious student at university.

Chapter Three presents the methodology and methods used in this study. The chapter begins by outlining the objective of this thesis: to understand the lived experiences of religious emerging adults within a tertiary education setting. Three important questions are posed to meet the study objective, about what being religious involves, why it is 
important and what it means. The framework for a strong research approach is presented that guides the reader to the methodology used for this study, hermeneutic phenomenology. A rationale for the selection of this methodology is included with giving young people a voice, the extensive use of quantitative research designs and the research question requiring an inquisitive/exploratory approach supporting the selection of a qualitative methodology designed to interpret lived experience.

The participant inclusion criteria is detailed and includes the participants needing to identify as religious, have lived experience of being religious, be enrolled at Victoria University of Wellington and be 17-25 years old. The recruitment strategies used to advertise and recruit the participants in this study are listed, including displaying hardcopy fliers, contacting key religious group leaders, sending fliers and emails to lecturers, speaking to a Christian group in person and getting my supervisor to make class announcements about my study. A qualitative research design was chosen because little is known about the experience of being a religious tertiary student. In the present study, the epistemology was constructionism (Crotty, 1998), the theoretical or philosophical perspective was (interpretative) phenomenology (Lopez \& Willis, 2004; Van Manen, 2014) and method of data analysis was interpretative phenomenological analysis (IPA) (Smith, Flowers, \& Larkin, 2009). The key stages used in the coding and development of sub-themes and super-themes are described. The data collection method was qualitative semi-structured open-ended interviews. Finally, the strategies used to ensure reliability/integrity and trustworthiness are discussed along with the ethical considerations of this study.

Chapter Four describes the key findings of this study. The chapter begins by describing the overarching essence or meaning of what it means to be religious for the students: engaging with the sacred. Parallels to this meaning are drawn with Pargament's (2001) definition of religion and a list of various manifestations of the sacred are included.

The findings of this study are presented thematically under four main super-themes: 1) having a relationship with God 2) being different to one's secular peers 3) being inter/intrapersonally challenged, and 4) being religious is constructive. Each of these super-themes is supported by numerous sub-themes that represent an interpretation of the lived experience and verbatim extracts (lived experience descriptors) from the students' interviews. 
Chapter Five is the final chapter of this study and is a discussion of the findings and their significance in relation to relevant literature and research. The implications of the findings for supporting and understanding religious students are discussed, along with how to improve their educational experiences for this group of marginalised and misunderstood young people. The benefits of changing the way tertiary institutions engage with religious students are outlined and a case is made for moving beyond tolerance of religious students on campus. Suggestions are made about how to further substantiate the findings of the present study and a number of recommendations are made for future research. The limitations of the study are outlined and conclusions drawn about the topic, the problem and the thesis. The next chapter reviews empirical literature surrounding young people and religion. 


\section{CHAPTER TWO: LITERATURE REVIEW}

\section{Introduction}

In the previous chapter the topic of this study was introduced. In this chapter the most relevant and contemporary literature pertaining to the research question of this study: $A n$ interpretative phenomenological analysis of religion in emerging adults within a tertiary education setting is reviewed. The studies that are included in this chapter reveal what topics surrounding young people and religion have previously been addressed, the research methods used to examine them, their strengths and limitations and the future directions for research they recommend. To begin the chapter religion is defined, contextualised in a New Zealand setting and positioned in the developmental period of emerging adulthood.

\section{Religion and Spirituality}

Many definitions exist that shed light on the characteristics of religion. An important distinction to make in this study is the difference between religiosity and spirituality. Religiosity is characterised in the literature as an "adherence to a set of doctrines or membership in a body of people who share similar beliefs about God, holy observance, and morality" (Davis, Kerr, \& Kurpius, 2003, p. 358). Spirituality on the other hand is characterised as being "closely related to transcendence, but without specific reference to formal religious doctrine" (Davis et al., 2003, p. 358). To separate these two terms, religion can be seen as sharing much in common with spirituality with the added element of theological structure and formality (Davis et al., 2003). With the distinction between religiosity and spirituality established, being religious in this study involved the participants' self-identifying as religious, being part of a formalised religious tradition and being able to converse about their religious participation and experiences.

\section{Challenges for Modern Day Religion}

The number of people who identified with a religion in New Zealand decreased $6.7 \%$ between the 2006 and 2013 censuses, with the emerging adult religious population now less than half of the total emerging adult population (Statistics New Zealand, 2014). Theorists and scholars have made suggestions for some time now to explain this trend. 
Hadaway and Roof (1988) in their evaluation of apostasy cited a number of challenges that churches face including younger people choosing not to participate, having objections to church teachings, not seeing church as relevant and lifestyle conflicts. Other challenges that have been acknowledged that apply more generally to religion come from a secularization paradigm that proposes that religious traditions are faced with modernization processes that "will eventually have a negative effect on the stability and vitality of religious communities, practices and convictions" (Pollack, 2008, p. 169). For example through religious perspectives being undermined by secularized perspectives (Uecker et al., 2007).

\section{Positive Youth Development and Religion}

One field that has a strong interest in religion is human development, where religion has been identified as a cogent source of developmental influence (Furrow, King, \& White, 2004). Religion has been examined at different stages in the developmental lifespan such as older adulthood. For example, previous studies have examined whether religion can act as a buffer against the fear of death (Wink \& Scott, 2005). Historically the human lifespan has been divided into developmental periods, each with their own unique developmental tasks, that when successfully completed, allow individuals to navigate to the next developmental period (See for example Havighurst, 1948). Religion has been linked to many tasks in emerging adulthood that surround identity, purpose, meaning and prosocial commitments (Furrow et al., 2004) and has been credited with assisting young people with existential issues such as suicidal ideation (Taliaferro, Rienzo, Pigg, Miller, \& Dodd, 2009). In this way religion can be seen as promoting positive youth development.

Positive youth development in New Zealand is defined as developing "the skills and attitudes they [young people] need to take part positively in society, now and in the future" (Ministry of Youth Affairs, 2002 p. 4), which has strong parallels with the goals and policies of universities. Despite this clear definition little attention has been given to positive youth development during emerging adulthood (Hawkins, Letcher, Sanson, Smart, \& Toumbourou, 2009). Positive psychology has shed some light on this topic, where Park (2004) points out that a psychological good life consists of support from positive institutions, such as education providers, to help young people have positive subjective experiences and individual traits. In order for this support to occur however, 
young people need to feel connected (Ministry of Youth Affairs, 2002) and like they belong in such institutions.

\section{Emerging Adulthood and Religion}

Despite the recognition of developmental periods across the lifespan it was not until recently that emerging adulthood was given the status of being its own unique period. Emerging adulthood has since been defined as the developmental period between adolescence and adulthood (Barry \& Nelson, 2005) typically focusing on the 18-25 age bracket (Arnett, 2000). This period has been distinguished from adolescence and adulthood by its developmental tasks, including; developing intimate and mature relationships with others (Scharf, Mayseless, \& Kivenson-Baron, 2004), being financially independent from one's parents (Arnett, 1997) and leaving home (Scharf et al., 2004). This age group is synonymous with a vast proportion of university (college) students, which is the defining characteristic of the emerging adults in this study.

Of particular relevance to the present study is that contemporary research and theory suggests that late adolescence and emerging adulthood are times when some young people:

(a) question the beliefs in which they were raised, (b) place greater emphasis on individual spirituality than affiliation with a religious institution, and (c) pick and choose the aspects of religion that suit them best (Barry \& Nelson, 2005, p. 246),

while others may reject their religion or cease attendance and affiliation. Emerging adulthood is an ideal time for the questioning, change and selection of various religious beliefs as it is a time when young people have existential questions about life purpose and meaning, where religion offers a commitment to encounters with an ultimate concern and purpose (Paloutzian, Richardson, \& Rambo, 1999). This study will explore and shed light on these experiences and suggest why they might question their beliefs and/or why they remain important to them.

\section{Emerging Adults' Religiosity and Experiences of Religion}

Change in religiosity is an area that has received extensive attention in empirical literature. A number of studies have examined the factors and variables that lead to or 
have been associated with changes in religiosity. Despite these studies, little is known about why these factors and variables influence religiosity.

Lee's (2002) study investigated religious change in college students. It used quantitative survey data and found that many factors in the college environment influenced students' religious beliefs, including: adopting liberal views, which decreased religious faith and getting married which increased religious convictions. The explanation for liberal views decreasing religiosity were attributed to them arguably running contrary to most monotheistic religions (Lee, 2002). Whereas the explanation for marriage increasing religiosity was attributed to married individuals being more inclined to attend religious services which strengthened their religious convictions (Lee, 2002). To better understand other factors leading to religious change, Lee (2002) suggested that a qualitative research design may be appropriate.

In another study, Bryant, Choi and Yasuno (2003) used quantitative survey data to explore how 3680 students' (58.9\% female, predominantly 18-19 years of age) first year college experiences impacted their spirituality and religiosity. They found the students were less likely to engage in religious practices, but were more likely to integrate spirituality into their lives. Religiousness and spirituality were highly correlated and in many cases predicted one another, with additional personal characteristics, institutional variables and college experiences also playing an important role. Although little explanation was given to support their findings, variables that were identified as being negatively associated with religiousness included being politically liberal and affiliating with Buddhism. Meanwhile variables that were identified as being positively associated with spirituality included discussing religion and spending time with family (Bryant et al., 2003). This study did not provide participants the opportunity to include items to report their own degree of commitment to religion (Bryant et al., 2003).

Uecker, Regnerus and Vaaler's (2007) study investigated religious decline in emerging adulthood (an unidentified number were college students) using qualitative in-depth interview data from a longitudinal study (Wave 1 included 20,745 American adolescents and Wave 3 included 15,197 of the Wave 1 respondents). They found that married young adults retained their religious commitment more than their single peers and that cohabitation was linked to religious decline in terms of diminished religious service attendance and self-reported importance of religion and disaffiliation from religion. The explanation they gave for marriage resulting in the retention of religious 
commitment was that "Marriage and religion are both social commitments; a young adult who is prone to make one commitment is also more likely to make the other" (Uecker et al., 2007, p. 1684). Cohabitation on the other hand was linked to religious decline because cohabitors may have been sanctioned and criticised for their choice to live together. The authors however conceded that they were only able to explain some of the variance of religious decline in their study.

Other quantitative longitudinal studies have provided a picture of how religiosity changes over time and the influence of university life. Stoppa and Lefkowitz's (2010) study investigated longitudinal changes in the religiosity of ethnically diverse American emerging adults (52\% female) aged 17-19, over their first three semesters of college. The students $(n=434)$ took part in a quantitative questionnaire that asked them about their religious affiliation, behaviours and beliefs at three stages. They found that whilst there were significant decreases in religious service and activity attendance, religious beliefs typically remained stable. These findings suggested that when we talk about young people being religious we need to consider practice as well as beliefs, because they may not be active or practising but still believe. Stoppa and Lefkowitz (2010) recommended that future studies "fully assess the actual meaning and content that emerging adults attribute to...affiliational identifications"(p. 8). Finally, Lefkowitz's (2005) study examined emerging adults' perceptions of changes resulting from their transition to university using open-ended questionnaires. She found a decrease in religious service attendance was the most common behavioural change and that many young people had a stronger sense of faith, with some participants becoming more open to other religions.

It is not just university or college attendance that influences religiosity. Other studies have found that family factors and context can shape religious beliefs and practice in young adults. Milevsky and Leh's (2008) study examined the relationship between intrinsic and extrinsic religiosity and adjustment in emerging adulthood. They used a quantitative questionnaire to ask 305 young adults (247 college students and 58 noncollege students) of which 116 were men and 189 were women, about their perceived parental marital satisfaction, religiosity, social support and self-esteem. In their European-American sample they found lower levels of religiosity were reported from emerging adults from families of divorce. The explanation given for this phenomenon was that early socialisation practices (or a lack of them) may influence religious commitments in later life (Hoge, Johnson, \& Luidens, 1993). In addition, those who 
were classified as intrinsically religious had higher levels of self-esteem. The explanation given for this phenomenon was related to previous research that has found a positive relationship between religiosity and adjustment in adolescent and older populations (Milevsky \& Levitt, 2004; P. B. Nelson, 1990). Milevsky and Leh (2008) suggested that future studies should broaden the religious indices used to better understand the dynamics of religiosity and adjustment.

Other earlier studies have also supported the connection between divorce and a decline in religiosity. Zhai, Ellison, Glenn and Marquardt's (2007) quantitative study of 1506 young adults (ages 18-35) found that religious attendance levels were significantly lower for young adults who had divorced parents compared to those whose parents were not divorced. The explanation given for this finding was that divorced fathers play much less of a role in the religious socialisation of their children than fathers who are not divorced. They cited the distinctive role of fathers as bridging the gap between young adults and religious attendance. Although Zhai, Ellison, Glenn and Marquardt (2007) felt they provided new insight into the relationship between parental divorce and religious involvement, they conceded that longitudinal data would have provided a more definitive explanation for their findings.

Despite these studies showing a change and often a decline in religious beliefs and practice in young adults, a number of studies have shown that religion and spirituality can have positive effects on the development and well-being of young people. Maltby, Lewis and Day's (1999) quantitative study examined the relationship between religious orientation and the psychological well-being of 474 students (251 males and 223 females aged 18-29) in the United Kingdom using questionnaire measures. They found that an intrinsic religious orientation (where one lives their religion) (Allport \& Ross, 1967) including personal prayer had a significant positive association with psychological well-being. On the other hand, an extrinsic religious orientation (where one uses their religion) (Allport \& Ross, 1967), such as attending church (a public manifestation of religion) was sometimes linked with less than positive associations of psychological well-being (Maltby et al., 1999). The researchers in this study recommended replicating their study among other adult samples and suggested that critical religious events and other factors involved in coping, such as stress, should be examined to better understand the relationship between religion and well-being. 
Genia's (1998) study explored the relationship between religious orientation and the mental health of college students using Allport's Religious Orientation Scale (Allport \& Ross, 1967). They found that greater existential wellbeing was reported by intrinsically religious students than extrinsically non-religious students, who were more depressed and had lower self-esteem. Kirk and Lewis's (2013) more recent study had a similar focus and explored religious behaviours and their impact on emerging adults' health and well-being using a college survey. Their study found that in instances where emerging adults participated in religious activities, they had a greater satisfaction of life and lower rates of substance abuse, mental illness and risky sexual behaviour. Religion provided the emerging adults with support and was a protective factor and source of life satisfaction. In a quantitative study published last year of the connection between religion-based support and mental health of 200 under-graduate students in the United States, Hovey, Hurtado, Morales and Seligman's (2014) found strong support for religion-based support (social interaction, instrumental and emotional) acting as a mediator between religiosity and mental health.

Several studies in the last five years have examined how religious attendance may act as a protective factor and improve life satisfaction and mental health in young adults. Doane's (2013) study examined the association between religiosity and subjective wellbeing of 324 Caucasian ( $85 \%$ female, average age 20.50) university students in the Republic of Ireland using various quantitative scales such as the Satisfaction with Life Scale (Diener, Emmons, Larsen, \& Griffin, 1985). The results from their study showed a positive association between service attendance and life satisfaction, and small positive correlations between service attendance, perceived social support, and life satisfaction. The researchers concluded that unique supportive relationships are fostered in religious communities. These findings suggested that young adults may find support in religious communities through relationships with others.

In another quantitative study conducted by Taliaferro, Rienzo Pigg, Miller and Dodd (2009), 522 college students responded to various quantitative scales, such as the Beck Hopelessness Scale (Beck, Weissman, Lester, \& Trexler, 1974), that explored dimensions of spiritual wellbeing (where spirituality was highlighted as being more inclusive than organized religion) in relation to reduced suicidal ideation. Their study found that frequent church service or church-related activity involvement (6 or more times in the last 30 days) was correlated with reduced suicidal ideation. In addition, students with higher levels of religious, existential, and spiritual well-being reported 12 
less frequent suicidal ideation than their peers with lower levels of wellbeing. The researchers in this study recommended that future studies should investigate meaning and purpose in life, as they may play an important role in the relationship between spiritual well-being and suicide risk (Taliaferro et al., 2009).

Anye, Gallien, Bian and Moulton's (2013) study used quantitative surveys to investigate spiritual well-being and its relationship with college students' health-related quality of life, such as "wellbeing and life satisfaction as opposed to indicators of morbidity and mortality" (Sawatzky, Ratner, \& Chiu, 2005, p. 155). The results from their study showed that more frequent participation in religious activities and higher levels of spiritual wellbeing resulted in longer periods of better physical and mental health. Young people who had lower levels of participation in religious activities and spiritual wellbeing had shorter periods of good physical and mental health (Anye et al., 2013).

The purpose of Byrd, Hageman and Isle's (2007) study of 161 American under-graduate students (43 men and 118 women with a mean age of 20.1 years) was to explain the frequently reported positive association between intrinsic religious motivation and subjective well-being using questionnaires. More specifically the aim of their study was to figure out whether the above association could be attributed to a more general intrinsic life orientation (where something is done because it is rewarding in and of itself), involving secular and religious domains (Byrd et al., 2007). The key result of their study was that an intrinsic religious motivation promoted subjective well-being independent of intrinsic secular motivations. Finally Nelms, Hutchins, Hutchins and Pursley's (2007) study examined spirituality in relation to health risks of college students. They found that considering a spiritual component when evaluating a decision involving risk that could have negative health effects, better health outcomes were experienced, because a spiritual component may have resulted in a "more harmonious and enlightened experience when confronting emotional challenges" (Nelms et al., 2007, p. 262).

All of the empirical studies in this literature review have come from Western, and mostly American populations and their findings may not be generalizable to populations from other cultures and countries. There is little research that has explored religion in emerging adults in New Zealand. Hsien-Chuan Hsu, Krägeloh, Shepherd and Billington's (2009) study explored religion/spirituality and international students' quality of life. The sample in this study included 218 domestic and 164 international 
students (mean age 23.78) at a New Zealand university. Using questionnaires they found that in both their samples of domestic and international students religion/spirituality correlated with psychological quality of life. The authors concluded that religion/spirituality might help international students cope with acculturation stressors. Limitations identified by the researchers in this study included the study not assessing levels of stress and daily hassles and not recording the number of years the international students had been resident in New Zealand.

A second New Zealand study by Gardner, Krägeloh and Henning (2014) used a questionnaire to explore the relationship between religious coping, stress and quality of life of 114 ( 81 indicated they were male and 32 female) domestic and international Muslim university students (mean age 25.89). Their results showed that international Muslim students were more religious/spiritual than domestic Muslim students. The suggestion given to explain this finding was that through integration into New Zealand (secular) culture spirituality/religiosity diminishes with time. Another important finding was that international Muslim students used more negative and positive religious coping strategies, which may have reflected the international students' lack of integration into New Zealand society which, would tend to make them slightly less religious/spiritual with time (Gardner et al., 2014).

Most of the studies presented have been quantitative in design and have looked at relationships between variables. Few studies have used mixed methods or a qualitative research design to explore or explain the importance of their findings. One recent study that used a qualitative research design was Rockenbach, Walker and Luzader's (2012) study. They used interviews to conduct a phenomenological analysis of college students' spiritual struggles. They found that despite the uniqueness of the experiences and descriptions given by the students, one word could be used to describe the essential meaning of their spiritual struggles: contrast (Rockenbach et al., 2012). Their study supported my case for employing a qualitative phenomenological design because they identified that the nuances and meanings of spiritual struggles had not been explored in previous quantitative studies, which was also the case for my study regarding religious experience.

In another study that included a qualitative element, Arnett and Jensen (2002) used interviews and questionnaires in a mixed methods approach to examine 140 American emerging adults' (aged 21-28) religious beliefs. The found that religious beliefs are 
highly individualised, childhood religious socialisation has limited effects and emerging adults are sceptical of religious institutions (Arnett \& Jensen, 2002). Although the authors did not state any limitations or strengths in their study, a strength commonly associated with a mixed research design is the way it helps to promote complementary strengths and non-overlapping weaknesses (the fundamental principle of mixed research) (B. Johnson \& Turner, 2003) of quantitative and qualitative research methods.

In addition to studies focusing on changes in students' and emerging adults' religiosity and the effect religion/spirituality has on the positive well-being of young people, other authors have focused on the negative realities of religiosity in tertiary settings, such as Hyers and Hyers (2008) and Rosik and Smith (2009). Hyers and Hyers' (2008) study explored discrimination experienced by 42 conservative Christians (average age 22 years) at a secular university. The students documented anti-Christian incidents using diaries, and found that discrimination most regularly involved the derogation of Christian beliefs, people and practices. A key strength of their study was that using diaries meant there was minimal faulty recall of experiences of discrimination due to time lapses. A limitation however was that some readers of their study may not view some of the students' experiences as discriminatory (L. L. Hyers \& Hyers, 2008), as what can be considered discriminatory is subjective. A second limitation was that little was known about the perpetrators of the discrimination recorded in this study. Information about the perpetrators may have provided background to such things as their attitudes and the context of their alleged offences (L. L. Hyers \& Hyers, 2008).

Rosik and Smith's (2009) study explored religious based discrimination of 96 Christian students (mean age 21.1) using a survey in secular and Christian university settings. They found that although incidents of discrimination were low in both settings, they occurred more regularly in the secular university setting where direct verbal insults and hearing others making disparaging remarks were the most prevalent forms of attack (Rosik \& Smith, 2009). A limitation of this study was the self-report data collection method that was used. Using this method meant it was unknown whether or not the reported incidents of discrimination actually occurred or were discriminatory, as the reported incidents may have been influenced by the respondents' past experiences of (perceived) discrimination (Rosik \& Smith, 2009). 


\section{The Research Question}

While this review has shown the depth of quantitative research conducted in emerging adulthood in the areas of religious change and the influence religion has on positive development and well-being, notable empirical gaps have emerged that prospective researchers could address. The first of these gaps is for research that includes participants from a diversity of religions. Empirical studies could draw on samples of students that are not exclusively Christian or Muslim. Second, qualitative research methods could be used that are invested in finding out the meaning of being religious. Many studies have identified the religiosity of young people, but have not explained why they are religious. Third, few studies have included New Zealand religious university populations, despite the extensive research that has been conducted overseas. Research that investigates samples from New Zealand could broaden the field of religion and young people. Fourth, little research has explored the voices of emerging adults so they can describe and have their lived experiences of being religious interpreted. As a result there is an opening for research that values the depth and richness of human experience where experiences are not quantified.

With the above empirical gaps in mind, the present study employs interpretative phenomenological analysis to explore what it means for emerging adults (17-25) to be 'religious' in a New Zealand tertiary education setting. 


\section{CHAPTER THREE: RESEARCH METHODOLOGY}

\section{Introduction}

The previous chapter included a detailed examination of research literature to highlight what research has been conducted, and what is already known about the experiences of religious emerging adults within tertiary education settings. The review of literature showed previous studies have been mainly quantitative and focused on changes in the religiosity and the role religion/spirituality played in promoting the positive well-being of young people. The literature showed there is a lack of qualitative studies that focus on the lived experience of being religious that explore what being religious involves, how important it is, and ultimately what it means to be religious. To gain the most detailed and rich descriptions of emerging adults' experiences of religion in a tertiary education setting, a thoughtful consideration of potential research designs was required. This chapter outlines the objective of this study, and proceeds to justify the selection of the qualitative research design used to meet the study's objectives. It outlines the participant selection criteria and recruitment methods, data collection and data analysis method and strategies used to ensure reliability/integrity and trustworthiness. Finally, the ethical implications throughout the research process are reviewed.

\section{Thesis Objective}

The objective of this study was to understand the subjective lived experiences of religion in emerging adults (17-25 year-olds) within a New Zealand tertiary education setting. To meet this objective this study explored the following research questions:

1. What does being religious involve? (e.g., what practices, rituals and activities are a part of the students' experiences?)

2. What is the importance of religion in the students' lives? (e.g., how does religion inform their identity, contribute to wellbeing and connectedness, and what are some of the advantages and disadvantages the students experience as a result of being religious?)

3. What does being religious mean to young university students? (e.g., what meanings can be ascribed to their experiences of being religious: marginalisation, feeling supported, being part of a community within an education context?) 


\section{Research Approach}

To lay a strong foundation for any research study researchers should consider four important questions:

1. What methods do we propose to use? (data gathering technique/procedure)

2. What methodology governs our choice and use of methods? (strategy/plan of action informing methods)

3. What theoretical perspective lies behind the methodology in question? (philosophical stance that will give context to the process being undertaken)

4. What epistemology informs this theoretical perspective? (theory of knowledge foundational in the theoretical perspective and methodology used) (Crotty, 1998)

These are discussed in the "reverse order" in this chapter, where the process of constructing the research design of the present study involved reflecting on my own personal research interests and strengths and previous empirical studies, as well as the empirical gap demonstrated in the review of the literature.

A qualitative research approach was chosen to meet the inquisitive and exploratory objectives of this research study. The choice to work within a qualitative research paradigm also informed the selection of the methodology and methods used.

\section{Epistemology: Constructionism}

Constructionism was the epistemology that underpinned this research study. Constructionism takes the view that: "all knowledge, and therefore all meaningful reality as such, is contingent upon human practices, being constructed in and out of interaction between human beings and their world, and developed and transmitted within an essentially social context" (Crotty, 1998, p. 42). Put simply, unlike a positivist paradigm whereby meaning is discovered and objective, in a constructionist paradigm meaning is constructed and subjective (Krauss, 2005).

When using a constructionist paradigm there is no one true interpretation (Crotty, 1998), but rather multiple possible interpretations. According to this theoretical perspective there are common themes in the lived experience of the participants and common meanings across the student sample. There are also personal, individual, unique and subjective experiences and meanings for each of the students. Regardless of what themes and meanings have been constructed by the participants about their 
experience of being religious, when data is collected about lived experience, it is not collected so it can be generalised to a larger population (Koch, 1995) or another sample. So the meanings and interpretation of those meanings are bound and situated within a context of space and time and may not be reflective of reality for students beyond the sample.

Crotty (1998) also makes the important distinction between constructivism and constructionism, whereby constructivism focuses on individual meaning making, whereas constructionism focuses on collective meaning making. Constructionism was an appropriate epistemology for this study as the source of meaning making came from multiple students and was used to explore the meanings of the phenomena being studied.

\section{Theoretical Perspective: (Interpretative) Phenomenology}

Phenomenology is a methodology focused on "the study of the lifeworld" (Van Manen, 1990, p. 9). The life world is: "what we experience pre-reflectively, without resorting to categorization or conceptualization" (Husserl 1970 cited in Laverty, 2003, p. 4). Phenomenological research aims at "gaining a deeper understanding of the nature or meaning of our everyday experiences" (Van Manen, 1990, p. 9) and because it focuses on the meaning of everyday lived experience it is an appropriate philosophical and methodological framework to use alongside constructionism. In order to gain an understanding of the phenomena of interest the researcher must use the perspective of the subjects or actors (for example emerging adults who are religious university students) themselves to describe how they experience the world (Kvale, 2009). Unlike a natural science which gains meaning from natural objects, phenomenology is considered to be a human science, because meaning is generated through experiences in the lived human world (Van Manen, 1997). Interpretative phenomenology as used in this study involved examining the accounts, stories and narratives about the students' lived experience of being religious, rather than examining their experience of the world directly.

In order to support the rigour of phenomenological studies a connection must be maintained between the phenomenology (research methodology) and the method used (Stubblefield \& Murray, 2002). By maintaining this connection the chance of conducting and completing research that is "ambiguous in its purpose, structure and 
findings" is greatly reduced (Lopez \& Willis, 2004, p. 726). With this in mind one must be aware that within the philosophical school of phenomenology more than one approach can be used. It is important to distinguish the differences between each approach to ensure the most effective phenomenological approach is used to achieve the desired outcomes (Lopez \& Willis, 2004). With the development of phenomenology being described as a philosophical movement (Lopez \& Willis, 2004) it can be considered a philosophy and methodology. Unlike other traditions and quantitative paradigms it lacks a fixed and clear set of prescribed methods for conducting research, hence warranting attention and consideration for the purposes of this study.

\section{Husserl's Descriptive Phenomenology}

Edmund Husserl (1859-1938) (Laverty, 2003) is considered to be the founder of phenomenology (Crotty, 1998). Husserl developed a descriptive phenomenological approach to address his dissatisfaction of science's attempt to apply natural sciences to human issues (Laverty, 2003). To remedy his dissatisfaction Husserl suggested experience could be used as a valuable object of scientific study, obtained through human consciousness (Lopez \& Willis, 2004). He believed a scientific approach with this philosophy could be used to identify the "essential components of the lived experiences specific to a group of people" (Lopez \& Willis, 2004, p. 727). This scientific approach would aim to reach true meaning by probing further and further into reality (Laverty, 2003). What he felt would result was a fuller grasp of what it means to be an individual who has experienced a particular phenomenon (Van Manen, 1997).

Husserl's descriptive phenomenological approach consisted of key assumptions that informed the investigation of lived experience. The first of these assumptions was that "there are features to any lived experience that are common to all persons who have the experience" (Lopez \& Willis, 2004, p. 728). These features common to different instances of the same phenomena were called essences. For lived experience to be described as a science there must be commonalities so a united description can result (Lopez \& Willis, 2004) from the experience being investigated. Once these essence(s) have been reached, a reality is constructed that can be "considered objective and independent of history and context" (Lopez \& Willis, 2004, p. 728). In order to gain an unbiased account of the common essence(s) derived from lived experience, Husserl believed that all prior personal knowledge must be shed (Lopez \& Willis, 2004), which 
was a second assumption of his. This process involves suspending one's judgements or beliefs to see things 'as they are' (Laverty, 2003).

\section{Heidegger's Interpretative (Hermeneutic) Phenomenology}

Martin Heidegger (1889-1976) (Laverty, 2003), a student of Husserl, modified phenomenology by adding an interpretative (hermeneutic) element. This interpretative element, as the name suggests, goes beyond mere description of lived experience to interpreting the hidden or underlying meaning behind the descriptions. "These meanings are not always apparent to the participants but can be gleaned from the narratives produced by them" (Lopez \& Willis, 2004, p. 728). For Heidegger the meaning of lived experience had a dual focus whereby experiences could be taken at face value (visible meaning) or they could be deceptive (hidden meaning) (Smith et al., 2009).

Hidden and visible meaning, although different from one another, should not be considered separate or mutually exclusive in all instances, as hidden meaning can be both a part of and a part from visible meaning (Smith et al., 2009). Meaning is also not just arrived at by the interpretation of the researcher, but rather by a process of coconstruction (Laverty, 2003). This process involves both the researcher and participant contributing their thoughts to the study of interest (Lopez \& Willis, 2004). One must also take note that "There is no one true meaning produced by any interpretive study, but the meanings that are stated in the research findings must be logical and plausible within the study framework" (Lopez \& Willis, 2004, p. 730).

Unlike Husserl whose descriptive phenomenological approach insisted on the use of bracketing to eliminate bias when describing phenomena, Heidegger rejected a 'presuppositionless' phenomenology on the grounds that anyone interpreting a phenomena presented cannot rid themselves of their prior experiences (Smith et al., 2009) and expert knowledge (Lopez \& Willis, 2004). Moreover these experiences and knowledge should, and can rather play a valuable role in determining what sort of research inquiry should be undertaken to generate meaningful knowledge (Lopez \& Willis, 2004).

As I myself am religious, identifying as a Roman Catholic and more broadly a Christian, I know from experience that having the chance to express one's self in a safe environment about being religious in a tertiary setting does not come along as often as it should. With this in mind and the criticisms of total bracketing not being possible, I used my prior experience to connect with and obtain rich descriptions of the lived 
experience of the participants, along with a consideration of previous research to choose a qualitative research design that would give tertiary students a voice. Having a deep understanding of Christianity meant I could spend more time probing further and further into the students' experiences (with the exception of the non-Christian students' experiences), so I did not have to spend long periods of time questioning them about basic Christian tenets.

\section{Methodology: Interpretative Phenomenological Analysis}

Interpretative phenomenological analysis (IPA) is a relatively new approach to qualitative inquiry which originated in the field of psychology, but has increasingly been used in human, social and health sciences (Smith et al., 2009). This approach is grounded in exploring and understanding lived experience. According to Dilthey (1976):

Whatever presents itself as a unit in the flow of time because it has a unitary meaning, is the smallest unit which can be called an experience. Any more comprehensive unit which is made up of parts of a life, linked by a common meaning, is also called an experience, even when the parts are separated by interrupting events (Dilthey, 1976 cited in Smith, Flowers, \& Larkin, 2009, p. 210).

It is these 'comprehensive' units that are most often the interest of an IPA (Smith et al., 2009).

When an individual engages with an experience they have had they are able to reflect on what it means (Smith et al., 2009). The data of this study are the reflections of the students' on their lived experiences. My challenge as the researcher was to understand what the individuals' reflections meant (Smith et al., 2009). In IPA this is called a 'double hermeneutic' because "the researcher is trying to make sense of the participant trying to make sense" (Smith et al., 2009, p. 3) of what they experienced, where multiple interpretations are possible.

In IPA the researcher combines empathic hermeneutics with questioning hermeneutics (Smith \& Osborn, 2010). This element of IPA involves the researcher not only taking the side of the participant about what their experience was like, but also questioning the participant about things they may be less aware of (Smith \& Osborn, 2010). The 
justification behind this element of IPA is two-fold in that it allows a richer more comprehensive analysis of participants' experiences (Smith \& Osborn, 2010) without a blind submission to their subjective perspective and a recognition that meaning can be constructed not only personally, but socially as well (Smith \& Osborn, 2010). In recognition of the importance of empathic and questioning hermeneutics in IPA, both types of questioning were used regularly throughout the interviewing and data analysis stages of this study.

\section{Rationale for Research Methodology}

When selecting an appropriate methodology to employ in a research study it is important to consider the views of earlier researchers. Good and Willoughby (2007) highlight that previous studies focusing on young people and religion "have largely failed to access actual voices of young people" (p. 391) and the literature review shows that many have used quantitative designs. A decision was made to use a qualitative paradigm and phenomenological methodology because this would allow for the exploration of what being religious involves, its importance and what it means to students. This data collection method would also privilege and provide students with an opportunity to have a voice and share their experiences.

The qualitative research design chosen met the objectives and research questions of this study that required an inquisitive and exploratory approach. Johnson and Christensen (2012) stated: "Qualitative research is used when little is known about a topic or phenomenon and when one wants to discover or learn more about it. It is commonly used to understand people's experiences and to express their perspectives" (p.33). An interpretative phenomenological methodology was chosen to best access the meanings of the lived experience of being religious within the sample population. By employing an interpretative phenomenological approach this research study had the aim of not only describing the lived experience of the religious students, but also interpreting the meaning of their experience. In order to gain such data for interpretation qualitative research can employ a range of data collection and analysis methods. 


\section{Data Collection and Analysis Methods}

\section{Participant inclusion criteria.}

The aim of recruitment in this study was to select participants who had lived experience of being religious, who were currently enrolled at Victoria University of Wellington. Participants needed to be able to articulate clearly and be willing to talk about their experience and were "diverse enough from one another to enhance possibilities of rich and unique stories" (Laverty, 2003). The emphasis of diversity in this study focused on the participants' experiences, although there was a strong representation of various religious traditions in the study sample. Demographic factors such as age and sex were considered to ensure the sample was not uniform.

Phenomenological studies tend to have relatively small sample sizes of between 10 and 15 participants (B. Johnson \& Christensen, 2012). Participants were recruited $(n=10)$, to take part in this study. Participants in the emerging adult stage of 17-25 years were recruited, with a purposive sampling method (B. Johnson \& Christensen, 2012) which ensured an equal mix of five males and five females. Participants took part in the study on a voluntary basis and could identify with any religious tradition, which assisted with gaining a diverse sample and a range of experiences of being religious. Each of the participants were enrolled at Victoria University of Wellington ], making the sample a convenient sample. No discrimination was made against potential participants regarding what each participant had previously or was presently studying.

\section{Recruitment strategy.}

Five strategies were used for advertising and recruiting in this study:

1. Hard-copy fliers were posted extensively throughout Victoria University of Wellington campuses on student notice boards and in public walkways (See Appendix A for a copy of the flier).

2. Each of the key contact people for the religious groups represented at Victoria University of Wellington as listed in the clubs directory were contacted by phone and were informed about the study. 
3. A flier and description of the study was emailed to lecturers in both the education and religious studies departments of Victoria University of Wellington, whereby several lecturers posted a notice about my study on Blackboard, the online communication forum between students and lecturers.

4. One Christian religious group was spoken to in person at their weekly gathering.

5. My supervisor advertised my study verbally in various classes he taught.

Multiple recruitment strategies were therefore used, which is appropriate when accessing a minority population sample (Caserta, Utz, Lund, \& De Vries, 2010).

\section{Method of data collection.}

When conducting a study using interpretive phenomenology a number of methods can be used, including personal accounts and diaries (Smith \& Osborn, 2010). Arguably the best and most popular method for ensuring reliability, however is the semi-structured interview (Smith \& Osborn, 2010) which "attempts to understand themes of the lived everyday world from the subjects' own perspectives" (Kvale, 2009, p. 27) through the descriptions they give. This form of interviewing is conversational in style and is guided by an initial template of questions that can be adapted and changed as interviews progress. The common advantages associated with conducting semi-structured interviews as opposed to structured interviews are: "facilitates rapport/empathy, allows a greater flexibility of coverage and allows the interview to go into novel areas, and it tends to produce rich data" (Smith \& Osborn, 2010, p. 59).

The data collection method for this study was open-ended semi-structured individual interviews, which is the traditional collection strategy for qualitative research (Lopez \& Willis, 2004) and the most regularly employed method of data collection when conducting phenomenological research (Bevan, 2014). The data I collected was transcribed by a transcriber who signed a confidentiality form, before the data was subsequently analysed (Kvale, 2009) (See Appendix B for a copy of the transcriber confidentiality form).

\section{Interview process.}

Before and during the interviews I built a rapport with each of the participants (HesseBiber \& Leavy, 2006 ). Building rapport has the purpose of helping the participant feel "safe, comfortable, and as though what they are saying is valued" (Hesse-Biber \& 
Leavy, 2006 p. 128). In addition, rapport-building acts as a quality assurance method. Pitts and Miller-Day (2007) highlight that establishing a relationship with study participants is a necessary requirement to ensure validity or trustworthiness in naturalistic enquiry. One way this occurred in the present study was through empowering and encouraging the students to speak about their own lived experience (rather than what they think I might have wanted to hear as a researcher). This measure was designed to ensure high quality data that reflected the students' experiences.

Before the interviews I met with the students to explain the aims of the study and what the interview would entail. The students were fully informed about what their participation would involve; taking part in an interview that would last approximately 12 hours, with a possible follow-up interview (See Appendix C for a copy of the study information sheets). The students were also given an opportunity to ask any questions they had about the study. The participants were provided with a guide to the type of questions that would be asked in the interview and were free to have those questions in front of them during their interview. The guide was given to them prior to their interview so they could think of specific life events and experiences of being religious, and begin to think about what aspects of their life worlds they wished to share. Providing the participants with an interview guide acted as a quality assurance measure that strengthened data collection as it meant the students had a visual (the interview guide) and an oral guide (myself as the researcher) to ensure what they shared was relevant to the study objectives.

At the beginning of each interview I read off a pre-written script (Jacob \& Furgerson, 2012). This script ensured consistency between interviews and that important information that needed to be shared with each participant was not forgotten. The script included a statement of the study title, the purpose of the interview, a self-disclosure of my religious identity and a reminder that the interview was about the participants' and their experiences. The early stages of each interview began with the participants being asked a general open-ended question inviting them to share some background information about themselves such as their age, where they are from and what they study. This first question, which was asked conversationally, had the role of easing the participants into the interview and laid the foundation for more complex questions that would follow. 
Throughout the interview prompts were used to encourage the participants to reflect on their experiences as part of the interpretative and meaning-making process or to give more detail about their lived experience. I also gave attention to any significant nonverbal cues as a way of adding to the understanding and expression of the participants' experiences beyond what was captured in the tape recordings (Tan, Wilson, \& Olver, 2009). No non-verbal cues were recorded that added to the meaning of the students' experiences.

The final stages of the interview followed a script of questions to ensure that the participants knew that the interview was coming to an end. Each participant was invited to share anything else they wanted to about their experience. I also asked the participants if they were willing to be contacted with follow-up questions and told the participants that I could be contacted if they had forgotten or would like to add details to their descriptions (See Appendix D for a copy of the interview guide).

The responses of the participants were recorded using a digital recorder at Victoria University of Wellington. The interviews lasted 40-80 minutes. It was judged that follow-up interviews were not necessary after consultation with my supervisor, because the descriptions from the participants were already detailed and rich enough for analysis. Moreover, none of the students requested a follow-up interview after they had been provided with a summary of their interview. After each interview the participants were given the opportunity to express any concerns and to generally give feedback about the interview.

\section{Data analysis method.}

When a researcher is analysing data in a phenomenological study, they are unable to entirely recreate the event where they collected the data (Tan et al., 2009). Instead the researcher is left with only an impression of the language of the interview (Tan et al., 2009) and the participants' narrative of events and their experience. With this degree of separation from the original interview I had the challenge of analysing what had been expressed. With this in mind, the data analysis method used in this study was IPA (Smith \& Osborn, 2010).

To analyse the spoken word of the students' subjective experiences of religion (Lopez \& Willis, 2004) IPA (Smith \& Osborn, 2010) was used. Whilst IPA follows a general lineal pattern, the process of analysing lived experience in this study was iterative. In 
the first instance of conducting my analysis the students' transcripts were checked for accuracy by listening to the audio recordings and comparing them to the transcriptions (Polit \& Beck, 2008). Checking the transcripts added to the methodological rigour of the study by ensuring that the exact spoken words of the students were analysed rather than inaccurately transcribed words. As a result all errors were corrected, and in instances where both the transcriber and I were unsure what the student had expressed, the student was approached and gave the necessary corrections and/or clarification that was required. This occurred on one occasion where a student used language from his own religious tradition that was not common to New Zealand English.

Van Manen (2014) details an orderly and effective method for exploring texts in the pursuit of thematic meanings that laid the foundation for the construction of themes in this study. In the first instance I completed a holistic reading of each of the students' interview transcripts. During this first 'naive' reading initial observations of analytical importance were briefly noted (Braun \& Clarke, 2006). After reading the transcripts and noting any initial analytical observations the transcripts were read again for a second time with a focus on the research questions and identifying emerging themes across interviews. Each of the significant statements in the transcripts were coded so they were relevant to the research question, for example one code was "being marginalised". This code highlighted that for one student part of their experience of being religious involved marginalisation.

Once each significant statement from the students' transcripts were coded, codes that were alike were categorised together that captured similar experiences such as being criticised or stigmatised. This was a meticulous process where I needed to have an open-mind about what the students had experienced beyond what they said. This process of analysis involved analysing the literal meaning of what was spoken and transcribed in the pursuit of constructing thematic meanings, as well as 'reading between the lines' to search for hidden meanings (Koch, 1999). Braun and Clarke (2006) point out that this process is therefore characterised by themes being constructed from the research data rather than being 'found'. 
After coding was complete I conducted a structural analysis of the codes across the data set whereby similar codes from each student were grouped together. During this stage I sought to "understand the content and complexity of those meanings rather than measure their frequency" (Smith \& Osborn, 2010, p. 66) and get to the essence of the lived experience of being a religious university student.

The codes which were based upon significant statements were then formulated into sub-themes which captured "something important about the data in relation to the research question, and represents some level of patterned response or meaning within the data set" (Braun \& Clarke, 2006, p. 82). The codes that made up each sub-theme were then checked against each other to ensure consistency. Each set of sub-themes were then grouped together under a super-theme (also known as a superordinate theme) (Smith \& Osborn, 2010) that was titled to accurately reflect the codes it represented.

By using IPA I was able to privilege the voices and words of the participants and their own religious experience, which is something that has been lacking in empirical literature (Good \& Willoughby, 2007). This was achieved by drawing on the lived experiences of the students and using the words they used to describe their experiences. Most importantly I completed a rigorous process of analysing the students' experiences to construct the meaning of those experiences.

\section{Reliability/Integrity and Trustworthiness}

Various strategies were used to promote trustworthiness (Lincoln \& Guba, 1985) in this study. Reflexivity, was used to promote credibility through the use of a reflective diary to ensure that any religious predispositions or biases I may have had would not affect my research. This occurred in place of bracketing pre-understandings of the topic, because it is not possible when using a hermeneutic phenomenological approach (Koch, 1995). Regular meetings with my supervisor also ensured my study remained credible by ensuring that my own religious preconceptions were not imposed on the actual lived realities of the students (Malterud, 2001).

I kept an audit-trail to document various decisions made in my study especially around the construction of themes. For example one audit trail entry included renaming my super-theme "being religious is worthwhile" to "being religious is constructive". Renaming this super-theme recognised that whilst being religious was worthwhile for the students by giving them benefits, it did more for them, in actually contributing to 
their development, meaning, purpose and 'being' as young people. Such a strategy ensured that my decision-making remained consistent and did not negate prior decisions that were made.

Member checking was used to ensure that the experiences of the participants were translated into data accurately (Lincoln \& Guba, 1985). This involved giving the participants the opportunity to check the accuracy of a summary of the findings of their interview (Krefting, 1991), which increased the credibility of my findings (B. Johnson $\&$ Christensen, 2012) by making the experiences of the students recognisable to them in the study's findings (Krefting, 1991).

When the participants were emailed a document outlining the key themes that I formulated from their interview, each of the sub-themes was substantiated with direct quotes from their own interview transcript. The participants were encouraged to confirm or challenge what had been formulated to ensure what they had said was accurately represented. The participants were also asked whether they agreed with, or could think of a better word or words for the sub-theme names that I formulated. Of the nine students who gave feedback about their summary, three of the students made comments that challenged or clarified the interpretation of what was sent to them. For example, two of the students reinforced points that were important to their experience that were not explicitly presented in their document. One student was not sure that saying religion “involves" certain things necessarily fairly represented the fluidity of his experience, for example in his university classes compared to other contexts. No recommendations for more appropriate theme names were suggested.

Whilst it is impossible for the findings of this study to be universally transferable, a level of transferability was achieved through providing the relevant background information of the study and a thorough account of the students' characteristics (See Table B for a table of the students' characteristics), the methods that were used and the study's findings (Malterud, 2001). Future researchers have a clear guide about what degree of transferability the present study would have for them in shedding light on their own research questions (Malterud, 2001) and findings. 
Finally, the use of low-inference descriptors, which are in the form of verbatim quotes from the students, are used extensively throughout my findings chapter. By citing these quotes the reader is able to understand the students' experiences from interpretations of their own words rather than any other more indirect source (B. Johnson \& Christensen, 2012).

\section{Ethical Considerations}

According to Johnson and Christensen (2012) the "treatment of research participants is the most important and fundamental issue that researchers confront" (p103). It is this ethical principle that guided the ethical decisions faced in this research study to ensure the students were protected from mental and physical harm (B. Johnson \& Christensen, 2012). An ethics application to conduct my study was submitted to and approved by the Victoria University Human Ethics Committee (See Appendix E for a copy of the ethics approval form).

\section{Informed consent, anonymity and confidentiality.}

The participants were required to give active and ongoing informed consent after they were fully informed about the study (Johnson \& Christensen, 2012). In the first instance participants were required to sign a consent form (See Appendix F for a copy of the consent form) to acknowledge their willingness and commitment to take part. At this time the participants were also informed that they were free to withdraw from the study without question or penalty at any time. All of the students were, however, retained for the whole study.

Confidentiality of the students' names and the information they gave was maintained, with only myself as the researcher, my supervisor and the interview transcriber having access to the students' first names and the information they gave, as outlined in the ethics consent form and information sheets. Anonymity of the students' identities was maintained throughout this research study with the students being giving pseudonyms. In addition I ensured that any identifying details, names, places or references to other people (university staff, peers, family) who should not be identified, were also removed. 


\section{Protection of students and the reputation of the university from risk or harm.}

A disclosure process was developed prior to the study and as part of the ethics application process. Participants were informed prior to interviews that if they shared information that revealed they or someone else was at risk, or that they had experienced trauma, religious persecution or serious discrimination that this would be discussed with them. The relevant information would be shared with my supervisor and an appropriate course of action implemented to ensure the student's safety and wellbeing (referral to student services, provision of information about student rights). No such information was shared by any of the students so no action based on the disclosure process was necessary.

To ensure the reputation of Victoria University of Wellington was protected and integrity upheld, all of the ethical principles and procedures as outlined and advised by the University Human Ethics Committee were followed once ethics approval was submitted and granted. This helped ensure that the study was thoughtfully planned, conducted and supervised.

\section{Summary}

This chapter outlined the objectives for this study to understand the subjective lived experiences of religion in emerging adults (17-25 year-olds) within a New Zealand tertiary education setting. In addition it detailed the research design, including the epistemology (constructionism), theoretical perspective (interpretative phenomenology), methodology (IPA), data collection methods (open-ended semi-structured interviews) and data analysis method (IPA) used in this study. A rationale and description of interpretative phenomenology and IPA was provided. The chapter discussed the interview process that took place with each of the students where they were invited to share their experiences of being religious. The measures to ensure the reliability and trustworthiness of my research processes and findings were presented and an account of the ethical considerations for this study were listed and detailed. The following chapter outlines the key findings and analysis of the findings of the study. 


\section{CHAPTER FOUR: FINDINGS}

\section{Introduction}

The previous chapter included a detailed discussion of the methodology and methods used in this study. Conducting open-ended and semi-structured interviews generated a detailed and in depth account of the students' experiences of being religious. This chapter presents the findings from analysing the students' interview transcripts to detail their experiences. These findings should be valued for their depth and richness as opposed to their generalizability.

The findings are presented thematically with four super-themes appearing that each have multiple sub-themes. All of the themes are supported and substantiated with verbatim extracts from the students' transcripts to support their inclusion. In hermeneutic phenomenology many interpretations of individuals' lived experiences are possible. With this in mind the interpretation of the researcher can and should be viewed as one of many possible interpretations.

The themes presented are not an exhaustive representation of all of the themes that emerged after the students' transcripts were analysed. The themes attempt to reveal underlying and hidden meanings and are those that best represent the students' experiences of what it means to be religious in a tertiary education setting.

Each story that was told was unique from one another and played a role in forming an understanding of what it means to be a religious student. With all of the students considering themselves religious and coming from a diversity of religious backgrounds there are both similarities and differences in what they shared.

\section{Findings}

A detailed IPA of the students' interview transcripts led to the development of a single overarching meaning or essence of what it means to be a religious student: engaging with the sacred. Engaging with the sacred was what the students did when being religious and studying. This overarching meaning developed from the analysis of the first interview that was conducted that indicated that being religious required active engagement and was a common aspect of the experience across all the participants. This 
meaning has parallels with the definition that Pargament (2001) gives to religion: "a search for significance in ways related to the sacred" (p. 32). This definition highlights the activity involved in being religious through it involving a search, and the object of one's search, the sacred: things, places and persons that are "Set apart for or dedicated to some religious purpose, and hence entitled to veneration or religious respect" (Oxford English Dictionary, 2013).

Pargament, Maygar-Russell and Murray-Swank (2005) provide a list of what the sacred can include:

$$
\begin{aligned}
& \text { material objects (crucifix, drugs), time and space (the Sabbath, } \\
& \text { churches, mosques), events and transitions (birth, coming of age, } \\
& \text { death), cultural products (literature, music), people (saints, monks, } \\
& \text { cult leaders), psychological attributes (meaning, self-actualization), } \\
& \text { social attributes (caste, patriotism), and roles (marriage, parenting, } \\
& \text { work) (p. 668). }
\end{aligned}
$$

Although there is much variation across religious traditions, Pargament and Mahoney (2005) highlight that they are united in their concern for things sacred. This concern is given an active function through individuals' efforts to not only find significance, but to also conserve it and transform it as they see appropriate (Pargament, 1999).

Engaging with the sacred has a dual focus where religious people are on a pathway, but at the same time seek a destination (Pargament, 1999). On this pathway religious people take part in prayer, rituals and other religious activities in the pursuit of what they believe is to come for them if they follow their religious tradition earnestly, for example reincarnation or resurrection. The overarching meaning of engaging with the sacred encompasses all experiences of being religious whether they are good or bad, individual or collective (Pargament, 1999).

For the students in this study engaging with the sacred involved: 1) having a relationship with God, of which some of the students specified who 'God' was for them; namely Allah for Asha, Bhagwan Swaminarayan for Vijay and Jehovah for Clarissa. It should be noted that throughout this chapter that 'God' is used as an allencompassing term for the deity each student worshipped 2) being different to secular peers 3)being inter/intrapersonally challenged 4) having a constructive influence in one's life. 
Table A: Essential themes of the students' religious experiences

\begin{tabular}{|l|l|l|l|l|}
\hline Overall meaning of being a religious student: Engaging with the sacred \\
\hline $\begin{array}{l}\text { SUPER- } \\
\text { THEME }\end{array}$ & $\begin{array}{l}\text { Having a } \\
\text { relationship with } \\
\text { God }\end{array}$ & $\begin{array}{l}\text { Being different to } \\
\text { secular peers }\end{array}$ & $\begin{array}{l}\text { Involved inter/ } \\
\text { intrapersonal } \\
\text { challenges }\end{array}$ & $\begin{array}{l}\text { Being religious is } \\
\text { constructive }\end{array}$ \\
\hline $\begin{array}{l}\text { SUB- } \\
\text { THEME }\end{array}$ & $\begin{array}{l}\text { Participating in } \\
\text { private and social } \\
\text { rituals }\end{array}$ & $\begin{array}{l}\text { Having different } \\
\text { beliefs, values } \\
\text { and philosophies }\end{array}$ & $\begin{array}{l}\text { Having } \\
\text { faith/religion } \\
\text { dismissed }\end{array}$ & $\begin{array}{l}\text { Praying is } \\
\text { therapeutic }\end{array}$ \\
\hline & $\begin{array}{l}\text { The relationship } \\
\text { requires personal }\end{array}$ & $\begin{array}{l}\text { Feeling confused } \\
\text { resolving conflict } \\
\text { of being } \\
\text { stigmatised/stereo } \\
\text { typed }\end{array}$ & $\begin{array}{l}\text { Not being } \\
\text { understood }\end{array}$ & $\begin{array}{l}\text { Being religious is } \\
\text { valuable }\end{array}$ \\
\hline & $\begin{array}{l}\text { Living life } \\
\text { according to } \\
\text { values }\end{array}$ & $\begin{array}{l}\text { Difference as } \\
\text { something } \\
\text { positive }\end{array}$ & $\begin{array}{l}\text { Criticism and } \\
\text { intolerance } \\
\text { and respectful } \\
\text { relationship with } \\
\text { a powerful friend }\end{array}$ & $\begin{array}{l}\text { Religion provides } \\
\text { support }\end{array}$ \\
\hline & $\begin{array}{l}\text { Negative } \\
\text { stereotypes }\end{array}$ & $\begin{array}{l}\text { Religion helps } \\
\text { defines your } \\
\text { purpose and } \\
\text { identity }\end{array}$ \\
\hline & $\begin{array}{l}\text { Religion has } \\
\text { benefits after } \\
\text { death }\end{array}$ \\
\hline
\end{tabular}

\section{Super-Theme 1: Having a Relationship with God}

The first super-theme was having a relationship with God. This defined a key part of the students' religious experience whereby the students had and strove to maintain a connection and commitment to God. Having a relationship with God involved participating in both personal/private and social rituals. For many students' their relationship with God was important and their actions of prayer and other forms of engagement reflected this reality depending on how they perceived their relationship. For other students their relationship was about adhering to religious teachings and principles. Despite at times there being overlap across the students' accounts, there were also unique aspects of their relationships with God. Each example below substantiates what having a relationship with God involved and meant for the students. 


\section{Participating in private and social rituals.}

Taking part in special private and social rituals and practices enabled the students to encounter God and strengthen their relationship. These rituals and practices can be described as rituals or customs that are important or inherent to the students in their various religious traditions. For all of the students carrying out these rituals or customs was a regular occurrence and an important part of maintaining a relationship with God.

Joan's relationship with God involved a weekly ritual of attending Mass and receiving the Eucharist (the Body and Blood of Christ): “if you're going to actually be consuming the Body and Blood of Christ every weekend...that's going to help a lot with your relationship with Jesus because you're going to meet with him every Sunday". During these encounters she felt a strong connection to God. Joan also valued her relationship with God: "focusing on the relationship with Jesus which is important". She saw the rituals built into her Catholic faith as supporting the development and maintenance of that important, intimate and personal relationship: "everything that is built around the Catholic Church is supposed to support you in having that relationship". Joan's partaking of the Eucharist helped make her relationship with God real and intimate, through actually meeting Christ in this personal encounter as part of her religious community.

Gregory's relationship with God involved "trying to take some time out...to pray or just read the Bible or...spend some time with God and...communicate with Him”. Mary's experience was similar to Gregory's, because she also used prayer to communicate with God: "praying is just like talking with Jesus". Clarissa also described the role of prayer in her relationship: "in relationship with God...I say a prayer...and...you can ask for specific things and sometimes they turn up and prayer is really important". For Gregory, Mary and Clarissa prayer provided the necessary means of communicating with and connecting to God.

For other students like Dave, prayer was also an important ritual and custom, which could be personal but also shared in a social context. For Dave both praying and discussing scriptures with other Christians were important ways of maintaining a relationship with God. Dave explained that for him the rituals involved both contact with God and others: "pray, that's the way we contact God" and: "meeting with a few people, a few other Christians, and enjoying a little bit of the Bible”. For Dave prayer could occur in a variety of ways and places, making his means of maintaining a 
relationship with God versatile and transportable. Dave's relationship with God was accessible and made participation in rituals and customs less bounded compared to those students who followed customs, rituals, traditions and practices which were bounded to specific physical and spiritual locations and times.

Henry, like Dave discussed the fluid nature of prayer and emphasised that: "Prayer can be both an individual and a group thing”. For Henry prayer was about "communicating directly with God" in an individual setting, like in the way he journaled to God every night. But it was also something that could occur in a group setting, like when he attends Mass. These times of prayer for Henry confirmed: "He's (God)... a part of your life and that He's looking after you". Prayer for Henry was what reinforced the bond between him and God.

Like Dave and Henry, prayer also helped Vijay maintain his relationship with God. One example of this from Vijay's experience was doing a private morning prayer ritual called a "puja" which he described as "a personal communication with God". During this communication Vijay took time to express his "feelings...and...concerns". Such prayer time for Vijay involved talking to God, which for him was like talking to someone next to him. Like Henry and Clarissa, Vijay also admitted that he does not always get answers from God when he questions him about things. Despite this reality Vijay said that he can "feel that presence" which convinces him that he does have a relationship with God, and that prayer is the ritual and catalyst for feeling that presence.

Prayer was also important for Asha, but she did not specifically state that she had a relationship with God, whom she called “Allah”. Her relationship was implied because she spoke of the fundamental importance of praying five times a day and being "in remembrance of God" every time she prayed, which she said involved "speaking to Him ". Prayer had the role of strengthening Asha's iman, which roughly translates from Arabic to English as faith. Prayer was the medium for communicating with God which gave Asha faith and a relationship with God.

It was difficult to determine how the rituals Sebastian took part in influenced or contributed to his relationship with God because Sebastian said "I don't really know if I have much of a relationship with God" and that he felt his relationship was "uncertain". Rituals that Sebastian took part in included "grace and prayer...pray at least once a day but often around three times a day and...grace before lunch and dinner". 
For Rachel, participating in private and social rituals was not key for having a relationship with God which made her an exception to the rest of the students in the sample. One of the reasons given for this was that she had not found "a particular format that gels". This may have been why she described her relationship with God as "Casual, distant? Guarded”.

While some students such as Joan, Sebastian and Henry emphasised the importance of personal/private and social rituals for providing a means to develop and sustain a personal relationship with God, for others like Dave, the rituals were less important than the relationship itself. For Dave being a Christian was about the personal experiences that he had in his relationship with God: "as opposed to...traditions dictating what... religion is about". Dave's emphasis was not on Sunday church attendance and said that despite the Bible giving more depth to your relationship: "you can definitely have a relationship with God without reading the Bible". Dave's emphasis was on "enjoying God" and knowing that: "He's someone that you can actually talk to".

\section{The relationship required personal commitment.}

Having a relationship with God was important and required the students to be actively committed. Students such as Clarissa who is a Jehovah's Witness shared: “it's all about you and your relationship with God" and "my relationship with Jehovah's very important". Students reflected on their commitment and level of participation in religious activities which helped to gauge their commitment. Clarissa had a personal commitment to "praising God" through "door knocking, attending all...her... meetings...and...saying prayers". All of these elements of praise in commitment to God were part of Clarissa's engagement as a religious young person.

Joan defined her commitment to her relationship as: "consciously and willingly participating in church life". She went on to share some examples of her personal commitment: "I adhere to the social teachings (of the Catholic Church)... and...now and then I go to retreats or Catholic events". Joan compared herself to her sister to highlight her level of commitment and said that her sister: "doesn't regularly attend church" and “doesn't search more about God". Joan's commitment was demonstrated by her active involvement in church life.

Henry, the only other Catholic in the study, also spoke about commitment to his relationship with God and the Eucharist: "I'm strongly committed to having a 
relationship with Jesus and to receiving the Body and Blood at Mass regularly". Like Joan, he placed a great deal of importance on this ritual. He suggested that the ritual made his relationship not only more personal or intimate, but meaningful. Receiving the Eucharist for Henry was a reminder of God's love: "it's just like a healing thing and it's just so...meaningful that God will let us consume Him...because He loves us so much”.

Being active and having a strong relationship with God also meant that the students needed to dedicate regular time and energy to that relationship and personal investment. Gregory said: "for me being a Christian is about my relationship with God and it's an active relationship". An example of being active that he shared was: "when you have... a relationship with a friend or you know anyone in your life...you're engaged with that person on either a day to day or even a weekly basis". For Gregory this meant praying, reading the Bible and communicating with God on a daily/weekly basis but also engaging with others who found these activities important: "It's not a passive thing, so it's about getting actively involved...with what I do". What laid the foundation for this commitment shown by Gregory was when he got baptised which in his words was: "a public reaffirming of your faith and saying...that...I do want to...have a relationship with God". Personal commitment for Gregory had a symbolic and sacramental manifestation. Being baptised symbolised that he had put "his hand up to be a Christian" in a formalised sacrament as part of his Christian tradition.

Vijay's commitment to his relationship with God can also be seen from the aforementioned "puja" he took part in where he had to "wake up earlier than...he...would wake up if...he...hadn't been doing...it". Vijay's experience highlighted a sacrificial element to commitment. For Vijay maintaining a relationship with God sometimes involved doing things he would not choose to do, such as waking up early in the morning. His commitment was made easier by the opening of a temple near him with statues where "God actually does reside" in them. This gave Vijay the opportunity to enhance his relationship and commitment to God, because with faith, when he looked at the temple statues he was convinced that "God...was...standing right in front of...him". On occasions when Vijay was not as committed and he "may disobey one of the spiritual orders" he felt his connection with God "weakening". For Vijay a relationship with God required personal commitment in the form of prayer and going to his temple weekly to keep that connection strong. 
Dave had a strong personal commitment to his relationship with God because in his experience it was his relationship with God that made his faith "real". Dave also added that for him a "relationship, personal relationship" was what summed up his experience of being religious. The key part of this personal commitment was focusing on "enjoying God" which came through strongly when he said: "at the end of the day...it is a personal experience... and as long as I am enjoying God personally...that keeps me going". Dave's experience highlighted that despite the commitment a relationship with God entails, it is sustainable through it being enjoyable.

While Rachel did not show commitment to her religion by going to church on a regular basis or participating in other private and social rituals, she did describe herself as religious and demonstrated her commitment to her "Casual, distant? Guarded" relationship in other ways. For example, she said: "I definitely stand up for myself about it (Christianity) if someone queried it. And I definitely call people on it if people start making...noticeably anti-Christian comments in my presence”. This commitment stemmed from the fact that Rachel did not "feel comfortable denying the fact that... she was...religious". Rachel's commitment to being religious was unique in the way she highlighted that having a commitment to one's religion does not necessarily solely rely on participation in rituals, but can also involve defending one's religion when it is attacked.

Mary's personal commitment to her relationship with God did not have a foundation of baptism like Gregory, so no sacramental commitment was present for her. Mary's personal commitment was characterised by her continued striving to be more committed, because her experience was that she was "slowly figuring out what it means to be a Christian and to be a religious person" and with her own self-reflection conceded: "I think I'm just young, and I don't have my priorities straight".

For the remaining two participants, Sebastian and Asha, it was difficult to determine whether their relationship with God required personal commitment. As mentioned in the previous sub-theme Sebastian felt he had an “uncertain” relationship with God. Despite this he could probably be described as being committed through his commitment to praying and saying grace before meals as mentioned earlier. Asha's reality was similar to Sebastian because she demonstrated her commitment by praying five times a day. She did however highlight the difference between herself and her Muslim peers who she said grew up with who were "not as faithful" as her. This suggested she may have been 
more committed to practising Islam than her peers. Whilst Sebastian and Asha's commitment was not as explicit as the other students, it was still present.

\section{Living life according to values.}

Being religious, engaging with the sacred and having a relationship with God also meant 'walking the talk' or practising the principles taught in their religion. Sebastian's relationship with God needed to be reflected in his philosophy and actions towards others where being a Christian gave Sebastian a guide of how he should act when it came to treating other people:

Treat your neighbour as yourself...has been my kind of core philosophy that I try to live by and it's not just like being kinder to others...it also means being kind to yourself...so...that you treat others how you treat yourself, so you don't give away everything because then you're valuing others more than you value yourself.

For Henry being religious and having a relationship with God meant acting according to models and not being afraid to act according to Catholic principles on campus: "I try to act as a person who follows Jesus" and: "on campus...it's just how I act”. Being a Catholic, Henry had Jesus as a model to follow and guide him regarding what actions were appropriate to live a wholesome life.

Gregory's relationship with God meant living according to values centred on Christ: "I think the main thing for me is just to live a life that is Christ-like". When asked what this involved Gregory said that it included "showing humility and showing respect and love for those around you and also being involved in the world and not just kind of separating yourself"'. Avoiding this separation meant Gregory did not consider himself as better or above other, especially non-Christian people. By Gregory not separating himself from the world he described his faith as progressive: "I drink...go to parties that sort of thing". This was Gregory's way of saying that there are things in the world that Christianity may not endorse that should not be ignored, as other Christians may ignore or condemn. His feeling was that Christians should understand what goes on in the world as a way of trying to imitate how Jesus lived his life in reaching out to people. Gregory used a biblical example to justify his commitment to his value system: "it's better to understand...these people because you know Jesus had lunch at tax collectors houses which back in the day you couldn't do that". By Gregory living the value of not 
separating himself from the world he was able to imitate Christ which strengthened his relationship with God

Clarissa held a similar value to Gregory where from her experience she did not agree with separating herself from the world: “we (Jehovah's Witnesses) are to live in this world, but not to be a part of it...so we can't exclude ourselves away in a little sector". Living in the world for Clarissa meant upholding the value of being "nice to everybody", but if they were not associated to her religion she would "limit...her...time with them". Although at times Clarissa did not agree with some things that were happening in the world and views that people had, she upheld her commitment to being a Jehovah's Witness by being integrated into society.

For Mary being religious also meant trying to live according to the principles of her religion. These principles were an ideal that people could aim for: "Being religious is genuinely striving to be more Christ-like. I think Christ embodies all the important aspects of being religious, like being loving, being faithful and being hopeful". Like Henry and Gregory, Mary felt that Christ is the ideal model for being a Christian. Meanwhile Asha, the Muslim student had a different model to follow. She emphasised the same commitment to living her life according to a set of values. Her commitment to a relationship with Allah was shown through her submission to His will and following the five pillars of Islam. To put it simply she said: "Well basically Islam it means submission, so submitting to God". Asha explained that she had a clear guide of values to live by as presented in the five pillars of Islam: "not backbiting, no gossiping, no lying, lying's really bad".

Vijay was very committed to and disciplined about living out the values and principles taught in his religion. The principles that Vijay mentioned as part of being committed to Hinduism included: "Do not steal, don't eat meat, don't drink alcohol...and...do not have a close relationship with women”. For Vijay living these principles was very much justified because he believed they would enhance his life: "whatever orders or spiritual commands we've got they're for our good and they give us a better life than if we did not follow them".

Dave's commitment to religion and his relationship with God was not heavily valueladen. The reason for this was because Dave's relationship with God was "not based on doctrine...or...teachings...or traditions and practices". Dave's emphasis was on enjoying God. Rachel also did not describe her relationship with God as heavily value- 
laden stating she only had one major value/guide: "Forgiveness is all I've got to be honest", which she conceded: "I'm not very good at that".

The values that Joan committed herself to were based on the traditional teachings of the Catholic Church. One of these values that Joan lived by was abstinence. Joan's commitment to abstinence took place despite her belief that what she was doing "is not that common anymore". Her commitment to abstinence was a sacrifice that acted as a reminder of her relationship with God.

\section{Having a 'real' and respectful relationship with a powerful friend.}

Some of the students described the nature and quality of their relationship with God as being an authentic connection with a friend greater than themselves. The students' relationship with God was reciprocal in that they showed gratitude and submission to God, in response to God being a source of life by forgiving and not judging them. Despite the reciprocity of this relationship the students recognised the power of God that transcended their own or anyone else's ability to good in their lives.

Unlike Henry and Joan who saw receiving the Eucharist as a fundamental part of supporting and strengthening their relationship with God, an important part of being religious for Dave was recognising the power and sacredness of God and "seeing God as a source of life". Acknowledging God as a source of life made Dave's relationship with God "real”. Seeing God in this way meant Dave recognised his subservient status within the relationship and his need to be grateful. Dave described his relationship with God as a "servant style relationship...you know God has done these things for me and now it's up to me to do what He wants me to do. So I try my best to be very submissive in terms of what He...guides me to do". Dave recognised what God had done for him, and despite God giving him free will to do what he wanted to do with his life, he submitted to the will of God out of gratitude and respect.

Clarissa also saw her relationship with God, whom she calls Jehovah as "definitely a direct thing" where she could go directly to Jehovah for prayer and guidance, rather than using intercessors as in other Christian traditions. She shared that Jehovah is powerful because: "Nobody else can forgive you. Nobody can condemn you, nobody can do anything”. It was evident that Clarissa's relationship with Jehovah required an investment of time and energy, because without Jehovah she could not receive things that were important to her like forgiveness. 
For other students, having a 'real' relationship with God meant having a more casual and equal relationship where there was less pressure and judgement. For example Mary described her relationship with God this way:

I think I have more of that brother sister relationship with Him (God) maybe because I'm... in real life closer to my brothers. But I have like casual conversations and like I tell him everything with no holds barred and there are very few people...I feel you can do that with without feeling the pressure of being judged. And I think praying...provides a catharsis almost of like say the therapist free of charge.

Mary in her relationship with God compared it to her mortal relationships with her brothers. She felt she gained something that transcended many of her other relationships because she knew that when she talked to God she would not be judged, but rather healed. While she considered her relationship with God as a friendship, she still felt that God's power “controls things you don't even realise he controls”. Mary's experience led her to describe her relationship with God as a friendly relationship: "it's enlightening having such a powerful friend". The power that God possesses made her relationship with God unique from her other mortal relationships.

For other students having a relationship with a powerful friend meant being more guarded or distant and having less regular contact. Rachel described her relationship with God this way: "In a telegram kind of way. You know like I wouldn't say I have a particularly fantastic one” and as previously described her relationship with God was "Casual, distant? Guarded". Rachel's experience was that although she prayed regularly prayer was more important "when things aren't going well". The guarded reality of Rachel's relationship with God resulted from her unwillingness to completely trust Him. For her this meant not being too hopeful, for fear of being disappointed. Rachel felt that she was responsible for her actions, and her prayers may not necessarily be answered how she would like even if she was to be less casual or distanced toward and from God.

Vijay like Rachel also felt that God was a powerful friend when things are not going well: "any time I have some difficulties...I can talk with God", but also in a general sense as well: "we believe God to be the all doer, you know nothing happens in this world without God's wish". Asha expressed God's supremacy by saying: "He's the 44 
creator of everything”. Gregory acknowledged the power of God through "the divinity of Jesus" which gave him a great respect for God who "did sacrifice Himself and...was resurrected afterwards.

Joan saw herself as having a 'real' and respectful relationship with God and compared herself to other people who she said were part of a "Catholic culture". Unlike the people she said only went to Catholic schools and clubs she had "actual true belief" and "thought about a relationship with Jesus". For Joan it was her relationship with God and her faith that set her apart from these people. Her relationship was authentic because she had great respect and was committed to "believing the teachings of the church and the teachings of God".

Henry also valued his relationship with God and had a profound respect for God as seen in the gratitude he had for the healing and love he experienced from receiving the Eucharist. Henry recognised the role that God played in caring for him when he said it's like "He's looking after you". This for Henry showed he had a strong appreciation for God. Sebastian also spoke about his great appreciation and respect in his relationship with God. Despite the uncertainty he had about the relationship, he was appreciative and grateful for the way that God took away any fear he had: "it's kind of like the opposite of fear...He's got my best intentions at heart so He'll guide me on the right path".

\section{Super-Theme 2: Being Different to Secular Peers}

The second super-theme was being different to secular peers. Being different was a key part of being religious, with this super-theme manifesting in a variety of ways for the students. Being different meant the students did not feel the same as their secular peers. Being religious meant having different views, values and philosophies and feeling abnormal compared to their secular peers. The students spoke about appearing and being perceived and treated as different. Difference also included having a different outward appearance in terms of the way they dressed and presented themselves. For most of the students being different was something negative. Two students did however see their difference as something that was positive and could be embraced. Being religious gave them a different perspective to their peers and helped them be critical of ideas presented to them at university. Not all of the students were aware of or talked about themselves as being different. 


\section{Having different beliefs, values and philosophies.}

Being different is summed up by Asha's statement about being religious: "It makes me unique and different". Students felt that their experience of being religious distinguished them from other students and this was due to them having different beliefs that included which behaviours are morally acceptable and how the world was created. The students became aware of their unique or different beliefs when attending lectures at university, because it was in this context they realised: "it...is quite a common thing... where...your ideas are contradictory to what you're learning in your lectures ... and what you believe is quite different" (Joan) and "a lot of things...weren't so much in line with my faith" (Gregory).

Joan and Gregory both felt their religion made them different because their beliefs were incompatible and did not align with what they were being taught. Sometimes their beliefs were not presented, which made them feel like their beliefs were not as valued as their peers'. Joan suggested a possible reason for this: "the basis of what I make my decisions on is actually not an accepted way of thinking in some of my classes".

Clarissa's views were different to many other people (including other students at university) because she is a Jehovah's Witness. This made her part of a wider group of people who "study the Bible directly and try and draw the most truthful unadulterated facts from it" and hold views and do things that are "a little contrary to what other people do...Like we don't do birthdays and Christmas”. Her religious beliefs and practices meant she was "constantly...standing out" and felt "a lot of pressure...to conform to...world standards" both inside and outside of university.

Henry did not find his religious beliefs and views were challenged in class as a computer science student. Unlike subjects such as philosophy where the reality of God is contested, there was typically no reason to discuss God and issues about religion in computer science. Henry did however find his beliefs and views were challenged in articles and letters in the student magazine at university: "it's got very interesting views on things that are often different to what I think". Henry rather than feeling different in a formal class setting felt different in an informal student publication. Although this publication did not personally attack him, it made him feel marginalised.

According to Gregory having different religious views were problematic because "as soon as you say something different from that...perspective which academics... and 
society has in general these days you...get shunned". This reality for Gregory came from academic rules and ways "kind of...getting...thrown out and tossed away when you want to talk about religion". Gregory's experience suggests that the classes he has been in have come from a single academic discipline that has not considered a religious perspective. Acknowledgement of such perspectives, when appropriate, is an important part of cultural responsivity in education that seemed to be missing from Gregory's experience.

Many of the students' values and principles that guided their actions distinguished them from their secular peers because of their religious groundings. Sebastian's life was guided by the Biblical teaching "treat your neighbour as yourself" and both Henry and Mary referenced Jesus Christ as a model of what it means to be a Christian in their respective traditions: "I try to act as a person who follows Jesus" (Henry) and "Being religious is genuinely striving to be more like Christ" (Mary). The students' secular peers did not have these religious groundings because they gained their values and philosophies by and through other means.

Two students, Joan and Gregory, both spoke about the advantage having different views gave them in an academic setting. Joan said:

I think being a minority...does make you very critical. Probably more critical of the things that you're taught or you're learning. Like if you believe something different to what you're being taught, when you're taught it you're gaining another perspective which is very important. Whereas students who aren't religious...it...might just be a reiteration of everything they've ever known and they might not be thinking about the other perspective which the minority believes.

Joan felt being religious made her sceptical when presented with information in a tertiary setting. This meant she did not blindly submit to what she was taught, but rather took the information on board as another perspective different to her own, for example the evolution, as opposed to creation of the human species. Gregory also shared: "I' $m$ able...to critically look at claims people make especially from science”. Gregory recognised that science and religion were quite often at odds with one another, took advantage of his religious knowledge and integrated it into science, when secular students could not. His religiosity provided a check on the legitimacy of what was presented to him and whether it fitted with his own beliefs. 


\section{Feeling confused resolving conflict of being stigmatised/stereotyped.}

Mary felt different and abnormal for being religious. She spoke about the incompatibility of her lifestyle as a religious young person and student, which for her was almost contradictory. Mary was aware that religious people and students can both carry negative connotations and be stigmatised differently: "student in and of itself has a stigma, like college kids are supposed to drink and party" and "there's that stereotype...of...Christians behaving in a certain way and one of that is not drinking”. This created a dilemma for Mary: "Like the fact that I don't drink. You get stigmatised. It is the norm but it's not a good thing and we get looked at wrong for it. So I think that's why I get so confused as a student ... and... a Christian”.

Mary's religious beliefs, practices and university student identity meant she had to resolve a conflict. She either conformed to student norms which were often counter to being religious or she had to "embody certain characteristics in certain environments" so she was not judged, but rather accepted. This meant she had to compromise values that she should be trying to live by as a Christian in order to fit in to the university environment, where she said: "there's a battle between...my Christian self and my worldly self". Whilst Mary wanted and thought that her faith "should happen 100\% of the time" it did not. Mary said: "I know what I should be doing but I don't always do it when He (God) wants me to do it". This led her to conclude that if she acted like other typical non-Christian students and used foul language: "being a student... ...world...ruin ...her...Christian chances".

\section{Difference as something positive.}

Both Asha and Vijay, who were the two non-Christians, had a different outward appearance because their religious traditions and customs required them to dress and appear differently to secular students. Asha for example wore a head scarf. She expressed strong reasoning for wearing a head scarf: "To hide beauty...to get respect...and not being judged for...showing your body and being judged for your...knowledge and your heart". This difference was positive for Asha as it helped ensure she was not objectified, but rather valued for things other than her appearance. Vijay's appearance as a Hindu meant he had a "tilak-chandlo" (red dot) on his forehead and sometimes a " $U$ " as well. The reasoning Vijay gave for his appearance was that "the U stands for the feet of God and the red dot is his ideal devotee". Vijay felt his 
tilak-chandlo contributed to his positive identity of being religious, because students were "more interested than trying to mock...his appearance”. Such interest gave Vijay opportunities to educate others about his religion.

Being a religious student, Joan felt that when she was presented with ideas in her lectures she had the willingness to "think...about the other (religious) perspective" and that she was able to "see both sides (the secular and religious sides) possibly easier". Joan's difference to her secular peers was beneficial: "if you believe something that is different to what you're being taught, when you're taught it you're gaining another perspective" and she gained pleasure from holding views that were challenging to her secular peers: "I kind of enjoy sometimes being the one to ponder a provocative question". Having a religious perspective enabled Joan to challenge and encourage others to broaden their consideration of what her and her peers were being taught beyond what was familiar or logical to them.

\section{Super-Theme 3: Being Religious Involved Inter/Intrapersonal Challenges}

The third super-theme was being religious involved inter/intrapersonal challenges. The students experienced a number of difficulties as a result of being religious. They spoke of having their faith/religion dismissed, misunderstood and not accepted. They also encountered stronger challenges that involved their faith/religion being criticised to the point where they felt marginalised and no longer willing to enter into discussions about religion with non-religious people. Interpersonal challenges were much more common across the student sample, but one student also experienced an intrapersonal challenge involving other Christians. Each example below substantiates what being challenged involved for the religious students, although not all of the students experienced inter/intrapersonal challenges.

\section{Having faith/religion dismissed.}

Sebastian shared an experience from one of his university courses where he felt that not only his own personal religion was dismissed, but religion in general: "they kind of accept that Atheism is the only true way and any discussion that was brought up (about religion) they kind of shot down". Sebastian felt, the religious views that he held were unfairly overlooked and dismissed in place of the mainstream Atheistic way of thinking. Henry had a similar experience and said: "everything is taught...in an Agnostic kind of 
way or even that God doesn't exist kind of way". Gregory added that science as a particular discipline did not entertain religious viewpoints: "I've always felt that especially in the sciences it's like an automatic dismissal of faith".

Rachel's experience of having her faith dismissed came from Christianity not being given the status of being worthy of discussion. She was frustrated when talking with students who would not engage in a discussion where religion was given a space: "having a conversation with someone who refuses to talk about the pros and cons of the argument it drives me nuts so I just don't go there" and "I haven't met many people who will actually... sit down and apply arguments equally to both sides". Rachel no longer has the patience to discuss religion with non-religious people. Not only does Rachel feel religion is unfairly treated, she has been unable to share and exchange worldviews with other students who are not familiar with religion. Such a reality for her has perpetuated ignorance of religion.

Dave was an exception to the other students. He thought religion was: "something people like to grab a hold of and try to...question”. For Dave this questioning of religion was negative, because he found it difficult to separate religion from his own personal Christian faith. When people questioned religion he felt it was an attack on his "personal space”. Rachel also felt when people spoke about religion it was negative, because from her experience people like to "point the finger at the radicals and talk about ...things like...child molestation...in...the Catholic Church" rather than "talk about the good things".

Mary also spoke about a time where she felt religion was dismissed. Mary had an experience in her class where her peers and lecturer were discussing why people have children when her lecturer said sarcastically that they were "a gift from God" and then said “I don't believe this". This left Mary feeling that a religious perspective about why people have children was not only undervalued, but rejected as wrong. This experience was discouraging for her in terms of engaging in her class as a student and religious person. This unnecessary rejection of something so important to her also left a bad impression as an international student, where her experience did not reflect the inclusion of diversity the university strove to uphold. 


\section{Not being understood.}

The students also mentioned the challenge of people not understanding their religion which led them to dismiss and view religion negatively. This point is shown by Gregory:

It's not by what we do in this world in terms of our deeds but actually by our heart and our faith that we have in Him and I think that's one of those things I think is important but one of these things that's quite misunderstood by a lot of people that aren't Christians.

Gregory pointed out that non-Christians often look toward Christians' actions as a way of defining them, which is only part of, or even misrepresents what being a Christian really means. For Gregory having faith was more important than doing good deeds to be a Christian.

A lack of understanding or a misunderstanding of Christianity led Henry to say: "They (secular people) can judge you according to those things that could be completely false". For Henry ignorance undermined the integrity and credibility of being religious unfairly. Sebastian shared an example of this with helping non-Christians: "I feel that it's wrong just to want to help them (non-Christians) just to try and make them a Christian". Non-Christians for example may interpret being helped by Christians as extrinsically motivated, through them "only being nice so...they (religious people)...can get to heaven" (Gregory), rather than helping them because it is the right thing to do.

One of Gregory's experiences was that "people just jump to conclusions...if you're a Christian...you must hate science". This led him to say: "I think there needs to be an understanding of...people's faith...I don't think there's enough of that". Gregory felt that there needs to be more opportunities for people to be able to share their faith as a way of addressing assumptions that are made about religious people. Such opportunities would help challenge what he called "the established...line of thinking for a lot of people... where...we...need ...to get rid of that stuff (religion)".

\section{Criticism and intolerance.}

The students also spoke about being criticised and religious intolerance. Rachel, had what she described as "her number one worst experience" being religious where her views were regarded with contempt: "these three chicks kind of cornered me and it was 
like the Spanish inquisition how could you possibly hold those views". Rachel said: “there's such a strong criticism of people who believe something that can't be proven". When Rachel tried to justify her view her peers said "well it doesn't really apply to me" and they decided that the only way her views could be explained was that she had been "indoctrinated" by her parents.

Rachel also shared: "I find it frustrating at times that people...can say quite negative things about being any religion under the Christian umbrella which totally would not be okay to say out loud in a group of people about someone who wasn't Christian ...say...someone who was Muslim”. From Rachel's experience there was something inherent to Christianity that meant it was treated with hostility:

it's almost like you're allowed to have a personal sense of religion in New Zealand because that's personal but the second you identify with a set one you're a Christian...and...I feel like there's almost, in New Zealand...a perception that if you're white you don't deserve to have a religion.

Clarissa held similar views to Catherine: "I mean there's a lot of acceptance for everything except religion you know. People are incredibly anti-religion and I think that's an education thing". Some of the participants felt that there needed to be a greater understanding of faith and religion. Educating people in a tertiary context about faith and religion may help soften the views of people who are anti-religion and may even help them better respect it.

Joan also spoke of an experience where she was treated unfairly as a result of sharing her religious view that opposed same-sex marriage: "they (mostly her friends boyfriends) were very aggressive and mean and bullying over twitter and person, they were texting me saying I was a bigot all these kinds of things". Joan was personally attacked for her views opposing same-sex marriage, which in her words was "more traumatising than anything that's happened at university”. For Joan, it was outside of a university context where she had her most negative experience as a religious young person. She found it difficult to defend her view which contributed to the trauma she experienced.

Sebastian mentioned the criticism of Christianity in the student magazine: "if...it...does bring up Christian topics it's quite often criticising them ...from an Atheistic point of 
view”. For Sebastian the student magazine was a medium for people to criticise and be intolerant of Christianity in a tertiary education setting.

\section{Negative stereotypes.}

All of the Christian students excluding Clarissa spoke about the negative stereotypes people gave them: "bible-bashing, conservative, judgemental. Like stuck up, you know holier than thou" (Rachel), and "a word often used is bigot" and "intolerant or...oldfashioned even" (Henry). Gregory's experience was that "sometimes some of the lecturers and even some of the students...talk like we're wackos... and...make a few like quips or quip things about religious people". Sebastian said he and other "people who believed in Christianity...were treated...as ignorant fools or...people who just don't want to open their eyes up to the truth" (Sebastian). Joan was frustrated with staff and students who saw Christians as an "annoying conservative voice”.

Other students suggested that the stereotypes they were given made them "not students...but rather...something else" (Mary). From the Christians' experiences they were considered "boring...weird... and...different" (Mary) which challenged the criteria non-religious students gave to students generally. Dave's suggestion for why he and the other Christian students experienced being negatively stereotyped was that Christianity had a "negative connotation". The students experienced a lot of hostility towards them through negative stereotyping which they found frustrating.

\section{Being marginalised.}

Being marginalised was an experience of the students whereby they felt they were a minority and held minority views that were not considered as valid as their secular peers' views. The students were typically marginalised during classes and tutorials and one student also shared that she felt her and her religious group was marginalised in their university club setting. Another student thought there was a double-standard that worked against Christians that marginalised them. The most regular marginalisation came from (non-religious) students rather than lecturers.

Joan highlighted the minority status that she held at university: "I'm one of a few out of the 21,000 who believe in God, well who would classify themselves as Christian" and what it means for her: "it marginalises me". She talked about an experience when she did a moral philosophy paper: "I felt marginalised...in my tutorial when I was the only 
person who thought that abortion was wrong”. This experience was difficult for Joan because she said she loved and adopted values based on the Catholic teaching on "the worth of life". Her view that opposed abortion made her feel marginalised because she did not have peers who supported her belief.

Joan also spoke about another experience in one of her tutorials where she mentioned God. One of her peers said that the reality of God was "so unlikely" at which point several of Joan's other peers started laughing as "if...she...was stupid". As a result of Joan's belief being challenged cynically, she felt that her beliefs were relegated to being less valid than her peers' beliefs. Despite Joan and her religious friends having their own Catholic club on campus which was positive for her, she said "I still think we are marginalised". Gregory also felt that religious clubs were marginalised: "you have your Christian fellowship groups here at Vic...but it's definitely kind of off to the side". The marginalisation of these Christian groups has meant their opportunities to connect with, educate and learn from other groups on campus, has been limited.

Gregory spoke about a double-standard that worked against Christians like him at university and in society more generally. From his experience, in the case of disagreeing with gay marriage "you automatically get called...homophobe". At the same time however "it's not alright to marginalise gay or lesbian people or...people from different cultures...but it's all good to marginalise Christians". Gregory's experience was that as a religious person part of a diverse university group he was not treated as fairly as people from other diverse groups.

Clarissa shared about the challenge and difficulty of having a minority status: "I think it is challenging...there's not many Jehovah's Witnesses at university. There's no Jehovah's Witness club or...anything like that" and trying to maintain her beliefs: "it's challenging to stick to those beliefs when everybody around you hates those beliefs". By Clarissa not having her own Jehovah's Witness club to be a part of at university and having people hate her beliefs she felt marginalised.

\section{Intrapersonal challenges.}

Dave spoke of the challenge of dealing with conflicting views on controversial topics such as same-sex marriage. Dave held different views to other Christians, because he is a liberal Christian and supports same-sex marriage: "A lot of Christians don't support that (same-sex marriage) but for me you know I'm not against it at all”. Same-sex 
marriage was an "awkward thing" for Dave to discuss with other Christians because he often felt hurt when they would pass judgement based on teachings that did not have scripture behind them. Judgement from other Christians seemed misguided and felt like a personal attack for Dave. In his opinion he felt that "you can live...in any sort of lifestyle... and...still believe in God".

Asha and Vijay were the only two students who did not speak of experiencing significant life and personal challenges from being religious: "I've never experienced bad within...my religion or being judged for it or anything...I haven't experienced anything like that just goodness from people”. She did however highlight one challenge she had in participating in her own religion that centred on the difficulty of reading the Koran: "It's hard because it's in Arabic and you must learn the language and you must learn the alphabet and it takes a long time”.

\section{Super-Theme 4: Being Religious is Constructive}

The fourth super-theme was being religious is constructive. Students felt that being religious was constructive despite the challenges they faced. Being religious meant the students experienced a number of benefits, advantages and support, and religion was seen as worthwhile and had a positive influence on their lives. Some of these benefits were immediate, others were delayed and others were experienced recurrently. Religion helped define the students' purpose and identity, gave them a unique perspective, perceived benefits after death and was of great value to them. Not only did religion help them as individuals generally, but also as students. Each example below substantiates why being religious is constructive and includes a range of the students' experiences.

\section{Praying is therapeutic.}

Sebastian spoke of what praying does for him: "it helps calm me, helps reassure me, sometimes it helps focus me”. The effects of prayer were therapeutic for Sebastian and helped him to concentrate. Vijay also spoke about how prayer helped him cope with the stress of studying and being a student: "Well it gives me...the strength to deal with the stress that the university life includes I guess...assignments, deadlines and things like that". For Sebastian and Vijay praying was an investment of time that gave them benefits that helped them deal with the stresses of their academic lives. 
Mary shared: "I think praying...provides a catharsis almost of like a therapist free of charge". She felt prayer was an effective way to express how she was feeling without any negative consequences. Unlike when speaking to other friends who judged her she could speak openly to God and not feel any shame. Clarissa also highlighted the benefits of prayer: "it's relaxing, it's calming, it destresses". Prayer for Clarissa was also therapeutic.

\section{Being religious is valuable.}

The importance that the students ascribed to being religious highlighted the worth they had for their respective religions. Religion was a necessity for them in the way that it was life-giving and promoted good health and prosocial behaviours.

Henry spoke of the status he gave to his own religion: "The most important thing in my life is religion. I guess it's just my experiences through it have highlighted my need and enhanced my belief in God" and "faith is the most important thing". For Henry it was his engagement in religion that highlighted the value of being religious and encouraged his continued involvement. Religion made Henry feel needed and connected to something greater than himself, namely his church family.

Vijay talked about how religion gave him sustenance on a daily basis and provided him with strength:

it's you know just as food and water...are important to have a healthy life...food gives me the physical strength and you know this religion gives me the mental strength to becoming a strong individual" and "I think life without religion for me is like life without oxygen.

Although Vijay did not speak about religion providing him with virtues that are encouraged in religion such as patience and compassion, it played a crucial role in helping him become a strong individual. Vijay's experience highlighted the different types of strength one needs to function in everyday life and the way religion can help meet those needs depending on the person.

Mary also spoke about the value of being religious: "I think it helps ground me and gives me peace" and "being a Christian has made me more humble which has made me more likeable and...approachable" and "being Christian helps me think more positively...optimistically”. The benefits Mary experienced from being religious gave 
her a foundation to life that helped her at a personal level and with her prosocial functioning.

\section{Religion provided support.}

The idea of religion being supportive was illustrated in the way it provided a source of help and encouragement to the students. This support came from both God and fellow religious people, most regularly in times of difficulty. The support the students received was intangible.

Henry shared: "I guess an advantage would be that (being religious) you've got this belief and you're part of this bigger thing and that you've got other people who will support you". He recognised that whilst most of his peers did not have the same values and beliefs as him, he was not alone as a single Catholic, but rather part of a wider church community consisting of many like-minded Catholics. Such a reality made Henry feel that he was not alone in his faith journey and could, for example, call on other Catholics to pray for him in times of need.

Mary said: "I think He (God) gives you a shoulder to lay on ... and...it (religion) gives you something solid to fall back on...like a solid rock". Mary felt confident that when life was uncertain she could go back to her Christian grounding and particularly God for support. One example she gave of this was having "casual conversations" with God "without feeling the pressure of being judged". In a world where Mary felt there was a lot of judgement, religion and God in particular reassured her in a way that gave her peace.

\section{Religion helps defines your purpose and identity.}

Religion helped define the students' purpose and identity: "I guess I get...direction, like...how I should live my life" (Henry) and "religion's just really kind of the guide for what I do" (Gregory). Religion for Henry and Gregory outlined the path that they should take and what they should do when journeying along that path in their lives. Clarissa said "It (religion) shapes my whole life...it shapes all my decisions and I think I've had a pretty good life". Clarissa's existence was impacted by the pervasiveness of her religion where it not only shaped, but also helps her make decisions. Clarissa also shared that as Jehovah's Witness "your religion is your identity". Her involvement in 
her religion provided an all-encompassing tradition about who she is and what she is meant to do with her life.

Being a Muslim was a defining feature for Asha who gained her life's purpose from Islam: "It's like I wouldn't have a purpose in life if I didn't have Islam I think". Islam for Asha was her reason and source of motivation for living life. Gregory shared: "It (Christianity) definitely defines what I do as a person". He gave the example of his interest in music which he can trace back to his younger years in church. Christianity promoted and instilled interests and beliefs in Gregory that have stayed with him from his childhood.

Sebastian said "in terms of who I am it's one of the most important things". Whilst Sebastian acknowledged Christianity as one of his identities at university, he said: " $I$ don't...think...it...has been my only identity". For Sebastian Christianity was one of several identities he had that contributed to his sense of self. Rachel said: "I think (religion)...contributes to your sense of self, your sense of belonging in a particular group that has some positive connotations to it". Despite Rachel recognising the difficulties that come with being religious, she acknowledged that there are parts of religion that can be affirming for her identity such as having a (religious) culture.

\section{Religion has benefits after death.}

Several of the students spoke about the benefits they will experience after they die. These benefits added an element of constructiveness that was not yet fulfilled that impacted their experience of being religious. Vijay said:

If you do good deeds then you move towards a better life... and you meet with God and his devotees...then you can get...out of the circle of birth and death....and you can attain God's abode. And you can eternally reside there with God.

Asha also shared what will happen to her when she dies based on her acts of charity where she will "build a life in the hereafter...and will have...Goodness in the hereafter". Finally Sebastian said: "being Christian is kind of choosing the harder option but you don't really look at it as inconvenient... and...you're not really looking at what's happening around you, you're looking at kind of the end". 
Each of these students highlighted the after-life whereby religion is ultimately constructive for them once they die. Whilst the benefits of religion after death were not experienced by the students, the motivation that they encouraged strongly shaped their experiences and how they lived their lives, seen for example through their commitment to prayer.

\section{Summary}

This chapter presented the findings from the analysis of the students' interview transcripts. Four super-themes with multiple sub-themes were presented and discussed under the title: being religious means engaging with the sacred. What this analysis revealed was that being religious involved: 1) having a relationship with God 2) being different to secular peers 3) inter/intrapersonal challenges; and 4) constructiveness. This analysis showed how all of the students to varying degrees had a relationship with God in their various religious traditions. Being religious meant taking part in religious rituals and having and maintaining a commitment to their relationship with God. Secondly, being religious meant being different from their secular peers. Several students experienced themselves as different, unique, dissimilar and in conflict with their peers and that they were dissimilar to them. Thirdly, being religious meant students experienced a number of challenges because they were religious, such as having their faith/religion dismissed and not being understood. This experience manifested in a variety of ways including how they were dismissed, misunderstood and were given negative stereotypes. Finally, despite the challenges the religious university students faced they all remained religious because they found it to be a constructive influence in their lives as emerging adults and as students. This was seen in the ways religion gave them purpose and a sense of identity. All of these super-themes with their multiple sub-themes were interrelated and will be discussed in detail in the following chapter. The chapter will discuss these super-themes in relation to existing research literature and theory and will address the implications of the findings of this study. 


\section{CHAPTER FIVE: DISCUSSION}

\section{Introduction}

The essential and overall meaning of being religious was engaging with the sacred. This meaning encapsulated the active nature of the students' involvement in and commitment to things with a religious purpose. Engaging with the sacred took on a variety of forms across the student sample as a result of who or what they considered sacred. An example of this was seen through two students seeing the Eucharist as sacred, whereas another student saw their prayer life in the same light.

Engaging with the sacred meant having a relationship with God, being different to secular peers, being challenged and religion being constructive. Although all four super-themes warranted super-theme status, the two that were most essential to understand being religious within an educational context were being challenged and religion being constructive. This chapter discusses the benefits and challenges of being religious in relation to theory, literature and the findings of previous empirical research, including: literature that explores the challenges Christians (in particular) experience in tertiary settings, as well as the benefits religious people experience in general. This chapter also discusses the limitations of the study, its implications for future research and makes recommendations for improving practice and the education experiences of religious students. This chapter and study concludes by suggesting that there needs to be a greater commitment to an inclusive education environment and an honouring of existing university policies targeting diversity. Such commitments would help religious students continue to engage with the sacred and feel safer and more supported at university and for their transition beyond their tertiary setting.

\section{The Challenges of Being a Religious Student}

Being a religious student at university meant being challenged. This experience was largely reported by the Christian students. These challenges included being different and part of a minority group and being criticised and not tolerated. The students found these challenges frustrating and they made their lives difficult. 
There are very few empirical studies that have explored the challenges that religious tertiary students experience while studying. Hyers and Hyers' (2008) and Rosik and Smith's (2009) studies have explored the challenges faced by Christian students and help shed light on the present study's findings. The non-Christians in this study experienced very few challenges in relation to being religious and there is some literature which helps explain this finding.

\section{Being different and part of a minority group.}

The students experienced challenges because they had different views, values and philosophies to their peers. At university they found themselves having to resolve the conflict of being stigmatised and stereotyped. The participants felt that other students did not understand them, their religion or the challenges they faced. They felt they and their religion were often dismissed, misunderstood, criticised and not tolerated, which left them feeling stereotyped, marginalised and judged.

Oyserman and Swim (2001) pointed out that the experience of 'difference' is dependent on social context. The students in the present study may have experienced themselves as different because of the context they were in, namely a secular tertiary context. This context not only made them feel different, but also positioned them as a minority and means they "possess an attribute that disqualifies them from full acceptance" (Oyserman \& Swim, 2001, p. 2) by their peers and society more generally. If they had been in another university setting (for example with all Christian students) difference may not have been a challenge in their learning environment or to their identity. Because the students were in a learning environment and community where contact between minority and majority groups occur, intergroup experiences were more pervasive for them which increased the likelihood of them experiencing stereotyping and prejudicial behaviour (Oyserman \& Swim, 2001).

\section{Having beliefs dismissed.}

Another way the students experienced being religious as challenging was through having their beliefs dismissed or not accepted by other students and staff. This dismissal involved the lecturers and peers undervaluing religion and not giving it the status religious students felt it was worth in terms of being a lens for discussion. 
Rokeach and Rothman (1965) suggested that people dismiss individuals' beliefs when they are incongruent with their own personal beliefs (Rokeach \& Rothman, 1965). Other empirical studies have also found that religious college students experience discrimination and have their beliefs dismissed. For example, Hyers and Hyers' (2008) study of 42 conservative Christian American university students explored religious discrimination in a secular university. This study extended the work of Rokeach and Rothman (1965). They found that $28 \%$ of Christians reported having their Christian beliefs derogated.

In the present study the students' secular peers and lecturers may have dismissed a religious perspective because they did not find value in those belief systems because they were not relatable or were challenging to what they believe. Having their beliefs dismissed may have affected the students' experience at university in several ways. It may have made them feel that they needed to divorce their religiosity from their student selves and they may have not felt comfortable bringing their 'whole' selves to university. It could also have made them feel divided from their secular peers, disconnected and that they did not fit in or belong on campus, despite being students.

\section{Being misunderstood.}

The students also found being religious challenging because they felt misunderstood. The misunderstanding the participants experienced was about the intentions of their actions as religious people, such as helping others and why they have faith. Nash (2007) suggested why students may feel misunderstood and why other students may not be aware or understand the backgrounds and beliefs of religious students:

We work hard in so many areas of higher education to engender respect, recognition, and understanding of cultural difference. But we do little to help students examine, and understand, their own, and others', religious backgrounds (or lack of them) (p.3).

Religious university students' peers may lack education and an understanding of different religions. Future research could assess the knowledge students have about different religions to gauge their level of understanding about belief systems that are not their own. Further research may also help illuminate the extent of religious ignorance and indicate what type of education needs to be implemented to promote awareness and understanding about religion. 


\section{Criticism and intolerance.}

Criticism and intolerance was another challenge the students faced, where their views were attacked when their religiosity was made known. The participants felt that they and their beliefs were unfairly treated and regarded with suspicion and contempt.

Religious and non-religious students may come to university with different worldviews. The Christian students spoke about situations where their beliefs about believing in God were viewed critically by their peers and the negative stereotypes (such as being conservative and judgemental) that people held about them. The students also spoke about experiences of hostility. One student was bullied for opposing same-sex marriage. The students experienced conflicts in beliefs with other students, where practising abstinence until marriage was contrary to both belief systems. Conflicts between secular science and religion were also experienced by the students where they felt faith was automatically dismissed with preference being given to secular science in their lectures.

Hyers and Hyers' (2008) study found a similar trend when students documented antiChristian incidents using diaries over a one week period and found students experienced: derogation of their beliefs, stereotyping, hostility, belief conflicts and secular science and religion conflicts. Hyers and Hyers (2008) suggested that derogation and ridicule is often engaged in for self-elevation, and may act as "an escape-valve for tensions and frustrations" (C. Hyers, 2008, p. 78). They highlighted that whilst secular universities are unlikely to endorse (all) conservative Christian beliefs, they should encourage discussions about belief structures beyond secularism so as to ensure students are not ridiculed or experience hostility for their beliefs (L. L. Hyers \& Hyers, 2008). Students in the current study did not speak directly about derogation of Christian people, practices and churches or interaction difficulties as found in Hyers and Hyers (2008) study. This may have been because the students described themselves as being ones to avoid faith-based discussions/arguments that may incite some of the above experiences.

Rosik and Smith's (2009) study of 192 conservative Christian students in public and private religious universities also found that students experienced a number of challenges similar to those found in the present study. They found that students were verbally insulted for having Christian beliefs and heard other students using disparaging remarks. Their study showed that religious discrimination was more frequently practised in public beyond the educational institution and private religious university 
setting they explored. None of the students in Rosik and Smith's (2009) study talked about being threatened with physical violence, having their personal property damaged, being spat on, being punched, hit, kicked or beaten, or being assaulted with a weapon. The students' experiences in the present study were also free of the above manifestations of discrimination. It appears that whilst the students often reported being verbally abused or challenged they were not the subject of physical violence and bullying. Whilst these findings may be indicative of the small sample size in each study, the experiences of discrimination by the students in the present study are mild in comparison to the possible discrimination they could have faced.

Oppression theory (Hodge, 2007b) can shed light on why religious discrimination can occur. This theory posits that when there is a difference in worldviews as well as a power differential, discrimination can occur (Farley, 2005; Wambach \& Van Soest, 1997 cited in Hodge, 2007b). The students may have felt different to their secular peers but also experienced a power imbalance that oppressed them where their minority worldview was depicted negatively and overlooked (Hodge, 2007a). In the current study an example of this power imbalance was reported by way of the student magazine which the students said typically criticised or made fun of religion from an Atheistic point-of-view. As the religious students' beliefs, values and philosophies were not part of the majority worldview their secular peers held, they may have resulted in them becoming targets of criticism and intolerance.

\section{Religious stereotypes.}

Being stereotyped was also a challenge for the religious students. McGarty, Yzerbyt and Spears (2002) outlined a criteria for understanding stereotypes: “(a) stereotypes are aids to explanation, (b) stereotypes are energy-saving devices, and (c) stereotypes are shared group beliefs" (p. 2). In summary, stereotypes are an impression or representation of a group that assists the perceiver to explain a group or individual with little effort in a way that is socially acceptable to the group they belong to (McGarty et al., 2002). According to McGarty, Yzerbyt and Spears (2002) a stereotype is generally based on "the erroneous perception of the co-occurrence of rare characteristics...and...minority group membership" (p. 9) where the rare characteristics are usually undesirable (McGarty et al., 2002). Hyers and Hyers (2008) also found that religious university students experienced stereotyping and the most frequent stereotypes manifested in the form of generalisations about Christians being "intolerant" and "extremist". In relation 
to the present study the stereotype of being intolerant recurred, whereas the stereotype of being an extremist did not.

Nelson (2009) made the important point that the categorization of people through stereotypes and prejudice is most frequent in situations when people are not known very well or cared about. It may be that because the students are not understood by their peers they are more prone to being stereotyped. This may also be compounded by the students' peers not being particularly interested in getting to know them as well (T. D. Nelson, 2009). Additionally Brodt and Ross (1998) point out that some stereotypes are valid or can act as an accurate prediction of a group. It may be that some of the stereotypes of the students were in fact true.

\section{Marginalisation.}

The religious students found being religious contributed to marginalisation. Marginalisation has been defined in the literature as "the state of being considered unimportant, undesirable, unworthy, insignificant and different resulting in inequity, unfairness, deprivation and enforced lack of access to mainstream power" (UNDP, 1996 cited in Messiou, 2012, p. 1).

There is little empirical literature about the marginalisation of religious students at university, however, Edgell, Gerteis and Hartmann's (2006) study of the division of believers and nonbelievers in America provided important insights to the present study. Their study suggested that an "increasing convergence around a core set of religious beliefs and practices...may reinforce intolerance of those who reject religion" (p. 214). This may mean that there is a convergence around secular beliefs and practices that encourages the intolerance of religion within tertiary and university education settings.

Goodman and Mueller's (2009) article about the invisibility, marginalisation and stigmatisation of Atheist students also provided reasons for why marginalisation occurs. Their study claimed that "non-believing perspectives in religious and spiritual developmental work" (p. 55) can act to reinforce marginalisation. They also suggested that efforts need to be made to normalize Atheism to combat marginalisation (Goodman \& Mueller, 2009). With this in mind, more may need to be done to support the students in the present study to feel that being religious is acceptable and "normal". Furthermore, the invisibility of religious perspectives from curriculum and material presented to students was also an issue. Lecturers may not include this material because it is not the 
majority viewpoint. This may mean that students who hold minority viewpoints feel that their viewpoints are not normal because they are invisible from the curriculum and discussion material.

\section{Personal and ideological challenges.}

Students in this study experienced challenges that came from responses and interactions with other secular students, staff and the wider university setting, but also personal challenges that came from having to cope with ideological/moral conflicts within themselves, and from other Christians.

One student's challenge of having competing personalities (a religious personality and a worldly personality) appears to be a topic of research yet to be explored. This phenomenon involved a competition of the student's religious personality, where she strove to imitate Jesus Christ by being loving and faithful. Along with her worldly personality, where she used foul language and did not act like a Christian. Future studies could explore both the religious and non-religious personalities and identities that students bring to and live out on campus. This may increase our understanding of how students experience intrapersonal conflict in ideology and identity.

Another student also shared that a Christian identity was not the only identity he lives out on campus. The concept of multiple dimensions of identity has been written about and researched extensively (See for example Jones and McEwen 2000 and Abes, Jones and McEwen 2007). Additionally having a religious identity has been recognised as an important dimension for people who are part of a religious tradition (McEwen, 2003). Future studies could focus more closely on the pluralistic and multiple identities of religious students.

Students also experienced challenges from within their own religious communities. One student found he was sometimes judged by other Christians. This was in relation to times when he shared his views on controversial issues such as same-sex marriage. Other studies have also found that there is variation in attitudes and values within religious communities. For example, Finlay and Walther's (2003) study of 1160 American students about religion and homophobic attitudes among university students found that in Protestantism a wide variety of attitudes exist. 


\section{Cultural and religious challenges.}

The students in this study raised a number of other issues relating to the challenges of being religious. First, the non-Christian religious students reported experiencing few or no challenges. They may have come from conservative religions where speaking negatively about their own religion is forbidden or frowned upon. The single Muslim student in the study did not report experiencing any challenges. Another possible reason may be that she lacked lived experience of being a student at the time of being interviewed (she had been enrolled for only one semester) and unlike the other participants who had been at university for at least one year, she may not have been at university long enough to have experienced any significant challenges. Alternatively she may not have felt comfortable discussing them with a Western researcher or been aware of them.

The only Hindu student in the study sample may not have experienced any challenges because he was born and grew up in New Zealand. He may have learned from experience about how best to live out his faith to not have challenging experiences at university and in society more generally. Alternatively he could have adopted religious coping strategies that mitigate or draw his attention away from the challenges he experiences (See for example Falb and Pargament 2014).

Other participants raised the important intersection of religion and culture. One Christian student felt that being white in New Zealand meant that you cannot claim religion as your culture, whereas if you are non-white you can. If such a reality was true it would inevitably have made being religious more difficult for the white students in this study.

\section{Being Religious is Constructive}

One of the reasons the young people maintained their religious faith and activity is because of the benefits it had in their life. Engaging with the sacred, despite presenting emerging adult students with challenges was also a constructive influence in their lives. Being religious brought students a number of benefits or advantages including: praying being therapeutic, personal value, support in times of need, a sense of purpose and identity, and benefits that come after death. 


\section{Praying is therapeutic.}

Being religious meant students often engaged in prayer and they found it calming, reassuring and therapeutic. One student also said prayer gave him mental strength to deal with assignments. Prayer was a medium for the students that put them in a relaxed state of mind generally and whilst completing their studies. Empirical studies have found similar benefits from praying.

Anye, Gallien, Bian and Moulton's (2013) study of 225 American college students about behavioural expressions of religious activities, found prayer was one of the best predictors of positive health. The positive health benefits the students experienced were both physical and mental, although it was not specified what these physical and mental benefits were. How exactly religious activity influenced health and well-being was not clear but one author suggested religion discouraging unhealthy behaviours such as abusing alcohol and smoking (J. W. Jones, 2004) as a reason for these benefits.

The finding that praying is therapeutic is also endorsed in literature which recognises that prayer is a positive and adaptive coping strategy (C. L. Park \& Slattery, 2013). Pargament, Kennell, Hathaway, Grevengoed, Newman and Jones (1988) have highlighted three prayerful approaches one can take towards God. First there is a collaborative approach where a person and God take responsibility for and address the problem one is having together. Second, there is a deferring approach where a person defers the responsibility of a problem to God. Third, there is a self-directing approach whereby God is recognised as giving people freedom to actively solve problems themselves. The third approach in particular was one that the students in this study adopted in their prayer life because using this approach the students could talk to and discuss their issues with God (Spilka \& Ladd, 2012). Moreover in this approach God serves as a "therapist" (Joris, 2008 cited in Spilka \& Ladd, 2012), which is one of the ways the students viewed God.

\section{Being religious is of personal value.}

The university students found being religious and having a relationship with God the most, or if not, one of the most important parts of their lives. According to the students religion was a source of life for them and meant they became stronger and more prosocial individuals. It gave them mental strength and made them more humble and likeable. 
The value university students give to religion and spirituality has been cited in previous empirical research. For example, Kane and Jacobs (2010) in their study of 204 American university students, found participants were likely to agree that religious and spiritual beliefs were important and valuable to them in the way they helped them deal with difficult situations. These difficult situations included overcoming problems such as substance abuse and depression. These beliefs were important because they ultimately helped the students promote and maintain good health (Kane \& Jacobs, 2010), especially through prayer and meditation.

The value of religion in helping students to be prosocial and optimistic about life has also been a source of more recent research and discussion. Stavrova and Siegers (2014) suggest that being religious provides people with a number of benefits and is valuable because "All world religions contain ethical principles that prescribe prosocial and other-regarding behavior" (p. 315). The students' commitment to following the ethical principles that characterised religion may be a reason why religion helped them to be prosocial. Students might also have found religion to be of value because it may have helped them redefine life stressors or given them a new direction in life (Pargament, Falb, Ano \& Wachholtz, 2013).

\section{Religion provides support.}

Religion also provided students with two important types of support: a social support network they could access in times of need and a relationship with God who was seen as a supportive force they could turn to. Being religious meant that the students could call on fellow religious people in times of difficulty and God especially when their religious social network was unable or refused to help them.

Previous studies and scholars have discussed the social support benefits religion provides. In Park and Slattery's (2013) study the students benefitted from being religious because it brought them into contact with other students who shared their religious beliefs and provided them access to supportive relationships. Doane's (2013) study of 324 Irish university students also found that "religious communities are environments that foster unique supportive relationships" (p. 61). Hovey, Hurtado, Morales and Seligman's (2014) study of 200 American university students found that the relationship between intrinsic religiosity and mental health was mediated by religious-based social support. In particular their study highlighted that it was the 
comfort of knowing one has a religious support network that was most important to the mental health of students. Students in the present study reported that there was a strong element of knowing that they could rely on God in times of need, which reinforced the supportive relationships they had with their religious peers.

While it can be claimed that secular individuals are also capable of having strong social support networks Ladd and McIntosh (2008) highlight that there are several differences between religious and secular social support. First, religion provides a "more or less coherent framework for understanding life" (Ladd \& McIntosh, 2008, p. 27). This framework or system consists of explicit and implicit propositions that religious traditions claim to be true (Spiro, Killborne, \& Langness, 1987). For the students in the present study, their religious traditions, with their various sacred texts and teachings helped explain how they should each live life, and reassured them that what they were taught and were attempting to live out was the truth. A second key difference, according to Emmons (1999) is that this "religious meaning system and its associated goals" can act as, and be, the most reliable source to make sense of adversity (Emmons, 1999, p. 151). The students acknowledged the way God helped them find meaning in minor experiences of adversity. For example, adversity was seen as something that made them stronger or tested their faith. A third difference, was that being religious enabled people to draw on the social support of prayer (Ladd \& McIntosh, 2008). The students in the present study did not mention that they had asked their religious family and friends to pray for them, but they may still have felt supported by knowing that being prayed for was a possibility.

These and other supportive benefits that come from 'being connected' to others through religion are well documented in the literature. Social support is of fundamental importance for young adults who are university students because it is a time of significant change and adjustment (Baqutayan, 2011). Emerging adulthood is a time when many young adults are seeking greater independence and want to gain more responsibility (Baqutayan, 2011). At the same time students experience many pressures such as being accepted by their peers and living in a world with mixed values (Baqutayan, 2011). All of these factors and many more can add to the academic pressures students face and their ability to perform well in their tertiary studies (Baqutayan, 2011). Social support however can be credited with helping to counter students' pressures. 
Park and Slattery (2013) said that "One of the most obvious benefits to those involved in organized religion is the social support that comes with that involvement" (p. 547). This support is varied and can include emotional support, as well as access to goods and services (Turner-Musa \& Wilson, 2006). Those involved in religion also gain a sense of community and connectedness (Falb \& Pargament, 2014) to other like-minded people.

For some of the students God was also a source of support. Ladd and McIntosh (2008) point out that social support for religious people, unlike social support for secular individuals includes the presence of a deity. In instances where a secular individual may not receive, or have their social support withdrawn from their network of contacts, they are unable to turn to God as a secondary source of social support (Ladd \& McIntosh, 2008). Pargament, Falb, Ano and Wachholtz (2013) endorse this point by including 'seeking spiritual support' as an important part of religious coping whereby God acts as a source of comfort, and brings reassurance through His love and care.

\section{Sense of purpose and a positive identity.}

Being religious meant students could draw upon their religion to help define their purpose and identity. Each of the students' religious traditions gave them direction, provided them with a constructive and helpful guide to living life and helped inform them when making decisions. The reality of religion defining one's purpose and identity has received extensive attention by researchers and scholars.

Many studies have focused on purpose and identity in young (religious) peoples' lives. In Leak's (2009) study of 228 American university students it was suggested that there is an empirical link between identity and faith development. This finding was attributed to a "conceptual overlap or common denominator between the two different types of active exploration of alternatives: moratorium in the realm of identity and openness in personal religiousness" (Leak, 2009, p. 213). Religion also seems to mediate between life purpose and well-being. Byron and Miller-Perrin's (2009) study of 103 American university students assessed whether or not life purpose is a mediator between the constructs of faith and well-being. Although Byron and Miller-Perrin's (2009) study could not assume causation in their findings, they found that: "faith seems to foster life purpose, and life purpose seems to foster well-being. Faith also fosters well-being, but primarily through its contribution to a sense of life purpose" (Byron \& Miller-Perrin, 2009, p. 68). 
Other studies have also supported the idea that religion can provide young people with a sense of purpose in life to guide their actions and development. In Maltby, Lewis and Day's (1999) study of 474 under-graduate students in the United Kingdom, an intrinsic orientation towards religion, was found to have a significant association with better psychological well-being, than extrinsic orientations. An intrinsic orientation involved living one's religious beliefs (Allport \& Ross, 1967) and was inclusive of practices such as personal prayer (Maltby et al., 1999) and an extrinsic orientation involved using religion, for things like status and security (Allport \& Ross, 1967).

Falb and Pargament (2014) highlighted that religion offers clear guidelines about what is right and wrong in such forms as commandments and precepts. According to Byron and Miller-Perrin (2009) "Faith is one construct that has been theorized to relate to life purpose" (p. 64). Moreover King (2003) pointed out that "Religion intentionally offers beliefs, moral codes, and values from which a young person can build a personal belief system" (p. 198) where such beliefs, codes and values encourage a healthy and positive way of living. Being religious may provide students with these benefits, but having a defined and healthy life purpose and identity have also been found to be an effective driver of academic success in education. Students who have a strong sense of purpose and identity (where they know who they are and what they want) have been found to do better academically and have been associated with being strong motivators to achieve classroom goals (Bronk, 2011). Conversely, a lack of purpose and identity in the lives of young people can also lead to both personal and social pathologies (Bronk, 2011) and so religious students who lack a sense of purpose and identity may also experience challenges.

\section{Benefits in the afterlife.}

Religion provided students with certain benefits that they anticipated would come after death. This reality was yet to be fulfilled, but shaped the experiences of the students. While the students were living life they were looking forward to the benefits they would receive in the afterlife. The students' perceptions of the afterlife motivated them to be committed to each of their religious traditions. A number of studies have investigated the potential benefits of afterlife beliefs in young people. For example, Flannelly, Ellison, Galek and Silton (2012) have found that a positive outlook towards the afterlife, including reunion with loved ones and eternal residence with God promotes good 
health. Park and Slattery (2013) also point out that afterlife beliefs can act as a source of comfort during times of trial or psychological distress.

Holding various afterlife beliefs in emerging adulthood has also been investigated in empirical research (Arnett, 2004). Using data taken from his broad study of emerging adulthood, Arnett (2004) explored young peoples' beliefs about what happens when they die. Using questionnaires as well as an extensive interview, he found that there was much variation in what the young people, whom over $80 \%$ had at least some level of college attainment, believed would happen. Of particular relevance to the present study are the students that had positive beliefs about the afterlife. Arnett's (2004) study highlighted the benefits of positive afterlife beliefs for young people such as the hope gained from believing in life after death and how these beliefs helped them deal with suffering. The findings of the present study were similar to Arnett's (2004) findings in that a belief in the afterlife encouraged the students' earnest participation and commitment to religion and contributed to perceived benefits for them.

\section{Implications and Recommendations}

There are a number of implications from this study for developing a deeper understanding of what it means for a young adult student to be religious and for improving the education and positive development of young people.

\section{Understanding the lived experience of religious university students.}

The phenomenon of being a religious university student was at the centre of this study and there are a number of issues that need to be considered regarding future research to understand this phenomenon. First, when studying religiosity it is important to consider that both the extent and intensity of religiosity occurs on a spectrum. The students' religiosity varied from being quite mild to devout. This for example was seen through some students only attending religious services rarely, whilst for others religion permeated virtually every aspect of their lives.

Second, being religious is multifaceted. Religion should be seen as something that can be lived out in a seemingly endless number of ways. For some of the students being religious meant having personal prayer time, attending meetings to explore their religion further and participating in international events with other like-minded believers. 
Third, students' lived experiences of religion can be very personal. For example they may want to keep what they pray about private. This may sometimes hinder a researcher's ability to gain access to the lived experience of students being religious. Researchers may need to concede that some aspects of being religious are too personal to be discussed and probed so as to ensure study participants feel safe and comfortable.

Fourth, students sometimes found articulating their experiences of being religious difficult. This can create a challenge for understanding and interpreting religious experience. This occurred in the present study when some students were unable to identify a word or metaphor that encapsulated their experience of being religious. Researching what it means to be religious may require employing additional or other research methods than the interviews used in this study, such as observations. Employing additional research methods that enable young people to express their lived experience (for example narrative, photography, art) may also broaden the possibility of co-creating meaning in instances where participants find it difficult to articulate their experiences.

Finally, it is sometimes difficult to understand and interpret experiences that are foreign to one's own existing knowledge or experiences. Some students in the present study took part in religious traditions that were unfamiliar to me. This required questioning these students more extensively to gain understanding, than in instances with students whose religious traditions I was more familiar with.

The present study and its findings challenge researchers to consider diversity when choosing participants, to rethink religiosity as being problematized and to consider utilising a hermeneutic phenomenological approach. This study and previous research shows that emerging adults who are religious do not make up a homogenous group. Many overseas studies had Christian samples when assessing religiosity and spirituality. These studies had little variety in their findings. The present study included a more diverse religious sample and this helped the reader appreciate that being religious is not experienced with uniformity.

Researchers also need to consider that the experience of 'difference' or experiencing challenges at university for being religious is not negative for all emerging adults. For example one participant in this study highlighted that the university had strengthened his Christian faith. By this student enduring the challenges he faced he grew into a stronger and more mature religious person. In this way being challenged was beneficial 
for him. Difference also needs to be considered in relation to the researcher's own experience and stance. This study showed that challenges can come from outside and within one's own religious tradition.

Many overseas studies highlighted the challenges religious people experience from sources outside of their religious tradition, such as being discriminated against by nonreligious people. Few studies have focused on challenges that are internal and come from others who share the same faith tradition. An example of this was seen through one Christian student feeling judged for agreeing with same-sex marriage. This understanding gives the reader a greater appreciation of the complexity of the challenges religious people face.

Researchers might also wish to consider the benefits and rigour that comes with utilising a hermeneutic phenomenological approach and IPA as a method of data analysis. Data analysis and interpretation in this study were iterative and ongoing and called for co-construction of themes and meaning. For example, whilst it was originally deemed that "being religious is worthwhile" best encapsulated a collection of the students' positive religious experiences, through further checking and deeper analysis of the hidden meaning in order to get to the essence, it was decided that being religious was more than worthwhile, it was constructive. By giving being religious the label of being constructive, the worthwhileness of religion was acknowledged as well as the experiences of religion building the students up, giving them life and helping them develop positively.

Employing a methodology like hermeneutic phenomenology, qualitative analysis is a personal process (Smith \& Osborn, 2010) that enables the researcher to be fully immersed in the data and acknowledges their role in interpretation. My interpretations throughout this thesis are subjective, so understanding is created through my own analytical lens. The transferability of such interpretations is dependent on other researchers seeing my interpretations as plausible and relevant to their studies. It is also dependent on the quality of data provided for those interpretations which need to include thick, rich lived experience descriptors.

\section{Supporting religious students.}

Students who are transitioning in and out of tertiary institutions as well as those currently studying may experience additional stressors (Baqutayan, 2011). It appears 
that being a religious student comes with additional challenges that occur at an interpersonal and institutional level. This study highlights the lived experience and meaning of being a religious student but also some of the benefits and challenges that religious students' experience studying within a tertiary education setting. There are a number of ways that tertiary providers can develop their awareness and understand the lived experience of religious students, support their development and address issues such as marginalisation and discrimination of religious people. These strategies include:

- Learning more about their lived experience and learning needs of young religious students;

- Improving equity and diversity through policy development;

- Integrating religion and inclusive teaching of ideological views into the curriculum;

- Improving student-teacher interactions;

- Addressing student-student interactions: reducing discrimination and marginalisation between students and promoting cooperation;

- Holistic development strategies.

Each of these will be discussed in more detail in the following section.

\section{Promoting awareness and understanding of religion.}

Being a religious student meant being challenged and sometimes being misunderstood by others. Universities need to consider what within their setting contributes to this and what can be done. Researchers and scholars have been debating for some time whether secular universities could be doing more to promote discussion and educate students about religion. Religion in universities is a contentious issue. Tisdell (2006) in her work highlighted that in the $20^{\text {th }}$ century discussion about religion and spirituality in secular universities was discouraged. Others such as Lindholm and Astin (2006) have noted that in American society the spiritual dimension of people's lives has traditionally been seen as too personal to discuss in both business and academic contexts.

The students in this study reported that discussing religion and sharing personal aspects of their faith at university was difficult and awkward. Scholars have noted that in recent times "In secular institutions, especially state-supported colleges and universities, there is often a strong prevailing ethos of avoidance of discussion and attention to religion and spirituality" (Dalton \& Crosby, 2007, p.2). For some students the separation of 
religion from education may not be problematic. Universities could do more to promote religious understanding on campus and better understand their religious student population. The emerging adults in the present study only represented a fraction of religious people at their university numerically and in terms of their faith tradition. When students enrol they should have the opportunity to declare their religion, so universities can develop a more accurate picture of religious students and what faith tradition they belong to in order to meet their needs.

Religious students could benefit from increased opportunities to participate in processes related to university governance, for example student representatives and from participation on councils. They could also benefit from participating in policy and service development. Religious students (like all students) need opportunities to work alongside their universities to have a voice and to help the university develop effective services and strategies for supporting religious students. This would help promote awareness and understanding of their experiences and needs and provide them with ways to report and provide feedback about their learning and other experiences on campus. Such feedback would be valuable to help the university improve the quality of its services and education experience and to help students feel they are active, valued and critical members of the academic and university community. This would also assist universities to provide meaningful activities and programmes that religious students feel reflect their backgrounds and needs, respect their culture and enable them to feel connected to the university. They could also provide more opportunities and actively encourage students to take part in curricular and co-curricular activities and programmes designed to include and showcase different religions and enable them to observe their own religious traditions. For example, recognising the unique observances of religious groups such as Ramadan for Muslims, in a culturally sensitive way.

\section{Improving equity and diversity through policy development.}

Improving equity and diversity through policy development involves universities acknowledging and including all demographics in their policies. Many universities have specific policies that seek to promote equity and diversity. Religion is a part of the definition of diversity. For example, Victoria University of Wellington has an Equity and Diversity Policy (Victoria University of Wellington, 2014) as part of their Equity and Diversity Strategy 2010-2014. Diversity is defined in section 3 as: 
Understanding, appreciating and realising the benefits of individual differences, backgrounds and experiences, reflected in members of the University community. These may include disabilities, differences of race, ethnicity, gender, sexual orientation, socio-economic status, age, religious beliefs or political beliefs.

This definition clearly recognises religion as an important part of diversity and a characteristic of the university community.

Universities need to ensure they have effective strategies in place to meet their aims of religious inclusion, for example by honouring the sections of (New Zealand) legislation they cite. Policies that are implemented need to be evaluated and kept up-to-date. Students and staff should be made aware of these policies to ensure they know their rights and what behaviour is acceptable on their university campus. Students must be made aware that discrimination, including religious discrimination, is unacceptable and can be disclosed and dealt with promptly.

One of the reasons why religious students experience challenges is that "In their efforts to be tolerant and respectful of differences, colleges and universities can mistakenly promote an atmosphere of benign neglect, indifference or even hostility toward religion and spirituality" (Dalton \& Crosby, 2007, p. 2). Whilst at an institutional and administrative level, tertiary education providers may not be openly hostile towards religious students, their (lack of) efforts creates a tolerant tertiary community, rather than a pluralistic community characterised by "learning, growth or transformation" (Kazanjian \& Laurence, 2007, p. 5). A pluralistic community is possible and something that universities and other tertiary providers should aim for. A pluralistic education environment is desirable because "Students need to be prepared to live and work collaboratively with those with whom they have profound and seemingly irreconcilable disagreements regarding the role of faith" (Subbiondo, 2006, p. 20). Not only will this create a respectful awareness of religion and spirituality (Subbiondo, 2006) in students and staff, but it will also help address the criticism that religious students experience.

\section{Integrating religion into the curriculum and inclusive teaching practice.}

The students in this study reported feeling that their religious views, perspectives and beliefs were either invisible, dismissed or criticised within the university environment 
by Agnostic/Atheistic teaching and a denial of their religious perspectives. Taking an integrative approach to the curriculum could help resolve this issue.

Oman, Flinders and Thoresen (2008) highlight the problematic nature of lecturers not including a religious perspective in their teaching where it is appropriate. In their opinion the way religion is taught or spoken about can ultimately affect the behaviour and values of students. They said:

if the importance of religion in history or as a source of what is good and worthwhile in life is not presented, or it is presented cursorily or simplistically, students may gain the false impression that religion is unimportant in larger society or is merely a collection of inexplicable superstitions, devoid of compassion, critical reflection, and wisdom (p.81).

Excluding or devaluing religion in lectures may deny or undermine its importance and its beneficial elements in an academic setting and in wider society.

Integrating religion and inclusive teaching of ideological views into the curriculum is a strategy that gives religion the status of being considered worthy of discussion and critique in academic settings. Several authors have made suggestions about how to improve awareness and inclusion of religious views in the curriculum. Subbiondo (2006) has advocated for an integrative approach. He says: "higher education should devote itself to creating and exploring initiatives that will integrate a respectful awareness of religion and spirituality into the curricular and co-curricular programs and activities" (p.20) of its campuses. Subbiondo's (2006) concern is that spirituality and religion have generally been relegated to religious studies and theology courses. Integrative learning, however, can be used to reduce the divide between tertiary education and religion and spirituality (Subbiondo, 2006). According to Huber and Hutchings (2004) integrative learning can include: "connecting skills and knowledge from multiple sources and experiences; applying theory to practice in various settings; utilizing diverse and even contradictory points of view; and, understanding issues and positions contextually" (p. 23). Integrative learning has in the past been credited with challenging narrow perspectives and liberating students from social constraints that stop them from participating responsibly in society (Huber \& Hutchings, 2004). In this way integrative learning can improve students' communication with one another and help address the misunderstanding and ignorance of students who are not familiar with 
religion. What this ultimately means for religious students, such as those in the present study, is that they can feel more connected to their peers and inclined to communicate with them.

Several suggestions have been made about how to include a religious perspective in tertiary settings and affirm religion and spirituality for students. One way for educators is to acknowledge that religion has been of profound importance in many peoples' lives in the past (Oman et al., 2008). At the same time they can promote the strengths and virtues that come from, and are endorsed in religion such as being compassionate (Saroglou, Pichon, Trompette, Verschueren, \& Dernelle, 2005) to help give value to religion and spirituality. A second suggestion is to encourage students to study spiritual models such as Jesus Christ and Mahatma Gandhi and their perspectives (Oman et al., 2008). This allows students to go beyond their own personal insights and experiences (Nord \& Haynes, 1998) to broaden their perspectives of religion. A third suggestion is for educators to invite guest speakers or generate discussion about the relevance of spirituality in various careers (Oman et al., 2008). This helps students recognise that religion and spirituality can and may play more of an important role in their future careers than they may think.

There are, however, a number of barriers to implementing an integrative curriculum. One such barrier is the separation of academic knowledge into disciplines (Schneider \& Shoenberg, 1999). The challenge to an integrative approach is that staff and students are faced with having to teach and learn about a wider diversity of topics and approaches when many students are not socialised to view disciplines as interdisciplinary, thus creating insularity (Schneider \& Shoenberg, 1999). A second barrier is that there can be resistance from teaching staff and administration to adopt an integrative learning approach and challenges that come with changing campus culture, staff and dwindling funding (Huber, Hutchings, Gale, Miller, \& Breen, 2007). A final issue is that universities need to assess in what way they can begin "adopting or creating initiatives suited to its educational character and mission" (Subbiondo, 2006, p. 29). With this in mind it may be that some initiatives are more appropriate to implement than others.

\section{Addressing student-student interactions.}

Being a religious student at university meant being challenged by peers and fellow students and experiencing marginalisation and criticism. Positive student relationships 
and connectedness and the importance of these have been of interest to scholars and researchers for some time. Johnson (1981) said that "Constructive student-student relationships are probably an absolute necessity for maximal achievement, socialization, and healthy development" (p. 5). There are a number of strategies universities can use to reduce experiences of marginalisation and criticism and promote positive relationships and cooperation between students.

Johnson (1981) has argued that the starting point for improving student-student interactions is to make sure that the students are already interacting. Following the establishment of interaction educators must ensure that it takes place in a safe and supportive context, so as to ensure learning goals are met and conflicts of opinion are managed (D. W. Johnson, 1981). Finally, educators should encourage and be supportive of students' interactions, while at the same time be willing to give them freedom to build relationships with one another (Sidelinger \& Booth-Butterfield, 2010). One such way to build relationships is to provide students with opportunities for cooperative learning (Deutsch, 1962; Johnson \& Johnson, 1975 cited in D. W. Johnson, 1981). Using a goal structure educators can correlate students' achievements against their cooperation with one another (D. W. Johnson, 1981). In this way students from varying backgrounds can interact with and get to know each other better, while at the same time unite with one another to achieve common goals. Teachers could encourage students to share their worldviews rather than focusing on religion when discussing identity and beliefs. This could encourage religious and non-religious students to be more forthcoming and receptive to discussion about religion. Presenting religion within a worldview may give their faith/religion institutional and intellectual credibility (Nord, 1995) and help prevent experiences where they feel they are being personally attacked. Glanzer (2004) has suggested that an effective way to address the dismissal of faith/religion, which can happen in student interactions, is to not focus discussion purely on religion when discussing identity and beliefs. This is because "one can deny having a religious identity or beliefs or one can easily claim that religious beliefs do not influence one's interpretation of experience" (p.3).

\section{Holistic development strategies.}

Each of the strategies and implications discussed above could be implemented individually or as part of an integrative approach to support positive development and learning in religious students. Astin and Astin (2010) recommend a holistic approach to 
religious discrimination and promoting understanding, but also suggest creating professional development programmes for staff, hosting guest speakers and organising forums. According to Astin and Astin (2010) "the higher education community can become more responsive to students' holistic development by paying greater attention to their inner lives" (p.8). Such a focus may also assist in the process of addressing the discrimination and marginalisation of religious students. The methods outlined by Astin and Astin (2010) to attend to students' inner lives include:

- "Offering opportunities for spiritual reflection and discussion during activities such as student orientation and programs targeting students during their first year and sophomore years;

- Using new faculty orientation as an opportunity to discuss ways to attend to students' spiritual development in the classroom and beyond;

- Creating professional development programs to prepare staff, faculty, and peer leaders to participate in and facilitate discussions on spiritual issues;

- Creating places for reflection and quiet dialogue on campus;

- Creating inter-faith forums on spirituality and religious diversity;

- Developing guiding principles to facilitate conversations on spirituality;

- Integrating discussions of spirituality in living/learning communities and residence halls;

- Hosting guest speakers and forums to encourage discussions on spirituality; and

- Incorporating spirituality into campus mission and vision statements" (p. 8).

\section{Inaction and tolerance is not good enough}

Inaction to address ignorance and nurture understanding about religion may come at a cost including religious Balkanization (the division and fragmentation of higher education campuses) and the "triumphalism and suspicion of others" (Nash, 2007, p. 3). Stereotypes such as Christian students being "goody two shoes" and "wackos" are problematic and the foundation on which fragmentation is built. In the words of Nash (2007): 
Stereotyping (no matter how trivial) frequently breeds counter stereotyping, born out of defensiveness and anger. Anger sometimes results in separation. Separation easily grows into separatism and isolation. Balkanization, in turn can lead to a defiant exclusionism" (p.3).

Such exclusionism is neither desirable nor acceptable in an environment where university students should feel included. It may be that religious students are not a 'visible' minority, so more may need to be done to ensure they are not excluded.

Students in this study felt like they were criticised and were at best only tolerated for being religious. Kazanjian and Laurence (2007) state that merely tolerating different religious views is not good enough. In their words:

Tolerance...is little more than conflict arrested. It is a harness applied to the destructive forces of ignorance, fear, and prejudice, and it provides a kind of wall between warring parties...As such, tolerance is not a basis for healthy human relationship, nor will it ever lead to pluralistic community, for tolerance does not allow for learning, growth or transformation, but ultimately keeps people in a state of suspended ignorance and conflict (p.5).

Kazanjian and Laurence's (2007) words are effective at illuminating the realities of tolerance. Whilst tolerance may be considered preferable to situations of physical violence or persecution it is only a starting point to pluralistic community. By implementing the aforementioned strategies to address religious discrimination, inclusion can become a part of the religious students' experiences so they can feel united with their peers in an environment where they can succeed and thrive.

\section{Limitations}

The present study used IPA to explore the lived experience of being religious in emerging adults' within a tertiary education setting. In order to conduct a successful study using IPA the research question one is attempting to answer must be a proper phenomenological question (Van Manen, 2014). This question should investigate something that is experientially recognisable and accessible so lived experience descriptions can be gained (Van Manen, 2014). The research question in the present 
study was a proper phenomenological one because it was formulated to gain an understanding about what it means and was like to be a religious emerging adult within a tertiary education setting. Moreover, the topic of interest in this study, namely one's personal experience of religion, was not something that the students had been asked about before. This added to the rigour of my study because the material that was asked about and collected was pre-reflective and experiential. To guarantee that future inquiries investigate phenomena that are experientially recognizable and accessible (Van Manen, 2014) researchers should ensure that once they have formulated a proper phenomenological question it remains at the centre of their research inquiry from the beginning to the end.

This study used purposive sampling which has a number of limitations. Johnson and Christensen (2012) point out that the generalizability of a study sample to a wider population is severely limited. They recommend obtaining a random sample from the target population to address this limitation, which due to time constraints was not practical in this study (B. Johnson \& Christensen, 2012). Related to the above limitation is that there is a strong possibility of researcher bias (Mugera, 2013, April) when recruiting a non-random sample of participants. Researcher bias however is typically only considered to be a limitation when poor judgements are made by the researcher (Mugera, 2013, April), of which none are apparent in this study.

When conducting a phenomenological study it is crucial that all of the participants that are included have sufficient experience of what is being investigated so they can reflect on it (Van Manen, 2014). All of the participants in my study were able to reflect on their lived experience of being religious, but there were some limitations in their (nature) of lived experience. First, one of the students had only been at university for one semester. This meant the student had limited experience of what it is like to be a religious student in a tertiary education setting. To avoid including participants with limited lived experience future studies could have a requirement about how much experience participants must have had to be included in the study that is being conducted, for example three to four years.

A second limitation was some participants had limited experience of 'being religious' and 'being a student'. For example, for the student in the sample who studied computer science, religion was never discussed or came up in his class discussions. This resulted in his experience of being religious and a tertiary student being limited. Future 
researchers who conduct research about religion in a tertiary education setting should consider the university major(s) of the students who take part in their study and ask participants whether religion has been discussed or is an issue in their classes. Such a consideration will help with the recruitment of samples that have students with deep and rich experiences of being religious and a student.

Third, the study included participants from a limited number of religions which narrowed the type of meanings being religious could take on. Phenomenological studies usually restrict their participants to a single characteristic, for example the same age group, or demographic background. They do this in order to get to the essence of their lived experience. However, future studies exploring religion in tertiary settings could consider focusing on religions other than Christianity and Islam and/or recruit a broader range of religious students from traditions that were not represented in this study or previous studies, including Buddhists and Jews. This would give the definition of what it means to be religious a deeper and richer focus and add to the understanding of the phenomena. Alternatively future studies could broaden the number of religious traditions to be studied, but focus on each religious tradition individually in detail and then explore 'being religious' in depth across religious traditions.

Fourth, there were differences in the lived experience of participants based on their developmental stage/age that could have influenced the findings. This could have influenced their experience but also their interpretation through the time they have had to develop their cognitive and meaning making abilities. In future, narrowing the age range of participants could help readers recognise the significant developmental differences that can exist between 17 and 25 year-olds.

The data collection method in the present study was semi-structured open-ended interviews. This method was effective in gaining deep and rich descriptions of the students' experiences, but did create some issues. One such issue was that the participants sometimes found it difficult to answer the questions I formulated. An example of this was the question I asked about what metaphor or word best describes being religious for them. I subsequently discarded this question as it did little to generate meaning about the students' experiences of being religious. A second issue to arise was lack of experience using phenomenological methods. Van Manen (2014) points out that in phenomenology it is important that the phenomenological method and question remain prominent in all stages of the research process. As a result of being an 
inexperienced researcher and interviewer using phenomenology there were times during data collection where the students' experiences were not always at the centre of my study. A situation where this occurred was when I asked about how other students perceived them. Such a question was not conducive to sound phenomenological inquiry, because it was not about the students' own lived experiences but rather focused on their perceptions.

A third issue was that the data about the students' experiences was collected indirectly by what the students said, rather than being witnessed first-hand. Future studies could broaden data collection to other methods such as observations of students' participating in their religious environments so data can be collected more directly. Such a suggestion has previously been made by Mattis (2002) who conceded that words may not always suffice to gain a detailed understanding of peoples' experiences of religion and spirituality. Fourth, the present study did not utilise follow-up interviews. Although they were deemed unnecessary, future studies that employ qualitative interviews may benefit from conducting secondary interviews to further probe areas of interest, clarify meaning and the significance of the language and experiences of participants.

An additional issue encountered during the data analysis phase of this study was interpreting the students accounts literally while at the same time searching for hidden meanings. At times it was difficult to determine whether there was something hidden in what the students said. In such instances I analysed the text around the extracts to gain further insight and to contextualise what was said. In situations when I was still in doubt I approached my supervisor and we discussed and contested possible meanings. The final decision about what the students' experiences meant was made by me because I had knowledge of the participants' interviews and had conversations with them before and after they took place. My own religiosity may also have affected the interpretation and analysis of findings in this study. Although my own religiosity may have strengthened the interpretation process by providing me with prior knowledge about some aspects of religion, as it was not possible to bracket my pre-understandings. My supervisor did, however, challenge me on various issues and constructions of meaning when they seemed to reflect my religious background more than the participants' lived experience. 


\section{Phenomenology and Interpretative Phenomenological Analysis.}

Many authors and scholars have highlighted the limitations of phenomenology and IPA. A leading problem in phenomenology is that the analysis stage of an inquiry is iterative in nature (Murray \& Chamberlain, 1999) and could theoretically continue infinitely (Brocki \& Wearden, 2006) where an individual interpretation of a researcher could not possibly exhaust the meaning of a text (Geanellos, 2000). Clarke (2009) agreed that an issue with phenomenological analysis is the time it takes and depth it requires. A second key problem is that researchers need to be aware of the limits of the representation of their data (Brocki \& Wearden, 2006). In some instances data may only represent the experience of one or only a few participants, which may not make the data essential to the data set's experiences.

Collins and Nicolson (2002) state that when employing IPA the "search for connections, similarities or divergences across cases misses a potentially richer seam of data, that of a contextualized, unfolding and sequential account within a single interview" (p. 627). It may be that in a researcher's pursuit of the essential meaning of their participants' experiences across their data set that they miss important points that illuminate the experience they are exploring from individual accounts.

Another problem is that researchers do not always recognise the theoretical preconceptions they bring to the study they are conducting (Brocki \& Wearden, 2006). This problem undermines the accessibility and clarity of one's research processes and findings to outsiders (Brocki \& Wearden, 2006). As IPA is a relatively new research paradigm (Larkin, Watts, \& Clifton, 2006) the extent of its effectiveness is questionable in some disciplines, even arguably in the discipline of the present study, education.

Ricoeur (1971) highlighted another limitation through the best way to assess the importance of an individual's lived experience being through guessing. Geanellos (2000) points out the limitations of such a phenomenological approach. First, it does not allow for the co-creation of understanding between the participant and researcher; second, it takes away the relational aspect of experience where one interacts with other people; and third it promotes authorial meanings that create singular and unchanging knowledge, because the emphasis is on the researcher's interpretation.

Lindseth (2004) also noted that using phenomenology as a research method can be plagued with issues such as participant recall. For example, even if a researcher recruits 
participants who have had an experience of the phenomenon of interest they may not remember their experience clearly or accurately. This problem is compounded by the fact that a researcher also cannot entirely recreate the event the participant has had, because they can only analyse the participant's account and not their real lived experience (Tan et al., 2009). With all of these limitations and challenges in mind it is not surprising that Larkin, Watts and Clifton (2006) have said that "accessing the 'experience' of individual persons is a notoriously problematic and complex pursuit” (p. 108) even using phenomenological research methods.

\section{Reliability/Integrity and Trustworthiness.}

Despite these limitations in the research methodology and methods there are strategies that can minimise these issues and promote reliability/integrity and trustworthiness. The strategies used in this study included: (i) keeping a diary to document my research decisions and reflect on whether my religious predispositions had affected my research; (ii) having regular meetings with my supervisor to ensure my religiosity did not influence the interpretation of my findings and (iii) member-checking with participants to make sure my interpretations were accurate. Each of these strategies promoted academic rigour in this study.

The reliability/integrity and trustworthiness of this study could have been strengthened if I had upskilled as a qualitative investigator (Patton, 1990 cited in Shenton, 2004) before beginning my study. This study was my first attempt at conducting research using IPA which meant I did not always employ sound IPA research methods. Another way the study could have been strengthened was if I had replicated the line of questioning from previous successful studies (Shenton, 2004). There are few qualitative studies that have explored religiosity in university students and this study did not look to previous qualitative studies regarding what questions they asked their religious participants. Doing so may have made the questions in the present study more refined and appropriate.

Another strategy that could have strengthened my research was utilising peer scrutiny throughout the various stages of my study (Shenton, 2004). Peer feedback from other researchers was not sought or received so they were not able to challenge the assumptions and interpretations I made about the students' experiences (Shenton, 2004). An additional strategy I could have used was utilising a random sampling method for 
the recruitment of participants to ensure they were representative of the larger religious university population (Hamil, Dufour \& Fortin, 1993 cited in Shenton, 2004). This strategy reduces recruitment bias but has been criticised for allowing the inclusion of inarticulate or uncooperative participants (Shenton, 2004).

Some authors and researchers have suggested that researchers should familiarise themselves with the organisation or groups that (potential) participants are going to come from (Shenton, 2004). This took place in the present study, where I contacted each of the religious groups at Victoria University of Wellington. However, I did not make a specific effort to dialogue with any of the groups I contacted other than making them aware of my study. This was with the exception of the Christian group I visited at their weekly meeting. Researchers need to balance encouraging potential participants and working with key gatekeepers without putting demands or pressures on the groups and organisations to participate (Shenton, 2004).

\section{Findings.}

There are several possibilities why some of the findings in this study were different to previous studies. First, the methods used to collect and analyse the findings in this study substantially differed to those used in previous studies. In Hyers and Hyers' (2008) study diaries were used to record experiences of discrimination. This study was also inductive, keeping in line with the phenomenological tradition of keeping an open and curious mind about phenomena, whereas previous studies have used deductive approaches. Rosik and Smith's (2009) study used surveys in a deductive approach, where their findings were organised under pre-existing categories. This may have resulted in a difference of findings and themes compared to the present study that used an inductive approach, where themes were developed thorough IPA and an iterative process. Another possible reason for the differences was because of cultural differences between students studying in tertiary institutions across countries. For example, the percentage of Christians in the United States of America (78.4\%) (PewResearch, 2013) is much greater than in New Zealand (48.9\%) (Statistics New Zealand, 2014). This demographic difference may account for some of the variance regarding minority status or being marginalised. Although it cannot be assumed that American Christian students feel more or less like they are a minority or marginalised compared to New Zealand Christian students, this demographic difference may explain why Christian students in previous American studies did not have or report these experiences. 
Differences in the student populations might also account for differences in findings. In Rosik and Smith's (2009) study half of their findings came from students attending a Christian university. Presumably this would mean the Christian students who took part in their study were not in an environment where they were a minority or marginalised, hence this experience was not reported in their study.

\section{Future Directions}

The present study focused on emerging adults' experiences of being religious within a tertiary education setting in New Zealand. In future the understanding of this phenomenon could be advanced in a number of ways by answering questions that arose throughout this study. Future studies may wish to consider the following questions:

1. Why is it that/do all Christians find being religious challenging while studying at (New Zealand) tertiary campuses?

2. Why is that/do all non-Christian religious people find being religious constructive while studying at (New Zealand) tertiary campuses?

3. What are the experiences of Atheist tertiary students on (New Zealand) tertiary campuses?

4. What are the experiences of non-religious students who attend classes and engage with religious students?

5. What have been educators' experiences of integrating and teaching religious students at New Zealand universities?

6. What are religious students' experiences of being stigmatised and stereotyped at university?

The present study found that the experience of challenge was more predominant in Christian students than the non-Christian students. While some of the students made suggestions about the reason(s) for this, it was not explored as part of the present study. An area of future research could include Christian and non-Christian religious students and explore the lived experiences of individuals who do not profess or affiliate with any religious faiths, or that attend classes with religious students. Future studies that include non-religious studies would help shed light on whether religious students and their nonreligious peers share similar or unique challenges and how they cope with these within educational contexts. 
Future studies could incorporate the experiences of educators in the role that they have played to integrate and teach religious students. Very little was gleaned from this study about the commitment of lecturers to include religion and religious students in education and what difference this might make to how religious students experience religion and being connected. Finally, it may be that in the first instance, tertiary providers could investigate the spectrum of religion on campus and the number of followers from each respective religious tradition. This would inevitably give a clearer picture of what being religious can look like and mean, and for what percentage of tertiary students this applies to. However, there is a need to follow up quantitative surveys with qualitative research like the present study to better understand why and how students experience being religious on campus.

\section{Conclusions}

This chapter discussed the research findings of this study in light of relevant empirical studies and literature and my own critical reflection on the findings. The essence of being religious for the ten tertiary students interviewed in this study was engaging with the sacred. This essential meaning encapsulated the students' experiences where they had an affinity to a higher being, were dissimilar to most of their peers, experienced difficulty and criticism and worthwhile benefits.

Two super-themes: being religious is challenging and being religious is constructive were discussed because they were the most relevant to the educational and developmental context of this study. The findings of this study echoed the findings of previous studies and also shed light on unique lived experiences of being religious in a tertiary education setting not explored in previous quantitative studies. The implications of the findings from this study were discussed to highlight what they meant for education in tertiary settings. The limitations of this study were identified and a number of suggestions made for future studies interested in exploring the experiences of religion and young people.

The present study highlighted the importance of an integrative approach in education where religion is included in curricular and co-curricular activities and programmes. The reason for this was because the students were engaged with the sacred, but were not necessarily engaged with their university in a way that made them feel like they were connected and that they belonged. The students gained enjoyment and strength from 
engaging with the sacred which helped their academic lives and positive youth development. Religion should be supported and nurtured for students who make positive gains in their youth development, because of the strong and significant developmental influence it can have (Furrow et al., 2004).

All students need to feel they belong and are supported in their learning. They also have a right to be educated in an environment free from fear, criticism and disrespect. In future, religious students may need to be more prominently identified as an equity group for targeted action at universities and in tertiary education providers' equity and diversity policies. This will help ensure that they are not only included, but can thrive at university in ways that promote their development as academics and future citizens. 


\section{References}

Abes, E. S., Jones, S. R., \& McEwen, M. K. (2007). Reconceptualizing the model of multiple dimensions of identity: The role of meaning-making capacity in the construction of multiple identities. Journal of College Student Development, 48(1), 1-22.

Allport, G. W., \& Ross, J. M. (1967). Personal religious orientation and prejudice. Journal of Personality and Social Psychology, 5(4), 432-443. doi: doi.org/10.1037/h0021212

Anye, E. T., Gallien, T. L., Bian, H., \& Moulton, M. (2013). The relationship between spiritual well-being and health-related quality of life in college students. Journal of American College Health, 61(7), 414-421. doi:

$10.1080 / 07448481.2013 .824454$

Arnett, J. J. (1997). Young people's conceptions of the transition to adulthood. Youth \& Society, 29(1), 3-23.

Arnett, J. J. (2000). Emerging adulthood: A theory of development from the late teens through the twenties. American Psychologist, 55(5), 469-480.

Arnett, J. J. (2004). Emerging adulthood: The winding road from the late teens through the twenties. New York: Oxford University Press.

Arnett, J. J., \& Jensen, L. A. (2002). A congregation of one: Individualized religious beliefs among emerging adults. Journal of Adolescent Research, 17(5), 451-467.

Astin, A. W., \& Astin, H. S. (2010). Exploring and nurturing the spiritual life of college students. Journal of College and Character, 11(3), 1-10.

Baqutayan, S. (2011). Stress and social support. Indian Journal of Psychological Medicine, 33(1), 29-34.

Barry, C. M., \& Nelson, L. J. (2005). The role of religion in the transition to adulthood for young emerging adults. Journal of Youth and Adolescence, 34(3), 245-255.

Beck, A. T., Weissman, A., Lester, D., \& Trexler, L. (1974). The measurement of pessimism: The hopelessness scale. Journal of Consulting and Clinical Psychology, 42(6), 861-865.

Bevan, M. T. (2014). A method of phenomenological interviewing. Qualitative Health Research, 24(1), 136-144.

Braun, V., \& Clarke, V. (2006). Using thematic analysis in psychology. Qualitative Research in Psychology, 3(2), 77-101.

Brocki, J. M., \& Wearden, A. J. (2006). A critical evaluation of the use of interpretative phenomenological analysis (IPA) in health psychology. Psychology and Health, 21(1), 87-108.

Brodt, S. E., \& Ross, L. D. (1998). The role of stereotyping in overconfident social prediction. Social Cognition, 16(2), 225-252.

Bronk, K. C. (2011). The role of purpose in life in healthy identity formation: A grounded model. New Directions for Youth Development, 2011(132), 31-44. doi: $10.1002 / y d .426$

Bryant, A. N., Choi, J. Y., \& Yasuno, M. (2003). Understanding the religious and spiritual dimensions of students' lives in the first year of college. Journal of College Student Development, 44(6), 723-745.

Byrd, K. R., Hageman, A., \& Isle, D. B. (2007). Intrinsic motivation and subjective well-being: The unique contribution of intrinsic religious motivation. International Journal for the Psychology of Religion, 17(2), 141-156. doi: 10.1002/j.2161-007X.1988.tb00735.x 
Byron, K., \& Miller-Perrin, C. (2009). The value of life purpose: Purpose as a mediator of faith and well-being. The Journal of Positive Psychology, 4(1), 64-70. doi: 10.1080/17439760802357867

Caserta, M., Utz, R., Lund, D., \& De Vries, B. (2010). Sampling, recruitment, and retention in a bereavement intervention study: Experiences from the Living After Loss Project. Journal of Death and Dying, 61(3), 181-203.

Clarke, C. (2009). An introduction to interpretative phenomenological analysis: A useful approach for occupational therapy research. British Journal of Occupational Therapy, 72(1), 37-39.

Collins, K., \& Nicolson, P. (2002). The meaning of 'satisfaction' for people with dermatological problems: Reassessing approaches to qualitative health psychology research. Journal of Health Psychology, 7(5), 615-629.

Crotty, M. (1998). The foundations of social research: Meaning and perspective in the research process. NSW: Allen \& Unwin.

Dalton, \& Crosby. (2007). Let's talk about religious differences: The neglected topic in diversity discussions on campus. Journal of College and Character, 9(2), 1-4. doi: $10.2202 / 1940-1639.1125$

Davis, T. L., Kerr, B. A., \& Kurpius, S. E. R. (2003). Meaning, purpose, and religiosity in at-risk youth: The relationship between anxiety and spirituality. Journal of Psychology and Theology, 31(4), 356-365.

Diener, E., Emmons, R. A., Larsen, R. J., \& Griffin, S. (1985). The satisfaction with life scale. Journal of Personality Assessment, 49(1), 71-75.

Doane, M. J. (2013). The association between religiosity and subjective well-being: The unique contribution of religious service attendance and the mediating role of perceived religious social support. The Irish Journal of Psychology, 34(1), 4966. doi: 10.1080/03033910.2013.775071

Edgell, P., Gerteis, J., \& Hartmann, D. (2006). Atheists as “other”: Moral boundaries and cultural membership in American society. American Sociological Review, 71(2), 211-234.

Emmons, R. A. (1999). The psychology of ultimate concerns: Motivation and spirituality in personality. New York: Guilford Publications.

Falb, M. D., \& Pargament, K. I. (2014). Religion, spirituality, and positive psychology: Strengthening well-being. In J. Teramoto Pedrotti \& L. Edwards (Eds.), Perspectives on the Intersection of Multiculturalism and Positive Psychology (pp. 143-157): Springer.

Finlay, B., \& Walther, C. S. (2003). The relation of religious affiliation, service attendance, and other factors to homophobic attitudes among university students. Review of Religious Research, 44(4), 370-393. doi: 10.2307/3512216

Flannelly, K. J., Ellison, C. G., Galek, K., \& Silton, N. R. (2012). Belief in life-afterdeath, beliefs about the world, and psychiatric symptoms. Journal of Religion and Health, 51(3), 651-662.

Furrow, J. L., King, P. E., \& White, K. (2004). Religion and positive youth development: Identity, meaning, and prosocial concerns. Applied Developmental Science, 8(1), 17-26.

Gardner, T. M., Krägeloh, C. U., \& Henning, M. A. (2014). Religious coping, stress, and quality of life of Muslim university students in New Zealand. Mental Health, Religion \& Culture, 17(4), 327-338. doi: doi.org/10.1080/13674676.2013.804044

Glanzer, P. L. (2004). Taking the tournament of worldviews seriously in education: Why teaching about religion is not enough. Religion and Education, 31(1), 1-19.

Geanellos, R. (2000). Exploring Ricoeur's hermeneutic theory of interpretation as a method of analysing research texts. Nursing Inquiry, 7(2), 112-119. 
Genia, V. (1998). Religiousness and psychological adjustment in college students. Journal of College Student Psychotherapy, 12(3), 67-77. doi: doi.org/10.1300/J035v12n03_06

Good, M., \& Willoughby, T. (2007). The identity formation experiences of churchattending rural adolescents. Journal of Adolescent Research, 22(4), 387-412.

Goodman, K. M., \& Mueller, J. A. (2009). Invisible, marginalized, and stigmatized: Understanding and addressing the needs of atheist students. New Directions for Student Services, 2009(125), 55-63.

Hadaway, C. K., \& Roof, W. C. (1988). Apostasy in American churches: Evidence from national survey data. In D. G. Bromley (Ed.), Falling from the faith: Causes and consequences of religious apostasy (pp. 29-46). California: Sage.

Havighurst, R. J. (1948). Developmental tasks and education. Chicago: University of Chicago Press.

Hawkins, M. T., Letcher, P., Sanson, A., Smart, D., \& Toumbourou, J. W. (2009). Positive development in emerging adulthood. Australian Journal of Psychology, 61(2), 89-99.

Hesse-Biber, S., \& Leavy, P. (2006 ). The practice of qualitative research. California: Thousand Oaks.

Hodge, D. R. (2007a). Progressing toward inclusion? Exploring the state of religious diversity. Social Work Research, 31(1), 55-63.

Hodge, D. R. (2007b). Religious discrimination and ethical compliance: Exploring perceptions among a professionally affiliated sample of graduate students. Journal of Religion \& Spirituality in Social Work: Social Thought, 26(2), 91113.

Hoge, R., Johnson, B., \& Luidens, D. A. (1993). Determinants of church involvement of young adults who grew up in Presbyterian churches. Journal for the Scientific study of Religion, 242-255.

Hovey, J. D., Hurtado, G., Morales, L. R. A., \& Seligman, L. D. (2014). Religion-based emotional social support mediates the relationship between intrinsic religiosity and mental health. Archives of Suicide Research, 18(4), 376-391. doi: 10.1080/13811118.2013.833149

Hsien-Chuan Hsu, P., Krägeloh, C. U., Shepherd, D., \& Billington, R. (2009). Religion/spirituality and quality of life of international tertiary students in New Zealand: An exploratory study. Mental Health, Religion \& Culture, 12(4), 385399. doi: doi.org/10.1080/13674670902752920

Huber, M. T., \& Hutchings, P. (2004). Integrative learning: Mapping the terrain. Washington: Association of American Colleges and Universities.

Huber, M. T., Hutchings, P., Gale, R., Miller, R., \& Breen, M. (2007). Leading initiatives for integrative learning. Liberal Education, 93(2), 46-51.

Hyers, C. (2008). The spirituality of comedy: Comic heroism in a tragic world. New Jersey: Transaction Publishers.

Hyers, L. L., \& Hyers, C. (2008). Everyday discrimination experienced by conservative Christians at the secular university. Analyses of Social Issues and Public Policy, 8(1), 113-137. doi: 10.1111/j.1530-2415.2008.00162.x

Jacob, S. A., \& Furgerson, S. P. (2012). Writing interview protocols and conducting interviews: Tips for students new to the field of qualitative research. Qualitative Report, 17(42), 1-10.

Johnson, B., \& Christensen, L. B. (2012). Educational research: Quantitative, qualitative, and mixed approaches. Thousand Oaks: Sage Publications.

Johnson, B., \& Turner, L. A. (2003). Data collection strategies in mixed methods research. In A. Tashakkori \& C. Teddlie (Eds.), Handbook of mixed methods on social and behavioral research (pp. 297-320). California: Sage Publications. 
Johnson, D. W. (1981). Student-student interaction: The neglected variable in education. Educational Researcher, 10(1), 5-10.

Jones, J. W. (2004). Religion, health, and the psychology of religion: How the research on religion and health helps us understand religion. Journal of Religion and Health, 43(4), 317-328.

Jones, S. R., \& McEwen, M. K. (2000). A conceptual model of multiple dimensions of identity. Journal of College Student Development, 41(4), 405-414.

Kane, M. N., \& Jacobs, R. J. (2010). Predictors of the importance of spiritual and religious beliefs among university students. Journal of Religion \& Spirituality in Social Work: Social Thought, 29(1), 49-70. doi: 10.1080/15426430903479262

Kazanjian, \& Laurence. (2007). The journey toward multi-faith community on campus: The religious and spiritual life program at Wellesley College. Journal of College and Character, 9(2), 1-13. doi: 10.2202/1940-1639.1123

King, P. E. (2003). Religion and identity: The role of ideological, social, and spiritual contexts. Applied Developmental Science, 7(3), 197-204. doi: doi.org/10.1207/S1532480XADS0703_11

Kirk, C. M., \& Lewis, R. K. (2013). The impact of religious behaviours on the health and well-being of emerging adults. Mental Health, Religion \& Culture, 16(10), 1030-1043. doi: doi.org/10.1080/13674676.2012.730037

Koch, T. (1995). Interpretive approaches in nursing research: The influence of Husserl and Heidegger. Journal of Advanced Nursing, 21(5), 827-836.

Koch, T. (1999). An interpretive research process: Revisiting phenomenological and hermeneutical approaches. Nurse Researcher, 6(3), 20-34.

Krauss, S. E. (2005). Research paradigms and meaning making: A primer. The Qualitative Report, 10(4), 758-770.

Krefting, L. (1991). Rigor in qualitative research: The assessment of trustworthiness. The American Journal of Occupational Therapy, 45(3), 214-222.

Kvale, S. (2009). InterViews: Learning the craft of qualitative research interviewing. Los Angeles: Sage Publications

Ladd, K. L., \& McIntosh, D. N. (2008). Meaning, God, and prayer: Physical and metaphysical aspects of social support. Mental Health, Religion \& Culture 11 (1), 23-38.

Larkin, M., Watts, S., \& Clifton, E. (2006). Giving voice and making sense in interpretative phenomenological analysis. Qualitative Research in Psychology, $3(2), 102-120$.

Laverty, S. M. (2003). Hermeneutic phenomenology and phenomenology: A comparison of historical and methodological considerations. International Journal of Qualitative Methods, 2(3), 21-35.

Leak, G. K. (2009). An assessment of the relationship between identity development, faith development, and religious commitment. Identity, 9(3), 201-218. doi: $10.1080 / 15283480903344521$

Lee, J. J. (2002). Religion and college attendance: Change among students. The Review of Higher Education, 25(4), 369-384.

Lefkowitz, E. S. (2005). “Things Have Gotten Better" Developmental changes among emerging adults after the transition to university. Journal of Adolescent Research, 20(1), 40-63.

Lincoln, Y. S., \& Guba, E.G. (1985). Naturalistic Inquiry. Beverley Hills: Sage Publications.

Lindholm, J. A., \& Astin, H. S. (2006). Understanding the "interior" life of faculty: How important is spirituality? Religion and Education, 33(2), 64-90. 
Lindseth, A., \& Norberg, A. (2004). A phenomenological hermeneutical method for researching lived experience. Scandinavian Journal of Caring Sciences, 18(2), 145-153.

Lopez, K. A., \& Willis, D. G. (2004). Descriptive versus interpretive phenomenology: Their contributions to nursing knowledge. Qualitative Health Research, 14(5), 726-735.

Maltby, J., Lewis, C. A., \& Day, L. (1999). Religious orientation and psychological well-being: The role of the frequency of personal prayer. British Journal of Health Psychology, 4(4), 363-378. doi: 10.1348/135910799168704

Malterud, K. (2001). Qualitative research: Standards, challenges, and guidelines. The Lancet, 358(9280), 483-488.

Mattis, J. S. (2002). Religion and spirituality in the meaning-making and coping experiences of African American women: A qualitative analysis. Psychology of Women Quarterly, 26(4), 309-321.

McEwen, M. K. (2003). New perspectives on identity development. In S. R. Komives \& D. B. Woodard (Eds.), Student services: A handbook for the profession (4th ed., pp. 203-233). San Francisco: Jossey-Bass.

McGarty, C., Yzerbyt, V. Y., \& Spears, R. (2002). Stereotypes as explanations: The formation of meaningful beliefs about social groups. England: Cambridge University Press.

Messiou, K. (2012). Collaborating with children in exploring marginalisation: An approach to inclusive education. International Journal of Inclusive Education, 16(12), 1311-1322.

Milevsky, A., \& Leh, M. (2008). Religiosity in emerging adulthood: Familial variables and adjustment. Journal of Adult Development, 15(1), 47-53.

Milevsky, A., \& Levitt, M. J. (2004). Intrinsic and extrinsic religiosity in preadolescence and adolescence: Effect on psychological adjustment. Mental Health, Religion \& Culture, 7(4), 307-321.

Ministry of Youth Affairs. (2002). Youth Development Strategy Aotearoa. Retrieved from http://myd.govt.nz/documents/resources-and-reports/publications/youthdevelopment-strategy-aotearoa/ydsa.pdf

Mugera, W. (2013, April). Non-probability sampling techniques. Paper presented for Research Methods LDP 603, University of Nairobi.

Murray, M., \& Chamberlain, K. (1999). Qualitative health psychology: Theories and methods. Thousand Oaks: Sage.

Nash, R. J. (2007). Understanding and Promoting Religious Pluralism on College Campuses. Spirituality in Higher Education, 3(4), 1-9.

Nelms, L. W., Hutchins, E., Hutchins, D., \& Pursley, R. J. (2007). Spirituality and the health of college students. Journal of Religion and Health, 46(2), 249-265.

Nelson, P. B. (1990). Intrinsic/extrinsic religious orientation of the elderly: Relationship to depression and self-esteem. Journal of Gerontological Nursing, 16(2), 29-35.

Nelson, T. D. (2009). Handbook of prejudice, stereotyping, and discrimination. New York: Psychology Press.

Nord, W. A. (1995). Religion and American Education: Rethinking a National Dilemma. Chapel Hill: University of North Carolina Press.

Nord, W. A., \& Haynes, C. C. (1998). Taking religion seriously across the curriculum. Alexandria: Association for Supervision and Curriculum Development and First Amendment Center.

Oman, D., Flinders, T., \& Thoresen, C. E. (2008). Integrating spiritual modeling into education: A college course for stress management and spiritual growth. The International Journal for the Psychology of Religion, 18(2), 79-107.

Oxford English Dictionary. (2013). "sacred, adj. and n.": Oxford University Press. 
Oyserman, D., \& Swim, J. K. (2001). Stigma: An insider's view. Journal of Social Issues, 57(1), 1-14.

Paloutzian, R. F., Richardson, J. T., \& Rambo, L. R. (1999). Religious conversion and personality change. Journal of Personality, 67(6), 1047-1079.

Pargament, K. I. (1999). The psychology of religion and spirituality? Yes and no. The International Journal for the Psychology of Religion, 9(1), 3-16.

Pargament, K. I. (2001). The Psychology of Religion and Coping: Theory, Research, Practice. New York: Guilford Press.

Pargament, K. I., Falb, M. D., Ano, G. G., \& Wachholtz, A. B. (Eds.). (2013). The Religious Dimension of Coping. New York: Guilford Publications

Pargament, K. I., Kennell, J., Hathaway, W., Grevengoed, N., Newman, J., \& Jones, W. (1988). Religion and the problem-solving process: Three styles of coping. Journal for the Scientific study of Religion, 27(1), 90-104. doi: doi.org/10.2307/1387404

Pargament, K. I., Magyar-Russell, G. M., \& Murray-Swank, N. A. (2005). The sacred and the search for significance: Religion as a unique process. Journal of Social Issues, 61(4), 665-687. doi: 10.1111/j.1540-4560.2005.00426.x

Pargament, K. I., \& Mahoney, A. (2005). Sacred Matters: Sanctification as a vital topic for the psychology of religion. International Journal for the Psychology of Religion, 15(3), 179-198. doi: doi.org/10.1207/s15327582ijpr1503_1

Park, C. L., \& Slattery, J. M. (Eds.). (2013). Religion, Spirituality, and Mental Health. New York: Guilford Publications.

Park, N. (2004). The role of subjective well-being in positive youth development. The Annals of the American Academy of Political and Social Science, 591(1), 25-39.

PewResearch. (2013). Religious Landscape Survey: Summary of key findings. Retrieved from http://religions.pewforum.org/reports

Pitts, M. J., \& Miller-Day, M. (2007). Upward turning points and positive rapportdevelopment across time in researcher-participant relationships. Qualitative Research, 7(2), 177-201.

Polit, D. F., \& Beck, C. T. (2008). Nursing research: Generating and assessing evidence for nursing practice. Philadelphia: Lippincott Williams \& Wilkins.

Pollack, D. (2008). Religious change in Europe: Theoretical considerations and empirical findings. Social Compass, 55(2), 168-186.

Ricoeur, P. (1971). The model of the text: Meaningful action considered as a text. Social Research, 38(3), 529-562.

Rockenbach, A. B., Walker, C. R., \& Luzader, J. (2012). A phenomenological analysis of college students' spiritual struggles. Journal of College Student Development, 53(1), 55-75.

Rokeach, M., \& Rothman, G. (1965). The principle of belief congruence and the congruity principle as models of cognitive interaction. Psychological Review, $72(2), 128-142$.

Rosik, C. H., \& Smith, L. L. (2009). Perceptions of religiously based discrimination among Christian students in secular and Christian university settings. Psychology of Religion and Spirituality, 1(4), 207-217.

Saroglou, V., Pichon, I., Trompette, L., Verschueren, M., \& Dernelle, R. (2005). Prosocial behavior and religion: New evidence based on projective measures and peer ratings. Journal for the Scientific study of Religion, 44(3), 323-348.

Sawatzky, R., Ratner, P. A., \& Chiu, L. (2005). A meta-analysis of the relationship between spirituality and quality of life. Social Indicators Research, 72(2), 153188. 
Scharf, M., Mayseless, O., \& Kivenson-Baron, I. (2004). Adolescents' attachment representations and developmental tasks in emerging adulthood. Developmental Psychology, 40(3), 430-444.

Schneider, C. G., \& Shoenberg, R. (1999). Habits hard to break: How persistent features of campus life frustrate curricular reform. Change: The Magazine of Higher Learning, 31(2), 30-35.

Shenton, A. K. (2004). Strategies for ensuring trustworthiness in qualitative research projects. Education for Information, 22(2), 63-75.

Sidelinger, R. J., \& Booth-Butterfield, M. (2010). Co-constructing student involvement: An examination of teacher confirmation and student-to-student connectedness in the college classroom. Communication Education, 59(2), 165-184.

Smith, J. A., Flowers, P., \& Larkin, M. (2009). Interpretative phenomenological analysis: Theory, method and research. Los Angeles: Sage.

Smith, J. A., \& Osborn, M. (2010). Interpretative Phenomenological Analysis. In J. A. Smith (Ed.), Qualitative psychology : A practical guide to research methods (pp. 53-80). Los Angeles: Sage.

Spilka, B., \& Ladd, K. L. (2012). The Psychology of Prayer: A Scientific Approach. New York: Guilford Press.

Spiro, M. E., Killborne, B., \& Langness, L. (1987). Culture and human nature. New Jersey: Transaction Publishers.

Statistics New Zealand. (2014). 2013 QuickStats about culture and identity. Retrieved from http://www.stats.govt.nz/Census/2013-census/profile-and-summaryreports/quickstats-culture-identity/religion.aspx

Stavrova, O., \& Siegers, P. (2014). Religious prosociality and morality across cultures: How social enforcement of religion shapes the effects of personal religiosity on prosocial and moral attitudes and behaviors. Personality and Social Psychology Bulletin, 40(3), 315-333. doi: 10.1177/0146167213510951

Stoppa, T. M., \& Lefkowitz, E. S. (2010). Longitudinal changes in religiosity among emerging adult college students. Journal of Research on Adolescence, 20(1), 2338.

Stubblefield, C., \& Murray, R. L. (2002). A phenomenological framework for psychiatric nursing research. Archives of Psychiatric Nursing, 16(4), 149-155. doi: 10.1053/apnu.2002.34393

Subbiondo, J. L. (2006). Integrating religion and spirituality in higher education: meeting the global challenges of the 21st century. Religion and Education, 33(2), 20-38.

Taliaferro, L. A., Rienzo, B. A., Pigg, R. M., Jr., Miller, M. D., \& Dodd, V. J. (2009). Spiritual well-being and suicidal ideation among college students. Journal of American College Health, 58(1), 83-90. doi: doi.org/10.3200/JACH.58.1.83-90

Tan, H., Wilson, A., \& Olver, I. (2009). Ricoeur's theory of interpretation: An instrument for data interpretation in hermeneutic phenomenology. International Journal of Qualitative Methods, 8(4), 1-15.

Tisdell, E. J. (2006). Diversity and Spirituality in Secular Higher Education: The Teaching Paradox. Religion and Education, 33(1), 49-68.

Turner-Musa, J. O., \& Wilson, S. A. (2006). Religious orientation and social support on health-promoting behaviors of African American college students. Journal of Community Psychology, 34(1), 105-115. doi: 10.1002/jcop.20086

Uecker, J. E., Regnerus, M. D., \& Vaaler, M. L. (2007). Losing my religion: The social sources of religious decline in early adulthood. Social Forces, 85(4), 1667-1692.

Van Manen, M. (1990). Researching lived experience: Human science for an action sensitive pedagogy. Albany: State University of New York 
Van Manen, M. (1997). Researching lived experience: human science for an action sensitive pedagogy. London: Althouse Press

Van Manen, M. (2014). Phenomenology of Practice: Meaning-Giving Methods in Phenomenological Research and Writing. California: Left Coast Press.

Victoria University of Wellington. (2014). Equity and diversity policy. Retrieved from http://www.victoria.ac.nz/documents/policy/academic/equity-and-diversitypolicy.pdf

Willits, F. K., \& Crider, D. M. (1989). Church attendance and traditional religious beliefs in adolescence and young adulthood: A panel study. Review of Religious Research, 31(1), 68-81.

Wink, P., \& Scott, J. (2005). Does religiousness buffer against the fear of death and dying in late adulthood? Findings from a longitudinal study. The Journals of Gerontology Series B: Psychological Sciences and Social Sciences, 60(4), 207214.

Zhai, J. E., Ellison, C. G., Glenn, N. D., \& Marquardt, E. (2007). Parental divorce and religious involvement among young adults*. Sociology of Religion, 68(2), 125144 . 


\section{Appendices}

Appendix A

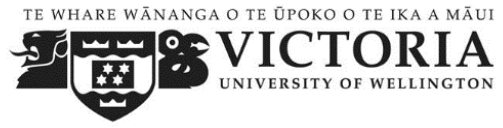

FACULTY OF EDUCATION

\section{BEING RELIGIOUS AT VICTORIA UNIVERSITY}

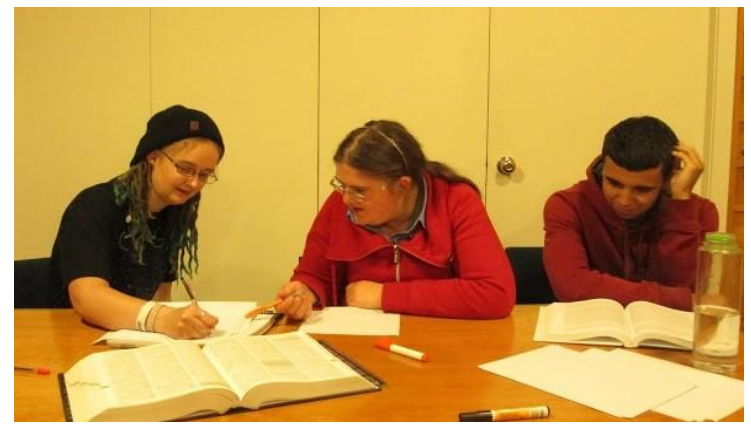

\section{Invitation:}

You are invited to take part in a research project about the experiences of religious university students aged 17-25. This will involve participating in a one to two hour confidential interview about your experiences as a religious university student on and off campus and what these experiences mean for you.

\section{Study objectives:}

This study will advance the understanding of Victoria University students' experiences of being religious in a tertiary education setting. The study will look to inform the development of programmes and practices to ensure that religious students at Victoria University of Wellington are included and supported.

\section{If you would like to participate, please contact:}

Thomas Dravitzki

MEd Student

Faculty of Education

Victoria University of Wellington
Mobile 0273840088

Emaildravitthom@myvuw.ac.nz

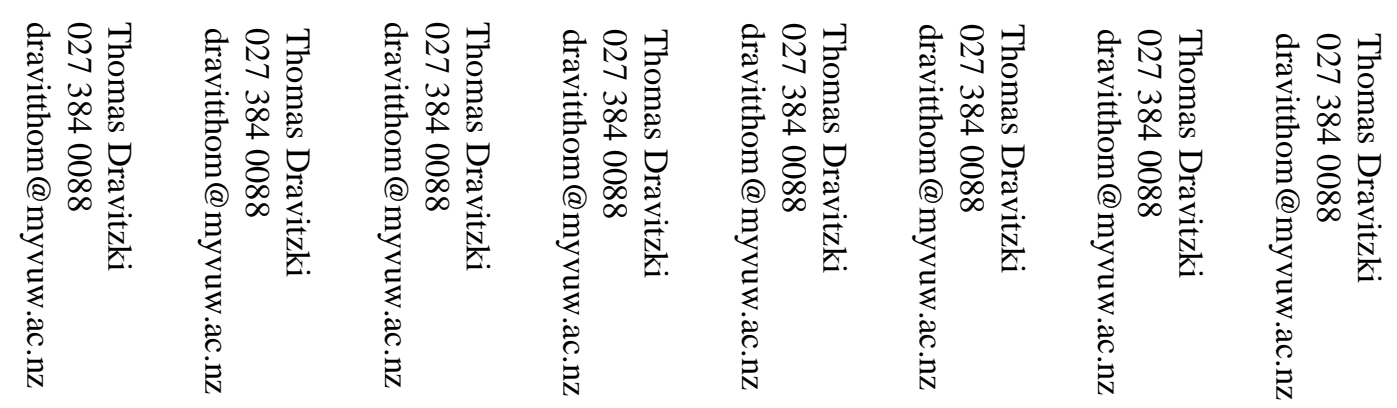




\section{TRANSCRIBER CONFIDENTIALITY AGREEMENT FORM}

Research Study titled: A phenomenological analysis of the construct of 'religion' in emerging adults within a tertiary education setting.

\section{Principal Investigator: Thomas Dravitzki}

- I have read the information sheet outlining this study.

- I have discussed with the researcher the nature of the research and have had any questions that I have had answered to my satisfaction.

- My role as the research transcriber has been outlined to me by the researcher.

- At all times the research information (tapes and transcripts) will be inaccessible to other persons.

- The researcher has assured me that he will debrief me following transcribing to address any issues that transcribing bring up for me.

- Most importantly, I understand and agree to keep the information I hear and type in the course of transcribing confidential to the researcher and myself.

Transcribers' Full Name:

\section{Signature:}

Date:

Researcher's Signature:

Date: 


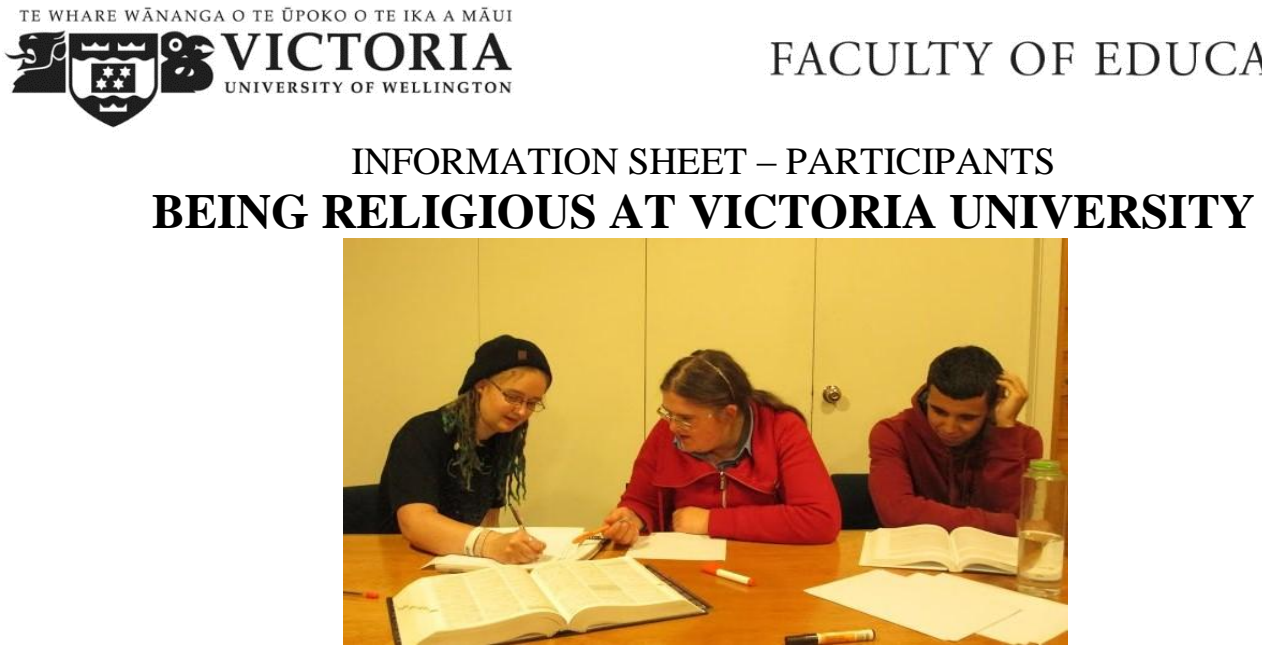

A study of the experiences of emerging adults (17-25 years of age)

Principal Investigator/Researcher: Thomas Dravitzki, Master of Education student with the Faculty of Education at Victoria University of Wellington.

Why is the research being done?

- Little qualitative research has been done in New Zealand that explores the experience of emerging adults aged 17-25 who are religious and how this influences their experiences as students. I want to know more about:

$\circ \quad$ What does being religious involve?

- What is the importance of religion in your life?

$\circ \quad$ What does being religious mean within a university context?

- This research will inform an understanding of youth development and students' perceptions of their learning contexts and experiences and findings will help will inform ideas about how to support religious students and the promotion of inclusive education.

\section{Participation (Do I have to take part?)}

- Your participation in this study is entirely voluntary (your choice). If you decide to take part you will be asked to sign a consent form to show you have agreed to take part.

- Information you provide will be kept confidential and no one (family/whānau, friends) will be told that you are being interviewed without your consent.

- You can withdraw from the study at any time prior to the interview and you can also stop and withdraw from the interview/s at any time. You can also withdraw your data from the study up to two weeks after the final interview.

- Participation in the study will not cost you any money, nor will you be paid to participate in the research.

\section{The interview/s (What will I have to do?)}

- Interviews will be conversational in style and will take place at the Victoria University of Wellington, Kelburn Campus (or another appropriate venue).

- The interview/s will be audio-recorded and will last approximately 1-2 hours.

- You may be invited to consider taking part in a follow-up interview so I can gain more detail about your experiences, their meaning, and give you the chance to add anything further that you wish to share.

- You will have the opportunity to review a summary of key themes from your interview. 


\section{Benefits and risks of being a participant (Why should I take part)?}

- In an increasingly secular (non-religious) country few opportunities arise for young people to voice their experiences, thoughts and perspectives about what being 'religious' means to them, how this might differ from spirituality and why they choose to be religious.

- There is a lack of national and international research on religiosity that involves young adults and students studying within a tertiary education setting.

- This research may help students develop a better personal understanding and appreciation of their own religion and how it shapes their educational experience and may help Universities better understand and support their student population.

- The health and wellbeing of participants is of the utmost importance throughout the research process. As a result of this, if at any stage during the interview/s you for example become upset or distressed the interview can be stopped. At this point you can stop your involvement in the study, reschedule the interview, or continue the interview when you feel ready to do so. Information regarding support and counselling services will also be provided to people who indicate they need some support around their experience.

What about the privacy and confidentiality of the information I provide?

- All identifying information and names will be removed from files, transcripts and notes. You will be able to choose your own pseudonym or fake name.

- All files and information will be saved in a secure filing cabinet or password protected file on the computer and destroyed at the end of the project.

- If you disclose during the interview, or any other time, that you (or those close to you) are at risk of harm I will discuss my concerns with you and what information will be passed on to my supervisor and appropriate services.

\section{What will happen to this research study?}

- This study is for fulfilment of a Masters of Education degree. A full copy of the study, in the form of a thesis, will be deposited in the Victoria University of Wellington Library.

- You may request a summary report of the overall study by filling in the appropriate details on the bottom of the Consent Form.

- The findings from this study, and short-quotes and de-identified data may be used in academic or professional publications and disseminated at academic conferences, and for professional development and training purposes. The research study is expected to be completed by March 2015.

\section{Research rights}

In New Zealand all research involving human participants must be approved by a Human Ethics Committee, which may be contacted if you have any concerns. Ethics approval has been granted for this study by the Victoria University of Wellington Human Ethics Committee (Reference Number 20867)

\section{You can also contact me:}

Thomas Dravitzki: MEd Student

Faculty of Education,

Victoria University of Wellington

Mobile: 0273840088

Email: dravitthom@myvuw.ac.nz

\author{
Or my supervisor \\ Chris Bowden \\ Faculty of Education \\ Victoria University of Wellington \\ Mobile: 0211758185 \\ Email: chris.bowden@vuw.ac.nz
}


Appendix D

TE Whare Wãnanga o te ŨPoko o te iKa a mäui

\section{FACULTY OF EDUCATION}

INTERVIEW GUIDE

A phenomenological analysis of the construct of 'religion' in emerging adults within a tertiary education setting.

\section{Principal Investigator: Thomas Dravitzki}

I want to understand your experience of being religious. I am looking for a description of your experience of religion and what it means for you.

\section{Interview Questions}

1. Tell me a bit about yourself.

2. Tell me a bit about your religion - what are some of the important practices, rituals, traditions?

3. What are some of the most important ideas in your religion?

4. What aspects of/or ideas in your religion do you most identify with or feel strongly committed to?

5. Why are these ideas important?

6. Can you tell me a bit about how religion shapes your life as a young person and student on and off campus?

7. Can you tell me about how important you think religion is for you?

8. What metaphor(s)/word(s) best summarise what being religious means for you?

\section{Wrap Up Questions}

1. Is there anything else you want to tell me about your experience that we have not discussed?

2. Would you be willing for me to contact you with any follow-up questions I may have about what we have discussed?

3. If over the next two weeks you remember something you would like to add you can contact me. 
Prompts (to clarify any ambiguous, missing, confusing information)

Prompts to gain further description

- How did that happen? When did that occur?

- You mentioned...can you tell me a little more about this event/experience?

- You talked about...what was your reaction to this?

- Can you tell me more about the events that led up to this?

Probes to clarify meaning

- What did that mean for you?

- What was that like?

Probes to encourage participant introspection and reflection

- What is an example of that?

- Why do you think that happened?

- What were your thoughts at the time?

- Can you tell me more about why this is so significant to you?

\section{Question specific prompts/probe}

1. You mentioned...can you tell me a little more about this tradition/activity?

2. You said on/off campus you feel...can you tell me a little bit more about why you feel this way?

You mentioned...happened to you on/off campus, can you tell me more about the events that led up to this?

3. Where do you think your strong commitment to...came/comes from? Is this different for men and women? Or different religions? Or different students?

4. You mentioned when...happened, how did this event change the way you practised your religion?

5. You mentioned the $\operatorname{word}(\mathrm{s}) /$ metaphor...can you tell me a little more about where this comes from?

\section{Questions following on from other interviews}

1. Another participant in this study said...

How do you feel about (for example, being religious) being described as...do you dis/agree, if so why? 
Appendix E

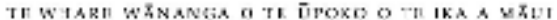

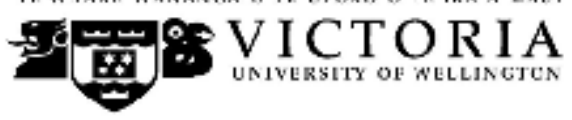

MEMORANDUM

Phone $\quad 0-4-4635676$

Fax 0-4-4635209

Email AllisonkirkmanAvuw.ac.nz.

\begin{tabular}{l|l}
\hline TO & Thomas Dravitzki \\
\hline COPY TO & Chris Bowden \\
\hline FROM & Dr Allison Kirkman, Convener, Human Ethics Committee \\
\hline DATE & 21 May 2014 \\
\hline PAGES & 1 \\
\hline \multicolumn{2}{|l}{} \\
\hline SUBJECT & $\begin{array}{l}\text { Ethics Approval: } 20867 \\
\text { A phenomenological analysis of the construct of 'religion' in } \\
\text { emerging adults within a tertiary education setting }\end{array}$ \\
\hline
\end{tabular}

Thank you for your application for ethical approval, which has now been considered by the Standing Committee of the Human Ethics Committee.

Your application has been approved from the above date and this approval continues until 1 March 2015 . If your data collection is not completed by this date you should apply to the Human Ethics Committee for an extension to this approval.

Best wishes with the research.

Allison Kirkman

Human Ethics Committee

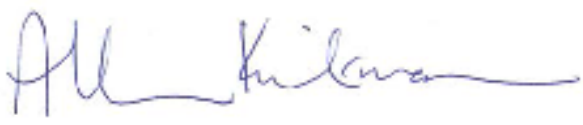




\section{Appendix F}

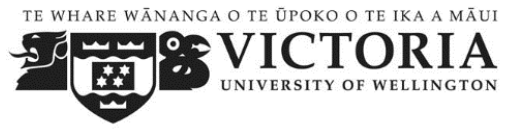

\section{FACULTY OF EDUCATION}

\section{PARTICIPANT CONSENT FORM}

I have read and understood the Information Sheet on "A phenomenological analysis of the construct of 'religion' in emerging adults within a tertiary education setting”.

I have had the opportunity to consider the information, ask questions and discuss this study. My questions have been answered satisfactorily.

I have had the opportunity to use family or whānau support or a friend to help me ask questions and understand the study.

I understand that taking part in this study is voluntary (my choice) and I know that I may withdraw from the study at any time and up to two weeks after the interview/s, but after that the interview/s would become part of the research data.

I understand that any information I provide will be kept confidential to the researcher (Thomas Dravitzki) his supervisor (Chris Bowden) and the person who transcribes the recordings of my interview(s). The published results will not use my name, information identifying location of events and people will be disguised or removed, and that no opinions will be attributed to me in any way that will identify me.

I understand that there is no payment for my or anyone else's participation in the study.

I understand that the audio-recorded interview and data pertaining to the research study will be destroyed at the end of the project.

I understand that any information used from the study for purposes such as publication in academic or professional journals or dissemination at academic or professional conferences will be anonymized.

I have had time to consider whether to take part. YES / NO

I agree to the interview being audio-recorded. YES / NO

I would like a summary of the interview/s transcript. YES / NO

I would like a CD/audio file of the interview/s. YES / NO

I would like a summary of the overall research results. YES / NO

I (full name) hereby consent to take part in this study.

Signature Date

Project explained by

Signature Date

Postal address for interview summary, $\mathrm{CD}$ and/or overall results summary

Email address for correspondence and copy of the audio file to be sent to: 
Table B: Characteristics of study participants

\begin{tabular}{|c|c|c|c|c|c|c|c|}
\hline $\begin{array}{l}\text { Participant } \\
\text { pseudonym }\end{array}$ & Sex & $\begin{array}{l}\text { Age in } \\
\text { years }\end{array}$ & $\begin{array}{l}\text { Religious } \\
\text { tradition }\end{array}$ & University major & $\begin{array}{l}\text { Time spent being } \\
\text { part of religious } \\
\text { tradition }\end{array}$ & $\begin{array}{l}\text { Place of birth and New } \\
\text { Zealand or International } \\
\text { student }\end{array}$ & Ethnicity \\
\hline Joan & Female & 19 & Roman Catholic & Law and History & 11 years & NZ/ NZ domestic student & NZ European \\
\hline Mary & Female & 22 & Protestant (Baptist) & Psychology & Since birth & Haiti/ International student & Haitian American \\
\hline Asha & Female & 19 & Muslim & $\begin{array}{l}\text { Education and } \\
\text { Philosophy }\end{array}$ & Since birth & Ethiopia/ NZ domestic student & Somalian \\
\hline Dave & Male & 20 & Christian & Law and Arts & Since birth & NZ/NZ domestic student & NZ European \\
\hline Sebastian & Male & 21 & Christian & Psychology & $\begin{array}{l}\text { As long as he can } \\
\text { remember }\end{array}$ & NZ/NZ domestic student & Pakeha/Maori \\
\hline Gregory & Male & 25 & Christian & Education & Since birth & NZ/ NZ domestic student & NZ European \\
\hline Clarissa & Female & 21 & Jehovah's Witness & $\begin{array}{l}\text { Criminology, } \\
\text { Anthropology and } \\
\text { Sociology }\end{array}$ & Since birth & NZ/NZ domestic student & NZ European \\
\hline Vijay & Male & 20 & $\begin{array}{l}\text { BAPS } \\
\text { Swaminarayan } \\
\text { Hindu } \\
\end{array}$ & $\begin{array}{l}\text { Biology and French } \\
\text { with a minor in } \\
\text { Statistics }\end{array}$ & $\begin{array}{l}\text { Hinduism } 20 \text { years, } \\
\text { BAPS Swaminarayan } \\
5 \text { years }\end{array}$ & NZ/ NZ domestic student & Indian \\
\hline Henry & Male & 23 & Roman Catholic & Computer Science & Since birth & NZ/NZ domestic student & NZ European \\
\hline Rachel & Female & 24 & Anglican & $\begin{array}{l}\text { Cognitive } \\
\text { Behavioural } \\
\text { Neuroscience } \\
\end{array}$ & Since birth & NZ/NZ domestic student & NZ European \\
\hline
\end{tabular}

